\title{
ASH-BASED BUILDING PANELS PRODUCTION AND DEMONSTRATION OF AEROCK DECKING BUILDING PRODUCT
}

\section{FINAL REPORT}

Start Date 2001

End Date 2007

Jointly Sponsored Research

Task 24 Final Report under DE-FC26-98FT40323

By

Alan E. Bland,

Principal Investigator, and

Jesse Newcomer,

Western Research Institute

Laramie, Wyoming

and

Hanafi R. Fraval, Chief Executive Officer, AeRock, LLC

Eagar, Arizona

June 2007

For

U.S. Department of Energy

National Energy Technology Laboratory

Morgantown, West Virginia

Kamalendu Das

Task 24 


\section{TABLE OF CONTENTS}

Page

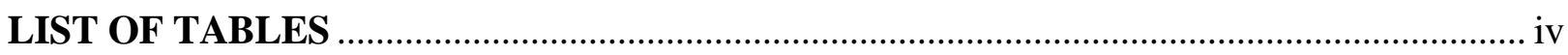

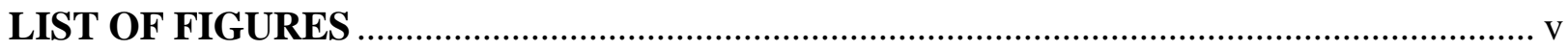

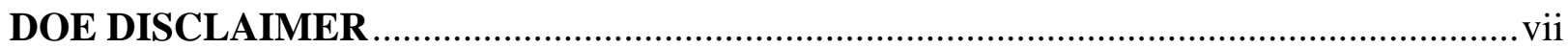

WRI AND AEROCK DISCLAIMER …………….......................................................

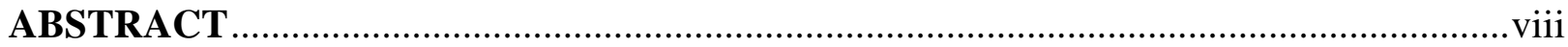

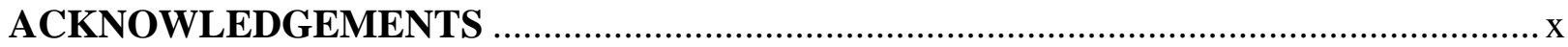

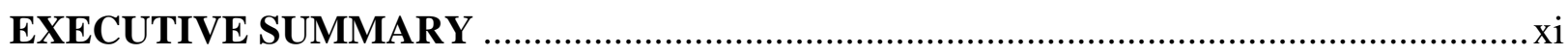

Project Objectives ……………………………………...............................................

Phase I Summary ………...........................................................................................

Pilot-Scale Production of Extruded Decking Material .......................................................

Phase II Commercial-Scale Demonstrations ...................................................................xiii

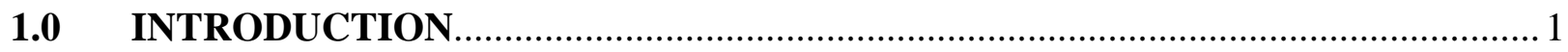

1.1 Green Building Product Market Opportunity …………………………………….... 1

1.2 Background of AeRock ..............................................................................

1.3 AeRock Building Products .................................................................................. 3

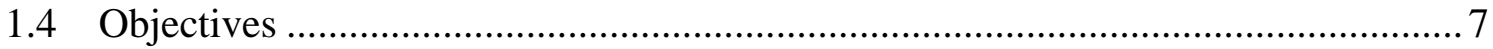

2.0 PHASE I - AEROCK COMPOSITE FORMULATION …………………............ 7

$2.1 \quad$ Phase I Equipment and Facilities ........................................................................ 8

2.2 Composite Formulation Testing ……………………....................................13

2.2 Phase I Results and Discussion...................................................................... 14

2.2.1. Unconfined Compressive Strength ........................................................... 14

2.2.2. Tension Strength Testing: .......................................................................... 17

2.2.3. Micro-chemical Observations ..................................................................... 23

2.2.4. Fiber Pull-Out Investigation .................................................................. 26

2.2.5 Other Performance Tests..........................................................................29

2.3 Pilot-scale Production of Extruded Decking Material ............................................31 


\section{TABLE OF CONTENTS (continued)}

3.0 PHASE II - COMMERCIAL-SCALE DEMONSTRATION $\frac{\text { Page }}{34}$

3.1 The Market for Decking Products...................................................................... 35

3.2 AeRock Deck Product Installation..................................................................... 35

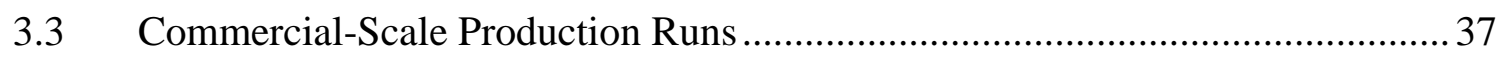

3.3.1 AeRock Decking Composite Formulation........................................... 37

3.3.2 Materials Shipped for Demonstration ....................................................37

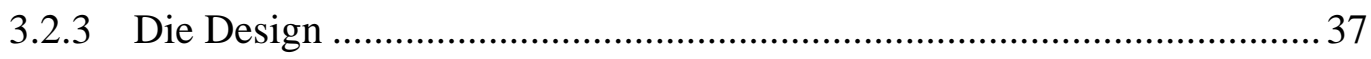

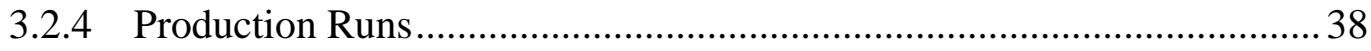

3.4 Demonstration of Applications of the AeRock Decking Product....................... 41

3.5 Product Comparison..................................................................................... 42

4.0 CONCLUSIONS AND RECOMMENDATIONS .............................................. 43 


\section{LIST OF TABLES}

$\underline{\text { Table }}$

Page

Table 1 Comparison of the MOR and MOE of AeRock Decking and

other deck products.....

Figure

\section{LIST OF FIGURES}

Fig. 1 AeRock residential housing concept........................................................................ 3

Fig. 2 Illustration of the AeRock wall panel product....................................................... 4

Fig. 3 Different types of AeRock wall panel structural members with

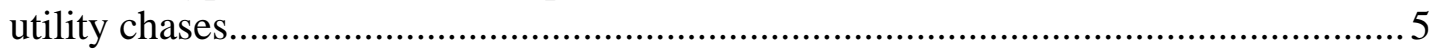

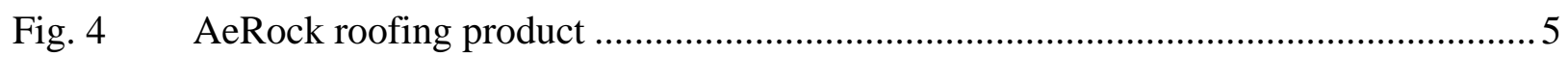

Fig. 5 Computer generated image of the AeRock Decking after

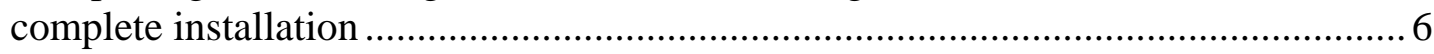

Fig. 6 Photograph of the AeRock test facility in Bellevue Washington used for the project................................................................................................ 8

Fig. 7 Photographs of the Haendle extruder used for the project...........................................

Fig. 8 Photograph of the computer controlled operation of the Haendle Extruder. 10

Fig. 9 Photographs of the Eirich mixer used in the testing (right) and the mixing action that it imparts (left).... 10

Fig. 10 Photograph showing the physical properties of the composite ingredients before (above) and after mixing with the Eirich mixer (right).

Fig. 11 Laboratory batch plunger extruder used to process samples for flexural testing.

Fig. 12 Photograph of composite specimens used for flexure testing.................................. 12

Fig. 13 Testing rig used for testing flexure strength of the composite formulations ............ 12

Fig. 14 Photograph of the Forney equipment used for unconfined compressive

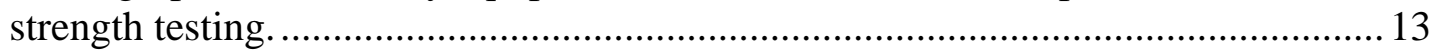

Fig. 15 Photograph pilot-scale extrusion of 1 -inch $x$ 1-inch for testing. ............................. 14

Fig. 16 Compressive strength specimen after testing.................................................... 15

Fig. 17A Unconfined compressive strengths for Cement A with and without fiber addition 15

Fig. 17B Unconfined compressive strengths for Cement B with and without fiber and with the addition of Class F DFGD ash. 


\section{LIST OF FIGURES (continued)}

Figure

Page

Fig. 17C Unconfined compressive strengths for Cement $C$ with different fibers

and the addition of Class F DFGD ash. ........................................................... 17

Fig. 18 Schematic and free body diagram for beams in Bending (top to bottom) ................18

Fig. 19 Flexure testing apparatus for the AeRock panel composite................................... 19

Fig. 20 Small beam flexure testing apparatus used for rod specimens

of the AeRock composite.................................................................................. 19

Fig. 21 Generalized force vs. displacement plot for typical AeRock composites ................20

Fig. 22 Representative flexure results for AeRock composites .......................................20

Fig. 23A Impact on MOR for different fiber additions to Cement B ..................................2 21

Fig. 23B Impact on MOE for different fiber additions to Cement B.................................. 21

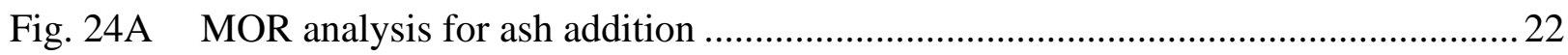

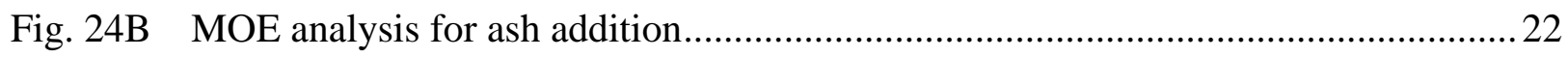

Fig. 25 Typical optimization testing of activators needed for certain

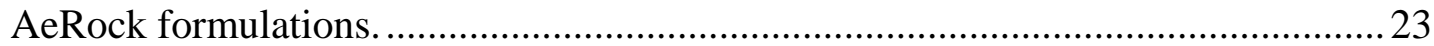

Fig. 26 Electron backscatter images of MRT cement/Class C ash (top) and MRT cement/Class F ash (bottom)................................................................. 24

Fig. 27A Elemental map of MRT cement /Class C-derived DFGD ash...............................25

Fig. 27B Elemental map of MRT cement /Class F fly ash ............................................... 26

Fig. 28 Illustration of untreated fiber pull-out in AeRock material ....................................27

Fig. $29 \quad$ Flexural testing results with fiber pullout ….................................................... 27

Fig. 30 Flexural testing results without fiber addition .................................................28

Fig. 31 Flexural testing results with good fiber adhesion .............................................29

Fig. 32 Impact of direct flame on AeRock product......................................................... 29

Fig. 33 Flame penetration test results for the AeRock composite .....................................30

Fig. 34 Flame penetration test results for gypsum wall board ........................................ 30

Fig. 35 Photograph of the extrusion of the AeRock wall panel product ..............................31

Fig. 36 Photograph of laboratory (pilot-scale) extrusion of AeRock

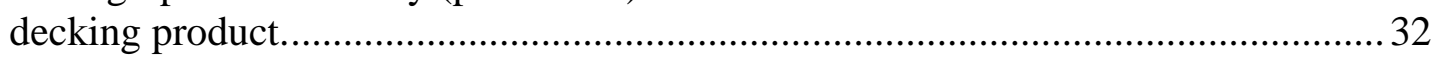

Fig. 37 AeRock’s decking product with various finishes applied..................................... 33

Fig. 38 Photograph of wood-grained finished AeRock decking product.............................33

Fig. 39 Photograph of the AeRock decking product demonstration....................................34 


\section{LIST OF FIGURES (continued)}

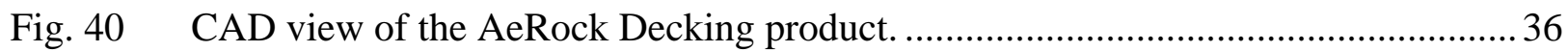

Fig. 41 Cross-section profile of the AeRock Decking product fastened to

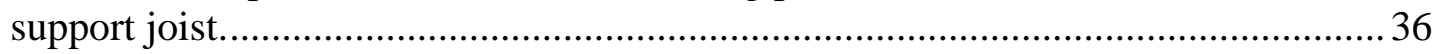

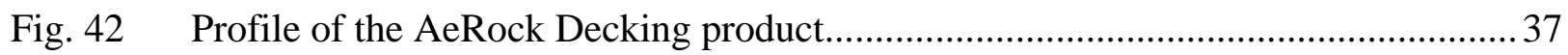

Fig. 43 Initial AeRock Deck production runs showing green product

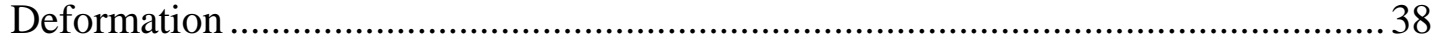

Fig. 44 Initial AeRock wall member production runs showing green

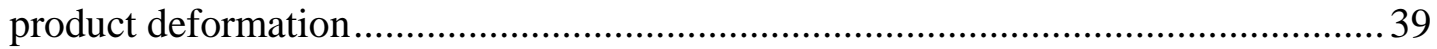

Fig. 45 Simultaneous commercial-scale extrusion of four separate trains

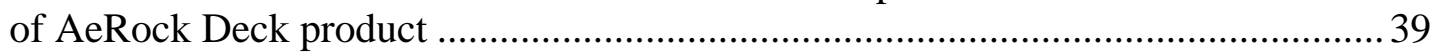

Fig. 46 Simultaneous commercial-scale dual train production of wall

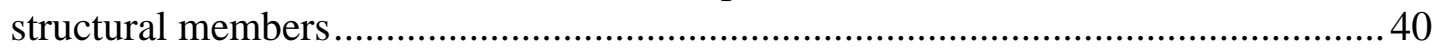

Fig. 47 Proposed profile of the AeRock Decking product............................................. 41

Fig. 48 Photograph of the AeRock Decking product installation including

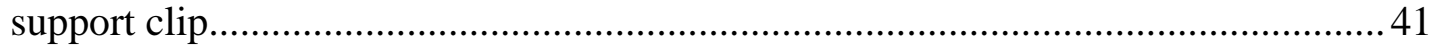

Fig. 49 Photograph of a marbled AeRock Decking finish (above)................................... 42 


\section{DOE DISCLAIMER}

This report was prepared as an account of work sponsored by an agency of the United States Government. Neither the United States Government, nor any agency thereof, nor any of their employees makes any warranty, express or implied, or assumes any legal liability or responsibility for the accuracy, completeness, or usefulness of any information, apparatus, product, or process disclosed or represents that its use would not infringe privately owned rights.

Reference herein to any specific commercial product, process, or service by trade name, trademark, manufacturer, or otherwise does not necessarily constitute or imply its endorsement, recommendation, or favoring by the United States Government or any agency thereof. The views and opinions of authors expressed herein do not necessarily state or reflect those of the United States Government or any agency thereof.

\section{WRI AND AEROCK CO-SPONSOR DISCLAIMER}

This research report was prepared by the Western Research Institute (WRI), as an account of work sponsored by the U.S. Department of Energy National Energy Technology Laboratory and AeRock LLC. The work was conducted by Western Research Institute, and industrial participant AeRock. Because of the research nature of the work performed, none of the participants nor any of the industrial co-sponsors nor any of their employees makes any warranty, express or implied, or assumes any legal liability or responsibility for the accuracy, completeness, or usefulness of any information, apparatus, product, or process disclosed, or represents that its use would not infringe privately owned rights. Reference herein to any specific commercial product, process, or service by trade name, trademark, manufacturer, or otherwise does not necessarily constitute or imply its endorsement or recommendation by the WRI or any of the participants and industrial cosponsors. 


\begin{abstract}
Western Research Institute (WRI) of Laramie, Wyoming and AeRock, LLC of Eagar, Arizona (formerly of Bellevue, Washington) partnered, under sponsorship of the U.S. Department of Energy National Energy Technology Laboratory (U.S. DOE-NETL), to support the development of rapid-setting, ash-based, fiber-incorporated “green” building products. Green building materials are a rapidly growing trend in the building and construction industry in the US.
\end{abstract}

A two phase project was implemented wherein Phase I assessed, through chemical and physical testing, ash, ash-based cement and fiber composites exhibiting superior structural performance when applied to the AeRock mixing and extrusion process and involved the conduct of pilot-scale production trials of AeRock products, and wherein Phase II involved the design, construction, and operation of a commercial-scale plant to confirm production issues and to produce panels for performance evaluations.

Phase I optimized the composite ingredients including ash-based cement, Class $\mathrm{F}$ and Class C DFGD ash, and various fiber reinforcements. Additives, such as retardants and accelerators, were also evaluated as related to extruder performance. The optimized composite from the Phase I effort was characterized by a modulus of rupture (MOR) measured between 1,931 and 2,221 psi flexural strength, comparable to other wood and non-wood building materials.

Continuous extrusion of the optimum composite in the AeRock pilot-scale facility produced an excellent product that was assembled into a demonstration for exhibit and durability purposes. Finishes, from plain to marbled, from bright reds to muted earth tones and with various textures, could easily be applied during the mixing and extrusion process. The successful pilot-scale demonstration was in turn used to design the production parameters and extruder dies for a commercial scale demonstration at Ultrapanel Pty, Ltd of Ballarat, Australia under Phase II.

The initial commercial-scale production trials showed green product sagging, as a result of the die design. After the third die was acquired and fitted to the extruder, satisfactory decking and structural panels were produced. Cured decking was shipped to the US but experienced significant breakage and damage during transport. Subsequent evaluations concluded that an alternative die design was needed that would produce a more robust product resistant to damage. 
In summary, AeRock Decking can be a commercially-viable non-wood alternative decking product. This project has provided WRI and AeRock the knowledge and understanding to make AeRock Decking a commercial success. However, a commercial demonstration that produces quality product and the subsequent evaluation of its performance is needed before commercial acceptance of the AeRock product. 


\section{ACKNOWLEDGEMENTS}

The authors acknowledge the funding support provided by the United States Department of Energy, National Energy Technology Laboratory under Cooperative Agreement Jointly Sponsored Research Program DE-FC26-98FT40323and from AeRock LLC. The authors acknowledge the contributions to the project from AeRock's Frederick N. Branchflower and Greg Emons (formerly of AeRock) and from Western Research Institute's (WRI's) Jesse Newcomer, Collin Greenwell and Brian Lowry (formerly of WRI). The authors also acknowledge the support of Dr. Susan Swapp of the Materials Characterization Laboratory of the University of Wyoming Department of Geological and Earth Science for the microscopic analysis of the materials. And finally, the authors are especially indebted to Kamal Das and Robert Patton for their thoughtful suggestions, guidance and encouragement. 


\section{EXECUTIVE SUMMARY}

It is an understatement that landfills are becoming filled and thereby placing a burden on prime natural resources as evidenced by the increasing prices of materials, such as in the construction industry. By recycling waste materials, the pressure on landfills, air pollution and potential groundwater pollution are reduced. At the same time, trees are saved and waste materials, such as used carpeting and other fibers and power plant fly ash, may be reclaimed and put to use. As a result, green building materials are a rapidly growing trend in the building and construction industry in the United States. Green building materials and construction practices are often defined as including recycled ingredients that are environmentally friendly and include waste wood, recycle plastics, recycled paper products and fibers, and coal combustion products (i.e. ash from coal-fired power plants).

Western Research Institute (WRI) of Laramie, Wyoming and AeRock, LLC of Eagar, Arizona (formerly of Bellevue, Washington) partnered, under sponsorship of the U.S. Department of Energy National Energy Technology Laboratory (U.S. DOE-NETL), to support the development of rapid-setting, ash-based, fiber-incorporated green building products. Since the AeRock process for producing building products will use essentially 100\% "green" recycle materials, principally ash, ash-based cement and fiber, the AeRock process results in a number of additional environmental benefits, such as when compared to wood, every 200 square feet of AeRock panel saves approximately one tree, and when compared with Portland cement, every ton of ash or ash-based cement used saves approximately one ton of $\mathrm{CO}_{2}$ emitted to the atmosphere.

\section{Project Objectives}

The overall goal of the multiyear project was to evaluate formulations and potential commercial building products produced by the AeRock process for a range of construction applications. Specific objectives were as follows:

- $\quad$ Assess, through chemical and physical testing, ash-based cement and fiber composites exhibiting superior structural performance when applied to the mixing and extrusion process,

- $\quad$ Conduct pilot-scale production trials of the AeRock products, and

- $\quad$ Conduct commercial-scale production trials of AeRock products and monitor the performance of the AeRock Decking product.

Phase I was instrumental in developing advanced composite formulations based on research into the underlying chemical and physical properties of the building materials, while 
Phase II involved the design, construction, and operation of a commercial-scale plant to confirm production issues and to produce panels for performance.

\section{Phase I Summary}

AeRock has a proprietary composite formulation for producing building-related products. Under Phase I, WRI and AeRock addressed the optimization of the AeRock composite formulations. This optimization would result in a composite to be used for the commercial-scale demonstration conducted under Phase II.

In Phase I, the AeRock-WRI team conducted engineering and chemical tests on a wide range of composite formulations, in order to optimize the ingredients. Composite formulation included ash-based cement such as Mineral Resource Technology (MRT) cement, Class F and Class C DFGD ash, and various fiber reinforcements. Special additives, such as retardants and accelerators, were evaluated as related to extruder performance.

Testing showed the three different ash-based cements when used alone had considerably different unconfined compressive strengths, ranging from 5,000 to 9,000 psi. However, all three cements showed unconfined compressive strength gains with the addition of fiber. Although the compressive strengths of the cements used in this study were below the typical 15,000 psi range for wood decking products, it was possible, through the addition of fibers, to increase these values and even exceed the range of typical wood products.

Testing also showed that the addition of different fibers influences the failure mode of the engineered composite material. Three different failure modes were observed; brittle failure with no fiber addition, failure with good fiber adherence to the matrix material, and failure with fiber pullout of the matrix material. Fiber-matrix adhesion is essential in order for the composite strength to approach the tensile strength of the fiber and to reduce dimensional warping.

The optimized composite from the Phase I effort was characterized by a modulus of rupture (MOR) measured between 1,931 and 2,221 psi flexural strength, comparable to other wood and non-wood building materials. These values are comparable with wood and non-wood building products.

\section{Pilot-scale Production of Extruded Decking Material}

Upon completion of the composite formulation tests and the associated strength testing, a pilot-scale production of the AeRock product was undertaken, that involved continuously extruding the optimum mix in a Haendle pilot-scale extruder. The resultant product was 
assembled into a demonstration for durability testing. Decking product generated with the pilotscale extruder was of good quality. It was also demonstrated that finishes, from plain to marbled, from bright reds to muted earth tones and with various textures, could easily be applied during the mixing and extrusion process.

\section{Phase II Commercial-Scale Demonstrations}

Based on the successful development of a quick-setting, high-strength, ash-cement-fiber composite, it was decided to conduct commercial-scale production runs and to demonstrate the performance of the product. The successful pilot-scale demonstration was used to design the parameters and extruder dies for a commercial scale demonstration at Ultrapanel Pty, Ltd of Ballarat, Australia under Phase II of the project. Dies were designed, a cargo-container of tonsized composite ingredients was shipped to Australia, and the Ultrapanel facility was modified to handle these commercial-scale production runs with the AeRock composite formulation.

The first commercial-scale production runs showed green product sagging, as a result of the die design. The first two generations of the commercial die, rippling and other undesirable effects occurred, causing the die to twice be modified before a satisfactory profile was found. The final die was then fitted to the extruder and satisfactory decking and structural panels were produced. Cured decking was shipped to the US but experienced significant breakage and damage during transport.

Subsequent evaluation concluded that an alternative die was needed that would produce a more robust product that would be more resistant to damage during transport was designed. Unfortunately, the cost of conducting another production run, including the cost of the new dies was prohibitive from an available funding perspective. Attempts were made to secure funding from private sources to continue the pilot- and commercial-scale product trials, but they have not been successful to date.

AeRock Decking can be a commercially-viable non-wood alternative decking product. This project has provided WRI and AeRock the knowledge and understanding to make AeRock Decking a commercial success. However, a commercial demonstration that produces quality product and the subsequent evaluation of the product performance is needed before commercial product acceptance. As such, it is recommended that additional funding be secured to conduct additional pilot-scale testing using the new die design. If successful, commercial-scale production trials, employing the new die design, could be conducted in the US in order to produce sufficient quantities of product for field demonstrations of the AeRock Decking. The product would undergo the full range of product performance tests necessary to launch the product to the industry. 


\subsection{INTRODUCTION}

It is an understatement that landfills are becoming filled and thereby placing a burden on prime natural resources as evidenced by the increasing prices of materials, such as in the construction industry. For example, the power industry in the United States produces more than 100 million tons of coal combustion waste products in the form of ash. Although this ash has been used in cement production and a number of other applications, more than 100 million tons are disposed of annually, increasing the costs of electricity and posing a liability to the industry. This beneficial reuse of the ash has been and remains a major goal of the industry and the U.S. DOE. By recycling waste materials, the pressure on landfills, air pollution and potential groundwater pollution are reduced. At the same time, trees are saved and waste materials, such as used carpeting and other fibers and power plant fly ash, may be reclaimed and put to use.

In addition, green building materials are a rapidly growing trend in the building and construction industry in the United States. This 'green' trend has been in full swing in the European and Scandinavian countries for the last decade or longer. Green building materials and construction practices are often defined as including recycled ingredients that are environmentally friendly. Green materials include waste wood, recycle plastics, recycled paper products and fibers, and coal combustion products (i.e. ash from coal-fired power plants).

\subsection{Green Building Product Market Opportunity}

Many different technologies are used in the building construction industry. In the United States, perhaps the most common is frame or stick building. Frame buildings are generally low cost, relatively fast to construct, and widely used. In general, they have limited fire and moisture damage prevention performance, and are subject to rot and insect attack, only modest energy efficiency, require both internal and exterior treatment and have limited performance in high wind and earthquakes unless special precautions are taken.

Numerous other techniques and materials are used in the building construction industry, including various types of concrete block with various insulation performance, poured-in-place construction, panelized construction, tilt-up panels, poured-in-place concrete panels, and brick structures.

Various block systems are available with many incorporating special insulation systems to improve thermal performance of a building. Most of these known block systems may also be constructed with reinforced steel in order to improve wind and earthquake performance as well as general building strength and durability. These systems require both interior and exterior finishing, although there are numerous techniques, where interior and exterior finishes such as 
painting can be applied with a minimum cost. Many block systems require interior plaster surfacing or the addition of drywall to the inside surface. Exterior siding or other finishing, such as stucco, is optional and is dependent upon design requirements.

Poured-in-place concrete systems, particularly the more modern stay-in-place form systems, have good durability, good fire and moisture performance and are resistant to insects. With suitable reinforcing, these systems have reasonable performance in high-wind and earthquake regions. However, they generally require interior and exterior treatment after the structure has been erected and insulation value is limited.

Panelized systems, particularly structural insulated panels (SIPs), have limited fire performance unless they are concrete-based. Panelized concrete systems have similar performance and characteristics to block systems. The new panelized SIPs, consisting of a sandwich of two layers of orient strand board (OSB) with a layer of expanded polystyrene (EPS), seek to provide higher thermal performance than other building systems. However, they are not water and moisture resistant and can be subject to rot and insect attack. They also still require finishing, both on the interior and exterior of the structure. Their performance in high-wind and earthquake conditions varies upon design but is generally considered to be good.

Consequently, there is still a need in the construction industry for a prefabricated wall, roof, floor and decking panel construction that meets all of the aforementioned objectives yet is lightweight, easy to install, inexpensive to produce, and takes advantage of environmentally expendable and recycled materials rather than using limited natural resources.

\subsection{Background of AeRock}

Formed in 1999, AeRock LLC (currently AerRock) is an entrepreneurial company, currently located in Eager, Arizona (formerly from Bellevue, Washington). For this report, the company name of AeRock will be used, since that was the legal entity that the work reported herein was performed.

AeRock is a technology development company with a mission of developing and deploying technology to produce environmentally-friendly, 'green' building products. AeRock' materials use essentially all recyclable products, such as coal-fired power plant ashes, ash-based cement, and waste fibers. AeRock was founded to conduct research and development activities leading to highly innovative green product that will have wide applications in developed and developing countries. 


\subsection{AeRock Building Products}

AeRock's goal and that of this project was to produce prefabricated extrudable construction products that are splinter-free and which will compete with wood in the residential housing construction market. The AeRock product line expects to compete with most structural members, whole wall, roof, floor, and interior trim products for the residential construction industry. In addition, AeRock products expects to compete as structural components and internal partitions in commercial buildings and emergency response shelters for use by government agencies. The benefits of AeRock composite formulation included its strength, fire, water, and insect resistance, green product status, and low cost of installation and maintenance.

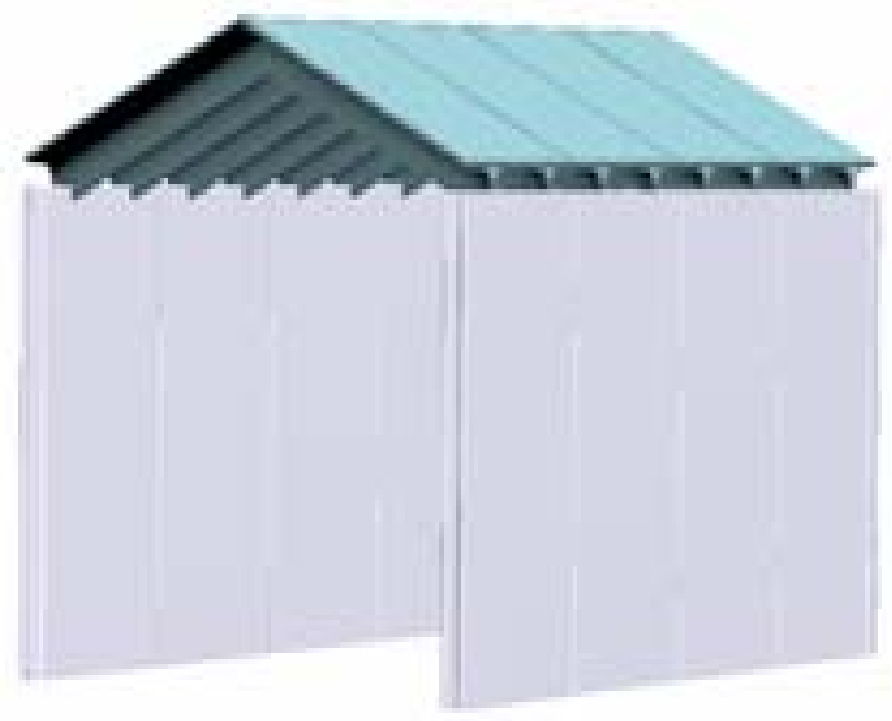

Figure 1: AeRock residential housing concept.

\section{$\underline{\text { Residential Housing }}$}

- Walls,

- Roofs,

- Decks,

- Floors, and

- Interior Trim

Commercial Building

- Structural Components, and

- Internal Partitions

\section{Governmental Housing}

- Native American housing

- Emergency Response (FEMA) situations

These AeRock technologies are patented or undergoing patent protection. The AeRock ash-based composites also employ hydraulic cement made from power plant ash. The patented cement composition is licensed to AeRock. The composite is reinforced with various fibers that provide flexure strength to the final product. The final composite is quick setting, thereby allowing for continuous extrusion production lines.

As an example, the AeRock wall building panels are a sandwiched construction with an insulating center. The structural member portions of the panels are produced of a proprietary composite formulation including ash, ash-based cement, and fiber that is extruded to the shape desired. The extruded product has modulus of elasticity equivalent to wood products. 
One of the benefits of extrusion is that it provides a manufacturing process that can make very precise, repeatable, and complex cross-sections. One has only to look at the revolution that has occurred in the plastics industry. Plastics in all its forms, including extruded products, have had a huge impact on almost every industry and facet of our lives.

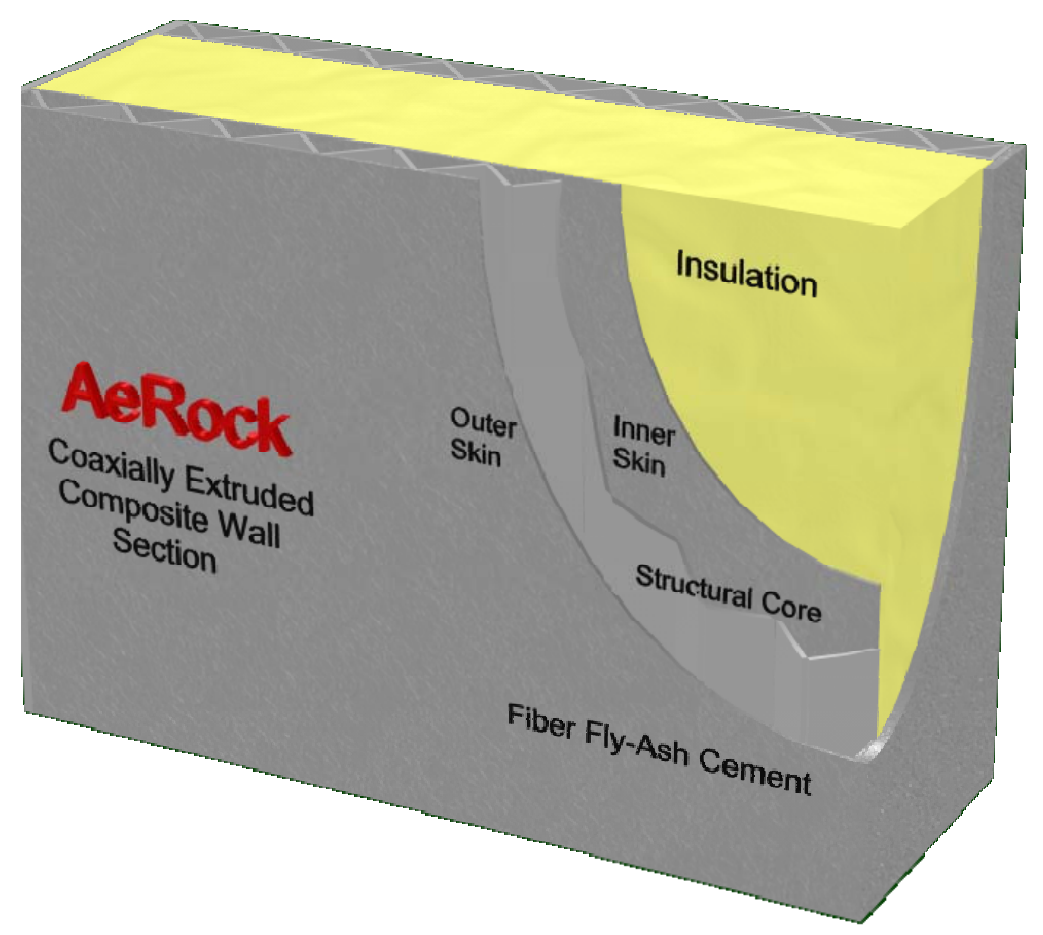

Figure 2: Illustration of the AeRock wall panel product.

The AeRock process provides the same flexibility, but with a fiber cement - a fiber cement that is part of a green process. One of the unique features of AeRock's cement that is it sets within minutes of extrusion, unlike Portland cement which takes up to sixteen hours to cure. AeRock intends to develop and deploy a unique extrusion system that includes unique mixing, conveying system to move product out of the extruder to the cutting bays.

The 20-foot long by 8-foot wide green extruded panels are cut to computerized specifications. As such, the openings for doors, windows, and utility connections are pre-cut at the production plant instead of at the construction site. The external and internal companion panels are assembled and the insulation material is added. The external surface is then primed, marked for assembly and delivered to the construction site. Since these products can be fabricated with lightweight components, transportation costs are lower than wood products. 
Figure 3: Different types of AeRock wall panel structural members with utility chases.

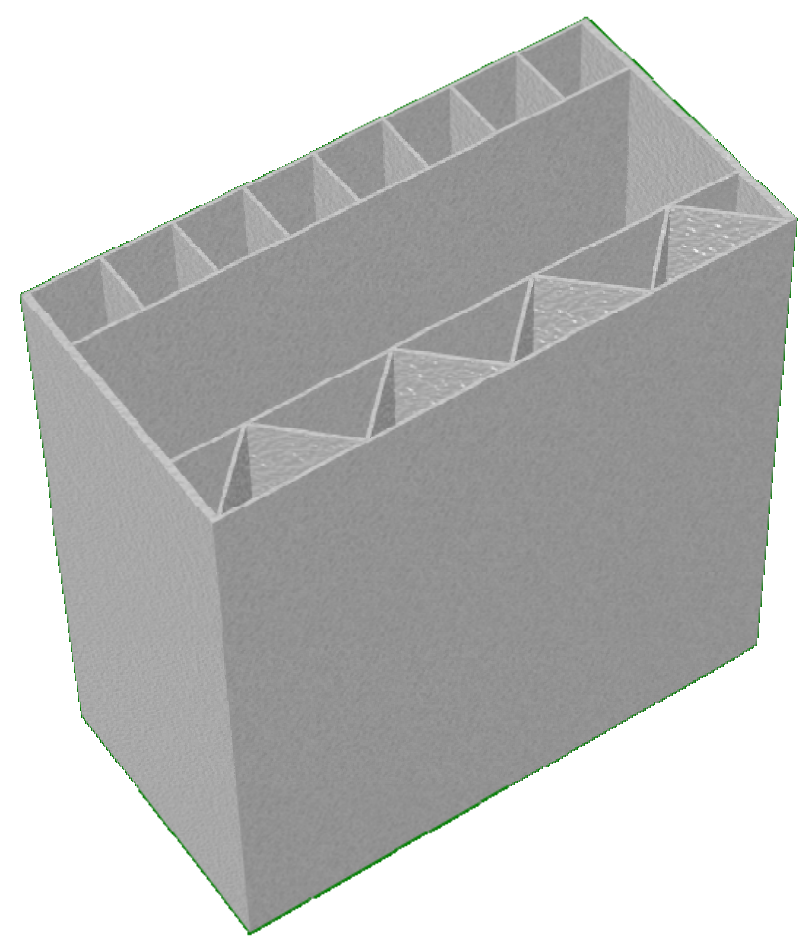

At the construction site, the delivered panels are interlocked according to the marked assembly order and position. The webbed construction of the panels allow for the running of utilities (Figure 3). The erected panels are then painted or stucco finished. The construction time for erecting the panels is quite short, resulting, in lower construction costs. Other application products are shown in Figures 4 and 5.

Due to the composition of the AeRock building products, the following attributes are anticipated.

- Strong (structural panel)

- Flexible (high wind and earthquake resistant)

- Fire resistant

- High thermal insulation,

- High sound attenuation factor,

- Water and insect resistant

- Cost competitive with wood products.

Figure 4: AeRock roofing product.

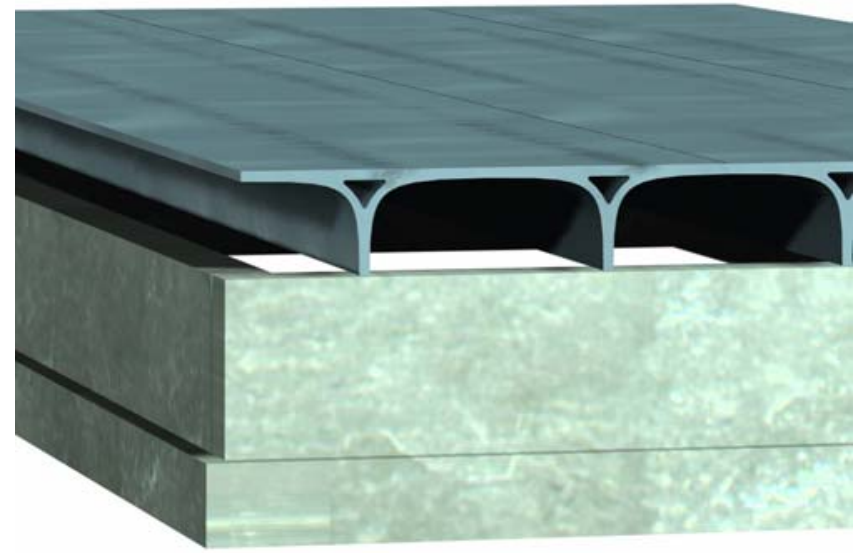


In addition to the attributes above, the AeRock process and resultant products showed a number of environmental benefits. The AeRock composite uses $95-100 \%$ waste materials thereby saving on landfills (environmentally green building products). Compared to wood, every 200 square feet of AeRock panel saves approximately one tree. Compared with Portland cement, every ton of ash or ash-based cement used saves approximately one ton of $\mathrm{CO}_{2}$ emitted to the atmosphere.

Figure 5: Computer generated image of the AeRock Decking after complete installation.

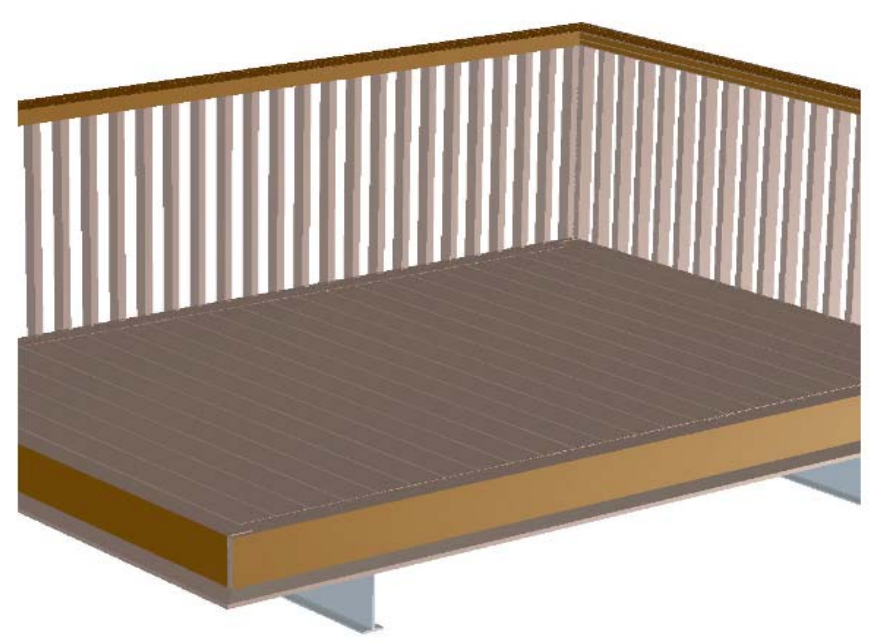

Initial work by AeRock was performed in conjunction with Forest Products Laboratories in Madison Wisconsin, Mineral Resource Technologies of Atlanta, Georgia, and RW Cooper of Chicago, Illinois. Funding for this work was through the Partnership for Advanced Technology in Housing (PATH) and from the Combustion By-Products Recycle Consortium (CBRC). The results from this early work were promising, but not consistent.

AeRock completed a significant amount of material testing on ash-based fiber-cements beginning in October 1999. The testing primarily focused on blending commercially available ash-based cements with one or both of two types of fibers; cellulose and polymer-based. A series of tests indicated that by blending up to $50 \mathrm{wt} \%$ commercial ash-based cement with dry flue gas desulphurization (DFGD) ash and fiber, appreciable gains in both modulus of elasticity (MOE) and compressive strength $(\sigma)$ over the cement-alone could be realized. The two types of DFGD ashes evaluated were Class C- and Class F-DFGD.

In 2001, WRI entered into a partnership with AeRock (and subsequently also including Ultrapanel Pty, Ltd of Ballarat, Australia) to support the development of a rapid-setting, ashbased, fiber-incorporated composite building product for producing products for the construction industry by means of the AeRock proprietary manufacturing process. AeRock has a patent pending on the formulation and on the process of making building panels from ash-based cement and fiber. As reported herein, AeRock and WRI jointly evaluated the AeRock process and its 
proprietary formulations under sponsorship of the U.S. Department of Energy National Energy Technology Laboratory (U.S. DOE-NETL).

The effort was designed into two Phases. Phase I was designed to expand on the composite formulation research and testing in order to optimize the formulation and to assess the potential of including DFGD ashes from $\mathrm{SO}_{2}$ spray drier control processes at bituminous and subbituminous coal-fired power plants into the AeRock formulations.

Phase II of the project consisted of pursuing the design, construction, and operation of a commercial-scale plant in Australia to verify the manufacturing process and to produce panels for subsequent performance testing.

\subsection{Objectives}

The overall goal of the project was to evaluate formulations and potential commercial building products produced by the AeRock process for a range of construction applications. The following objectives were to be addressed.

- $\quad$ Assess, through chemical and physical testing, ash, ash-based cement and fiber composites exhibiting superior structural performance when processed in extrusion process.

- $\quad$ Conduct pilot-scale production runs of the AeRock Decking product.

- $\quad$ Conduct commercial-scale production runs of AeRock products and monitor the performance of the AeRock Decking product.

\subsection{PHASE I - AEROCK COMPOSITE FORMULATION}

WRI and AeRock, under Phase I of the project, addressed the optimization of the AeRock composite formulations. In order to accomplish this, a specialized set of equipment was brought together to produce and test the composite formulations. Phase I specifically addressed the optimization of composite formulation that would be used for the commercial-scale demonstration conducted under Phase II.

The focus of Phase I was the development of the composite formulation that included ash-based cement such as Mineral Resource Technology (MRT) cement, Class F and Class C DFGD ash, and various fiber reinforcements. In addition, the effort included the evaluation of additives, such as retardants and accelerators that are necessary for extruder performance. Mineral Resource Technologies (MRT) of Atlanta holds two patents for its ash-based cement 
products. The MRT Cement ${ }^{\mathrm{TM}}$ products are made primarily from coal-fired electric utilities fly ash and can replace traditional Portland cement in many types of cement applications.

Phase I also addressed the assessment of the engineering properties of the different composite formulations. The extrudability of the mix was the primary indicator of the composite formulation. If the composite could not be extruded the mix was rejected from a performance perspective. For those composite formulations that showed acceptable extrudability, the flexural strength and the unconfined compressive strengths were used as further indicators of the performance quality of the composite formulation. Additional tests such as stability and fire resistance were determined on select composite specimens.

Furthermore, scanning electron microscopy (SEM) was employed to investigate the interactions of the composite constituents. After finding an optimized mix that could be pursued in Phase II commercial-scale demonstration, aesthetic additives in the form of dies and textures were evaluated.

\subsection{Phase I Equipment and Facilities}

Both AeRock and WRI supplied existing equipment to the Phase I effort. WRI supplied specialized mixing equipment and AeRock purchased specialized extruding equipment.

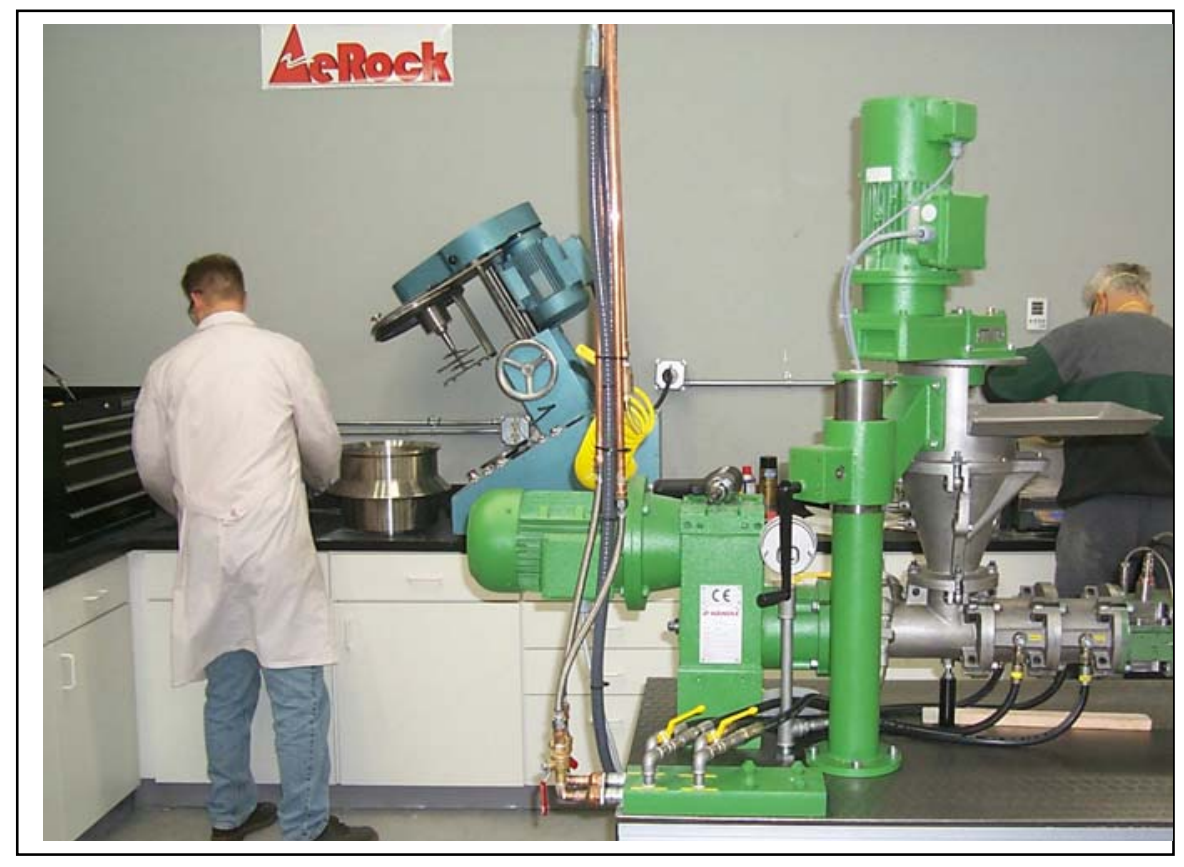

Figure 6: Photograph of the AeRock test facility in Bellevue Washington used for the project. 
The equipment was consolidated in AeRock's laboratory in Bellevue Washington.(Figure 6). The extruded products were made using a Haendle Lab Extruder PZVMR 8d (Figures 7 and 8). The extruder is completely computer controlled and scales-up to other extruding equipment deployed in industry.
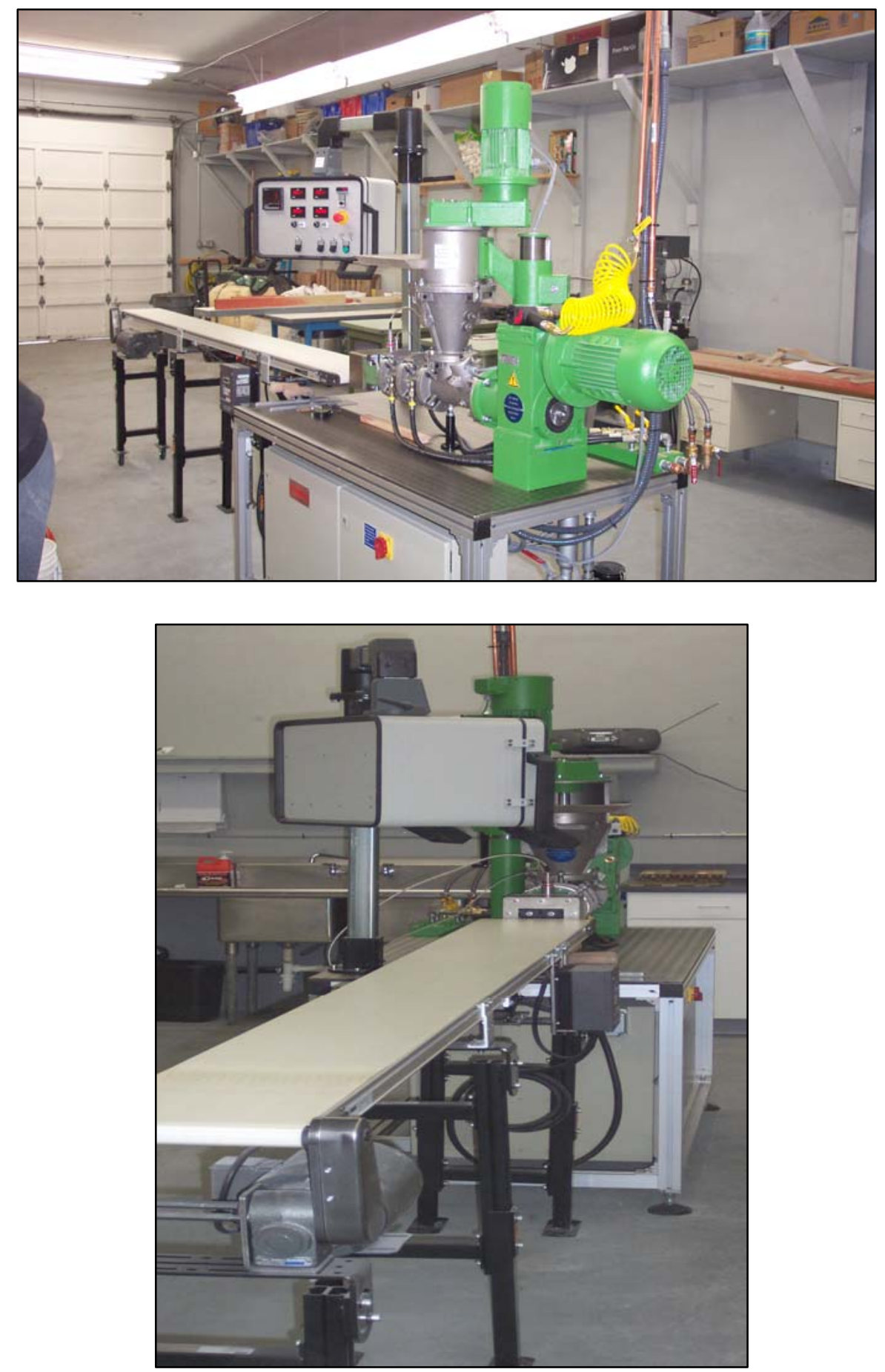

Figure 7: Photographs of the Haendle Extruder used for the project. 


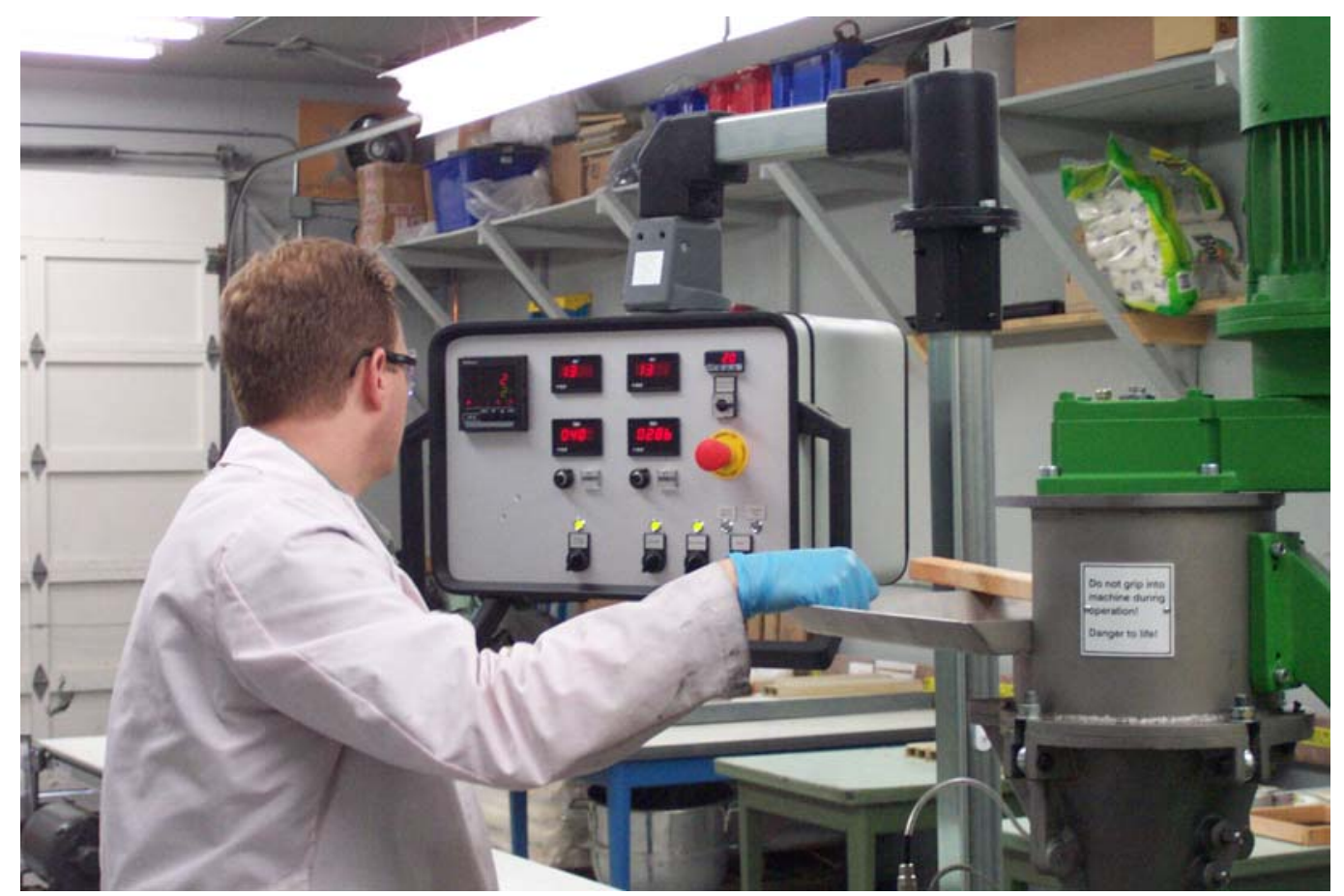

Figure 8: Photograph of the computer controlled operation of the Haendle Extruder.

WRI's Eirich model RV 02 high intensity pan mixer was used to achieve intense mixing of the composite materials to be fed to the Haendle extruder. The Eirich mixer (Figure 9) employs both rotation of the mixing bowl and high speed rotor action. The dry, often fluffy, ingredients can be mixed into a compactable product that is then extruded (Figure 10).
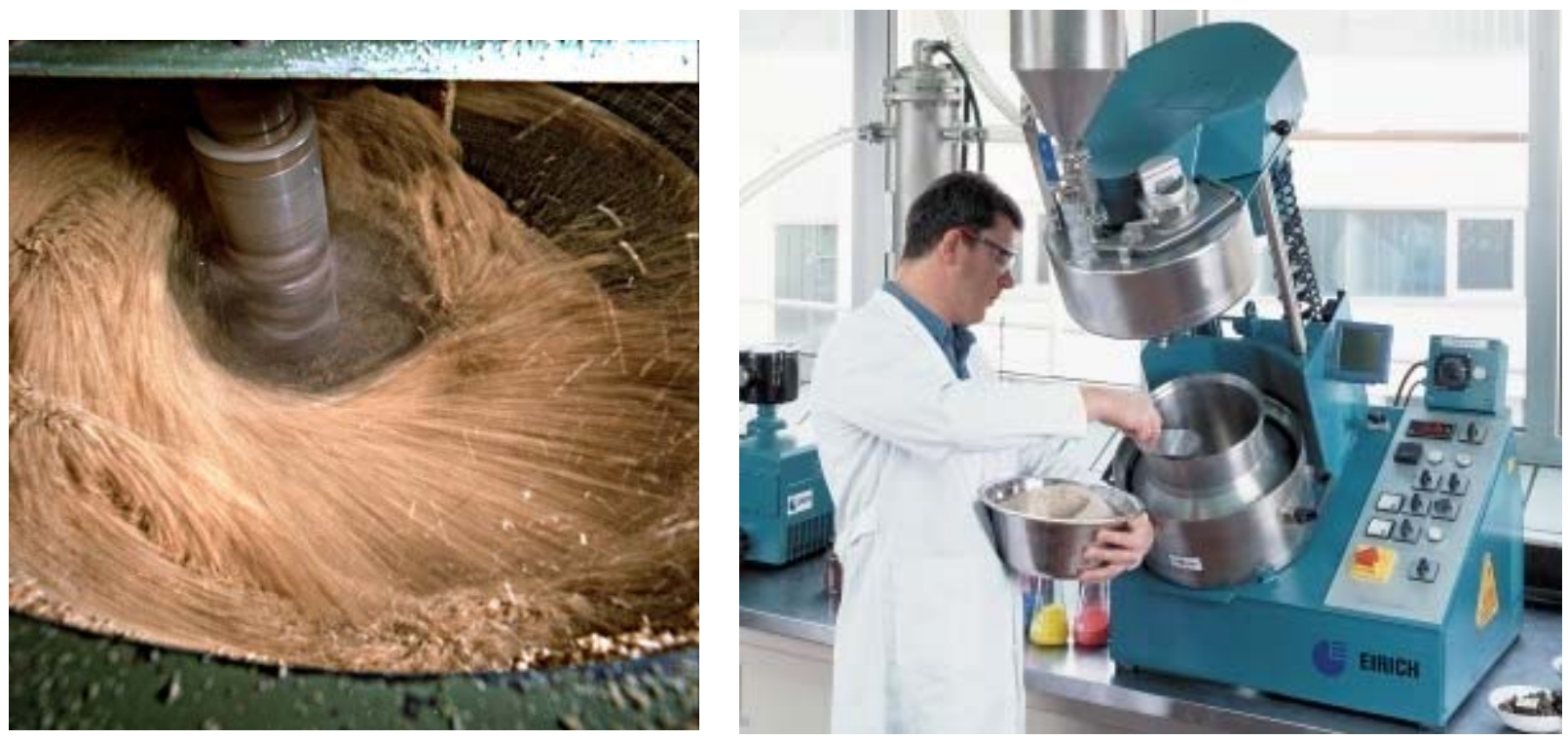

Figure 9: Photographs of the Eirich mixer used in the testing (right) and the mixing action that it imparts (left). Courtesy of Eirich 


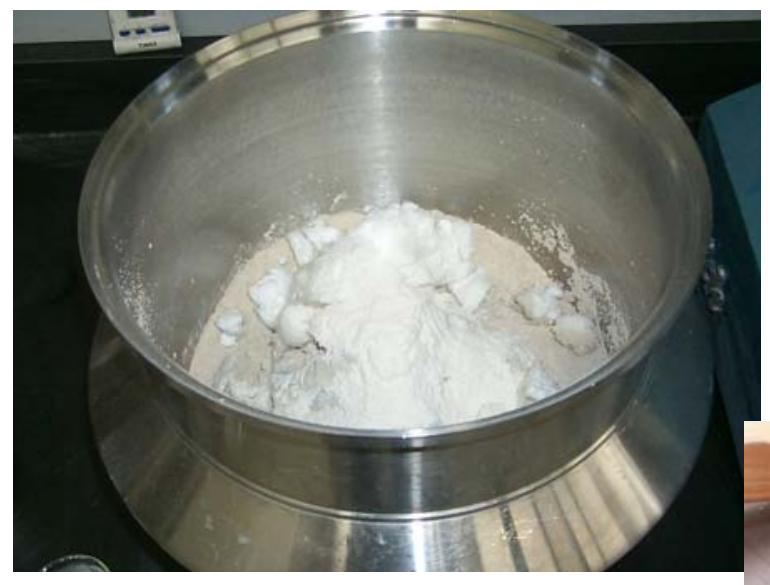

Figure 10: Photograph showing the physical properties of the composite ingredients before (above) and after mixing with the Eirich mixer (right).

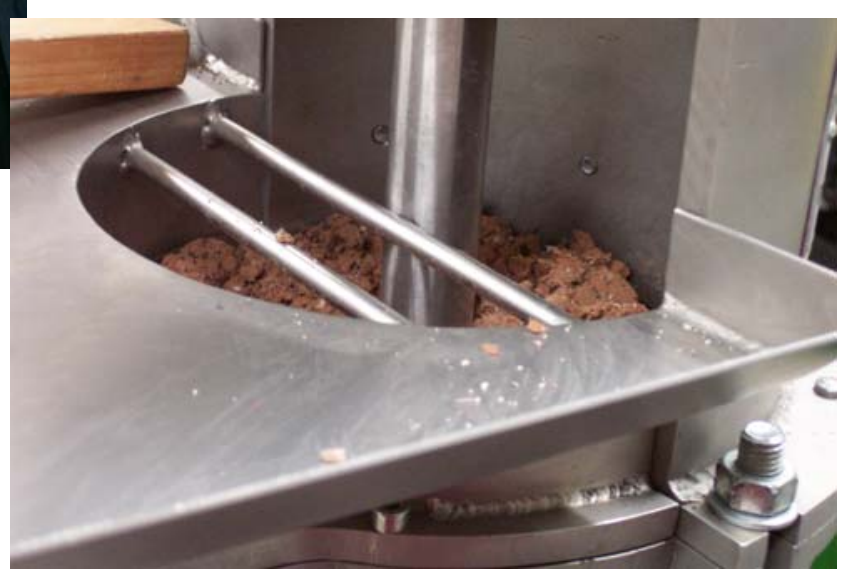

Extrusions of different composite formulations to produce specimen for flexure testing were accomplished using a custom made batch plunger extruder (Figure 11). The specimens (Figure 12) were subsequently cured and testing in the flexure test rig shown in Figure 13).

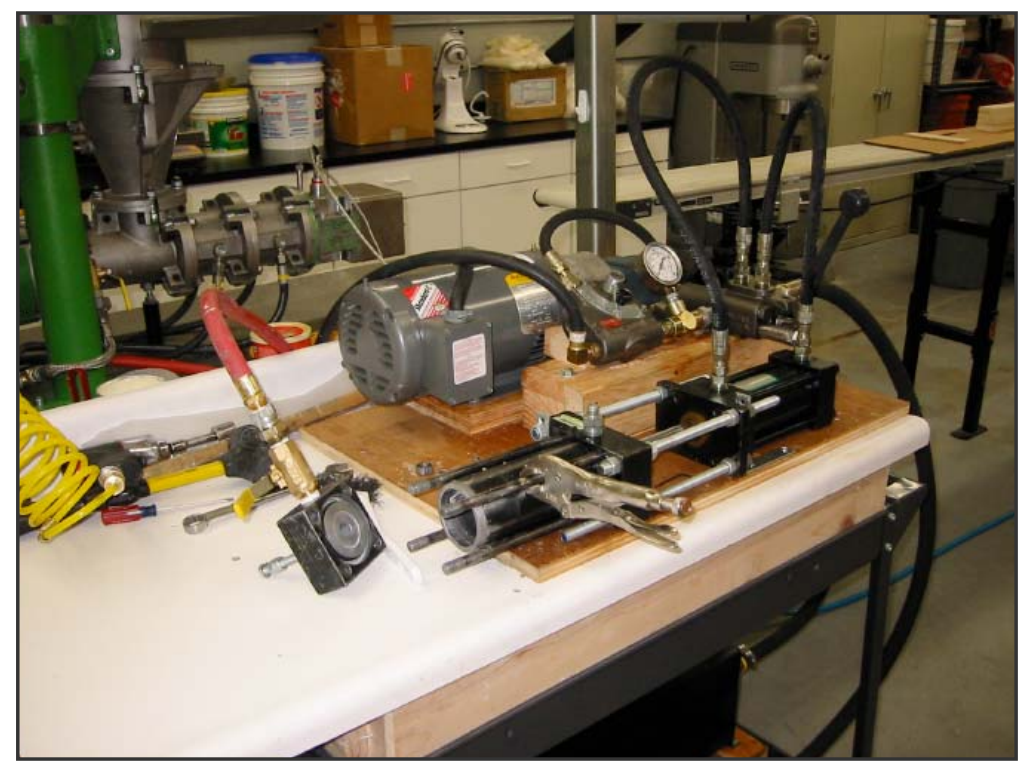

Figure 11: Laboratory batch plunger extruder used to process samples for flexural testing. 


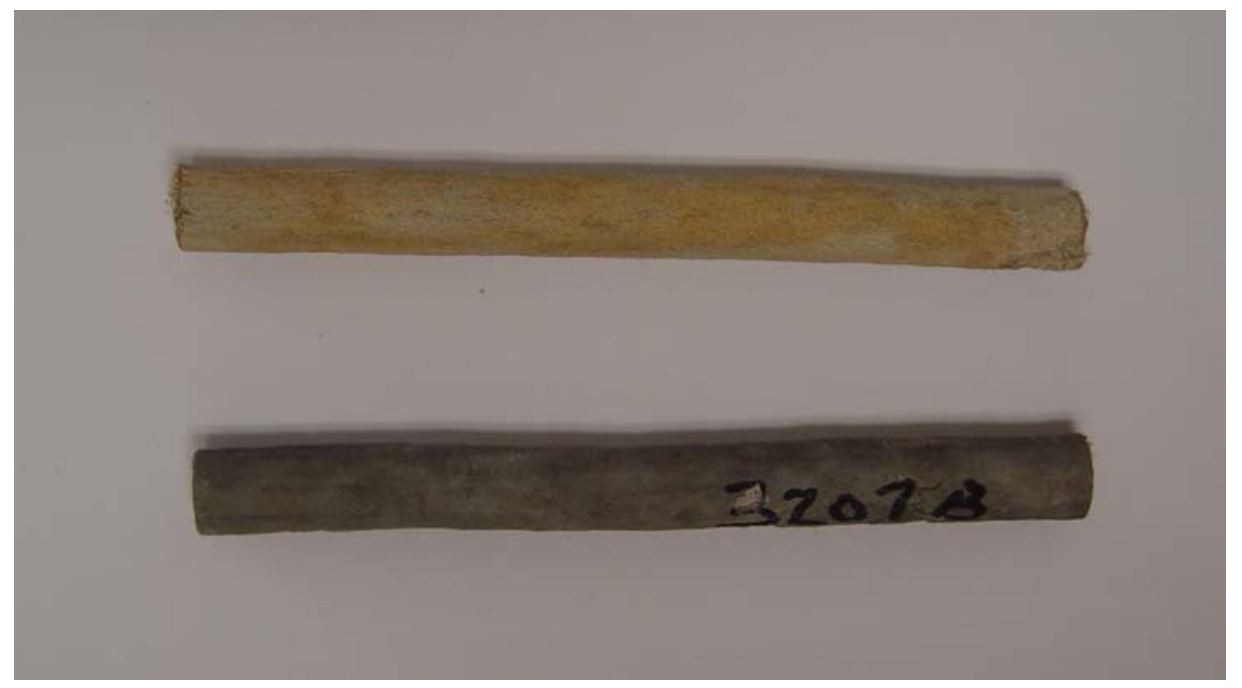

Figure 12: Photograph of composite specimens used for flexure testing.
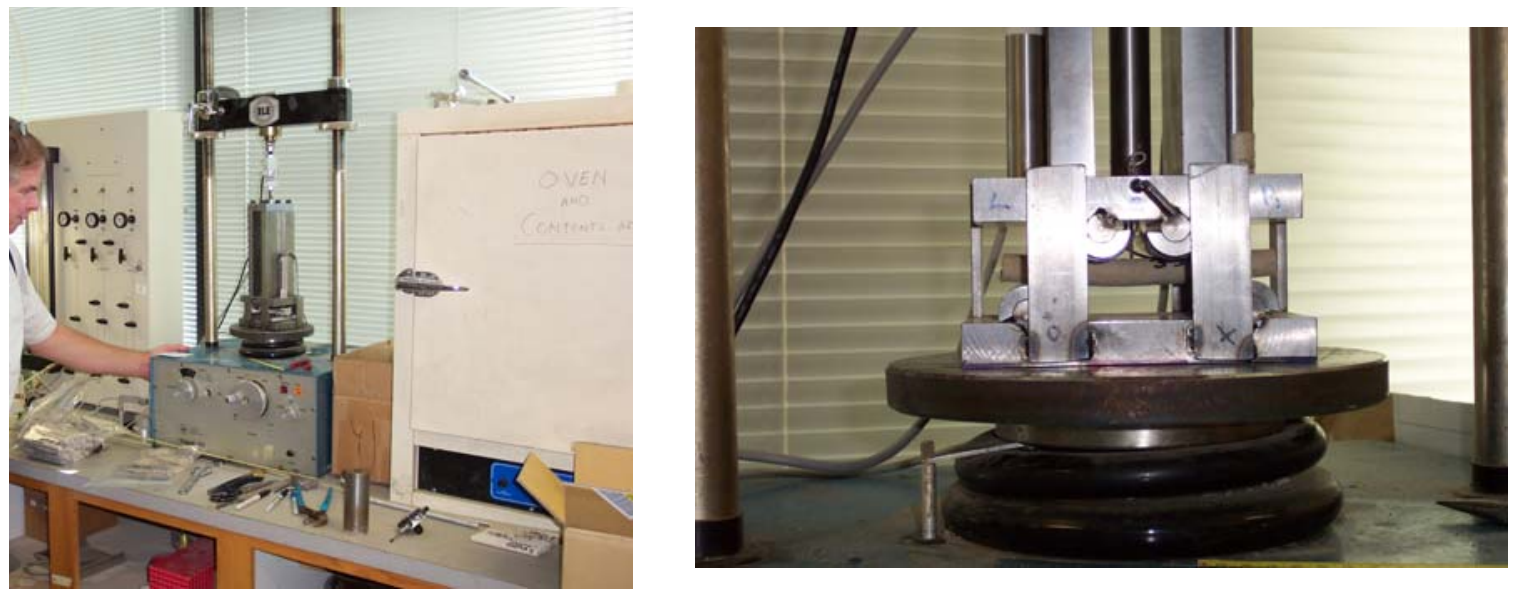

Figure 13: Testing rig used for testing flexure strength of the composite formulations.

Unconfined compressive strength testing was performed by WRI using a standard 2-inch cube mold to form specimens to the projected extruding density via WRI’s Forney F-25-F-F96 compression testing instrument (Figure 14). 


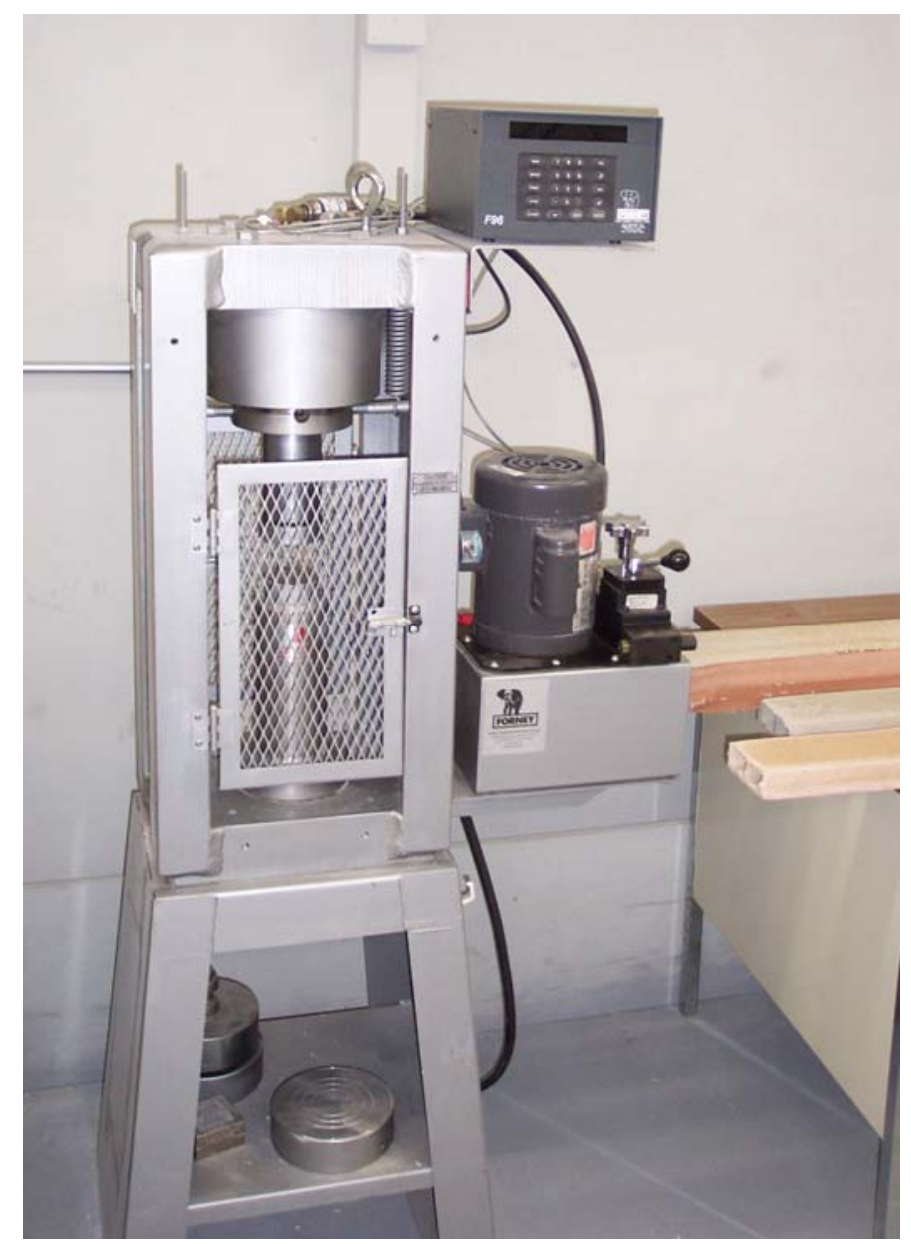

Figure 14: Photograph of the Forney equipment used for unconfined compressive strength testing.

\subsection{Composite Formulation Testing}

Using the equipment and facilities presented in Section 2.1, WRI and AeRock developed an extensive mix formulation experimental program. Over the life of the testing since 1999, thousands of composite formulations specimens have been fabricated and tested. As part of the WRI/AeRock program, WRI and AeRock tested a matrix of specimen formulations that were used to optimize the final AeRock formulations.

The Phase I testing was focused on resolving optimum water addition for extrudability, optimum fiber addition for flexural strength development, ash addition for strength development, and retardants and accelerators for strength and extruder performance. 


\subsection{Phase I Results and Discussion}

A series of different mixes were tested in order to obtain a detailed view of the ingredient interactions that influence optimization of these composite materials. The composite ingredient combinations reported herein represent the best mixes. Figure 15 shows the production of 2-inch by 2-inch specimens for testing.

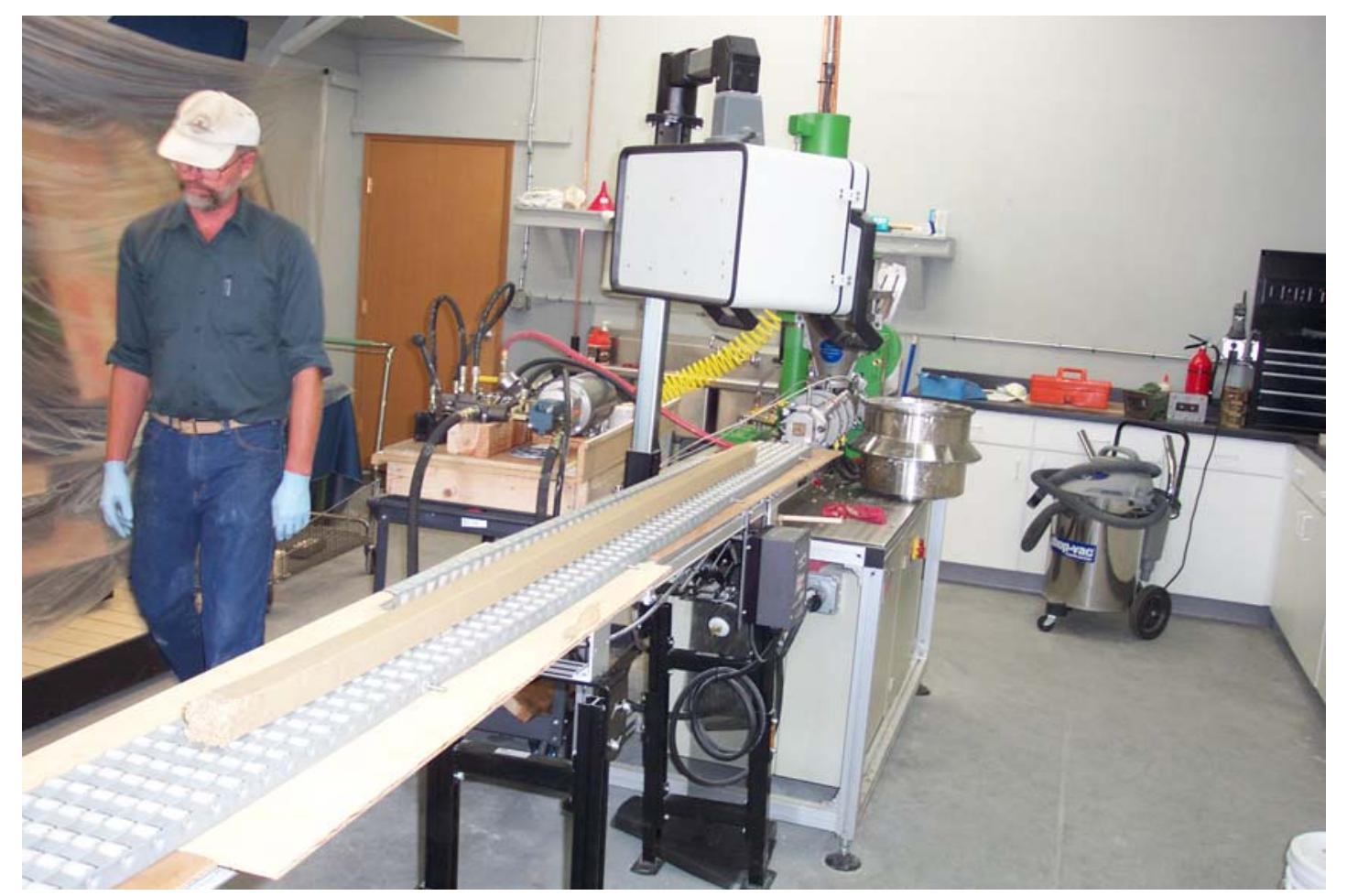

Figure 15: Photograph pilot-scale extrusion of 2-inch x 2-inch for testing.

2.2.1. Unconfined Compressive Strength: Two-inch cubes of the mixes were fabricated and run in triplicate to ascertain the unconfined compressive strength of the resulting composite material. In addition, extruded and cured composite formulation were cut and tested. These extruded composites were tested both with the direction of the extrusion and perpendicular to that direction. There was concern that the fiber orientation parallel to the extrusion direction would result in different strengths. There was some differences noted, but they were not substantive. An example of an unconfined compressive strength specimen after testing is depicted below in Figure 16. The breakage pattern contains both the features of a brittle material and a flexible material. 


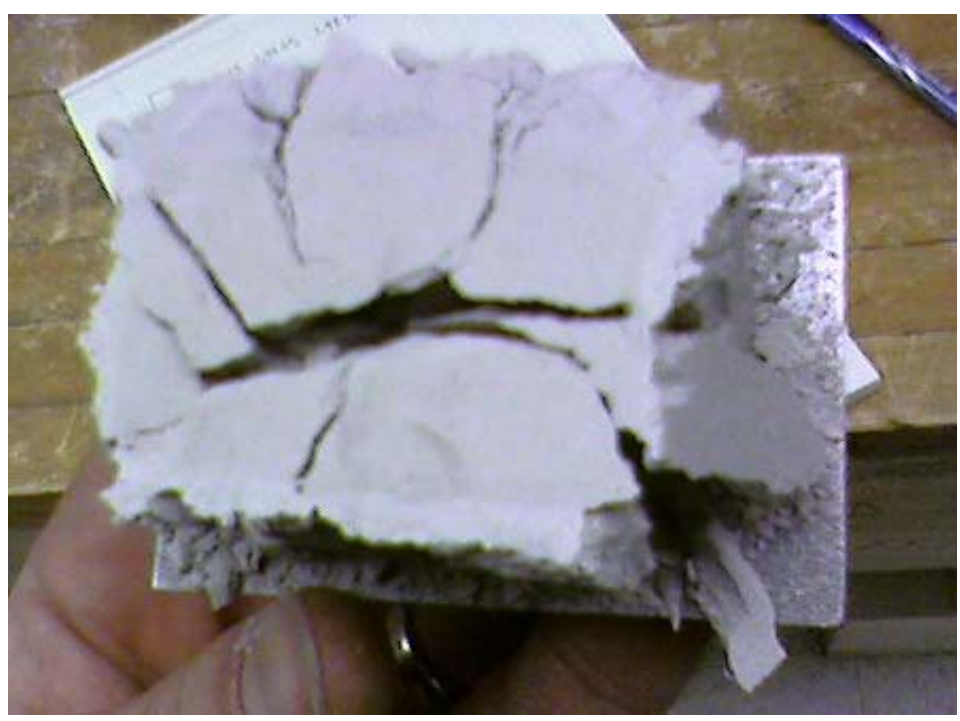

Figure 16: Compressive strength specimen after testing.

Plots of the final product unconfined compressive strength testing results are shown in Figures 17A through 17C.

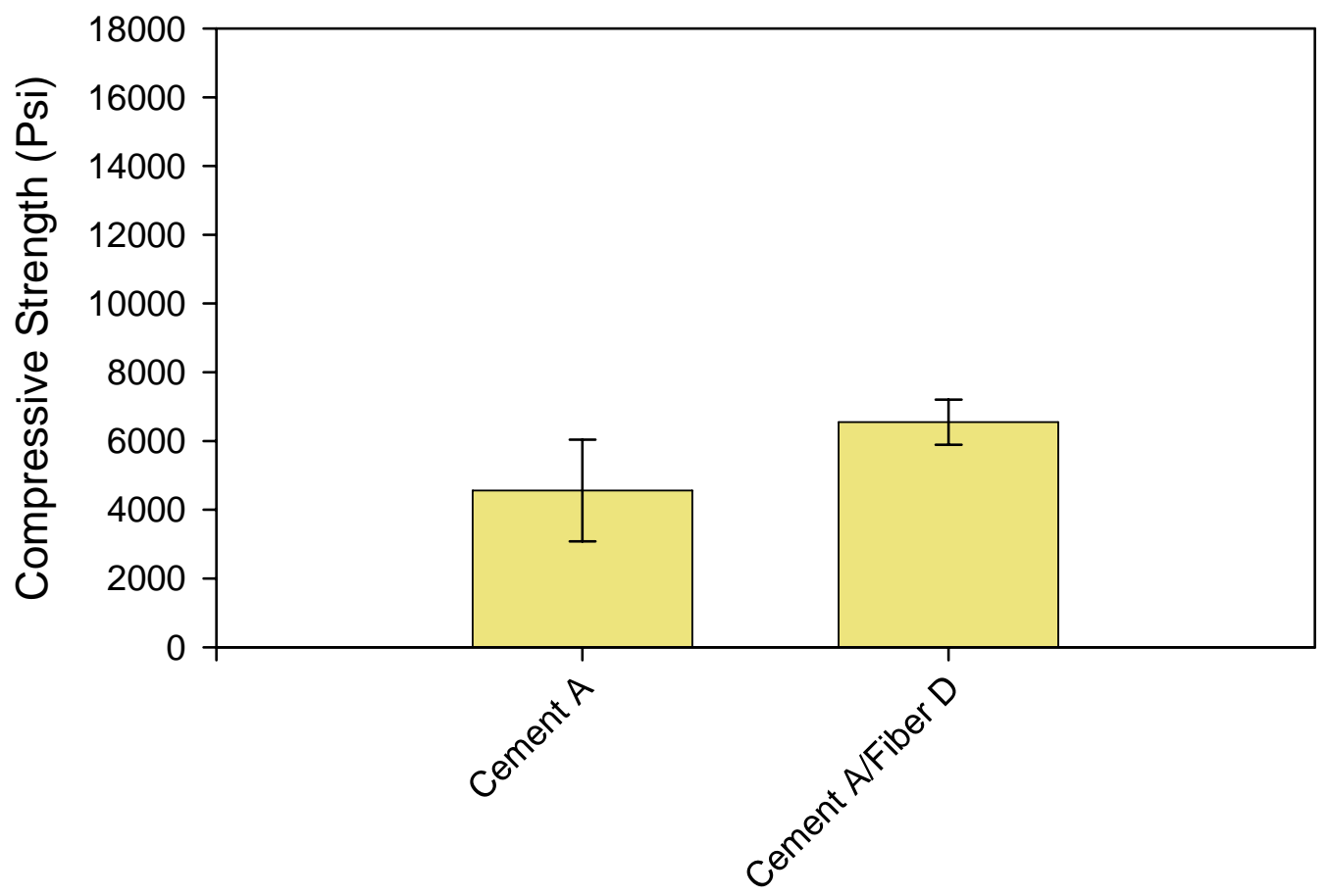

Figure 17A: Unconfined compressive strengths for Cement A with and without fiber addition. 


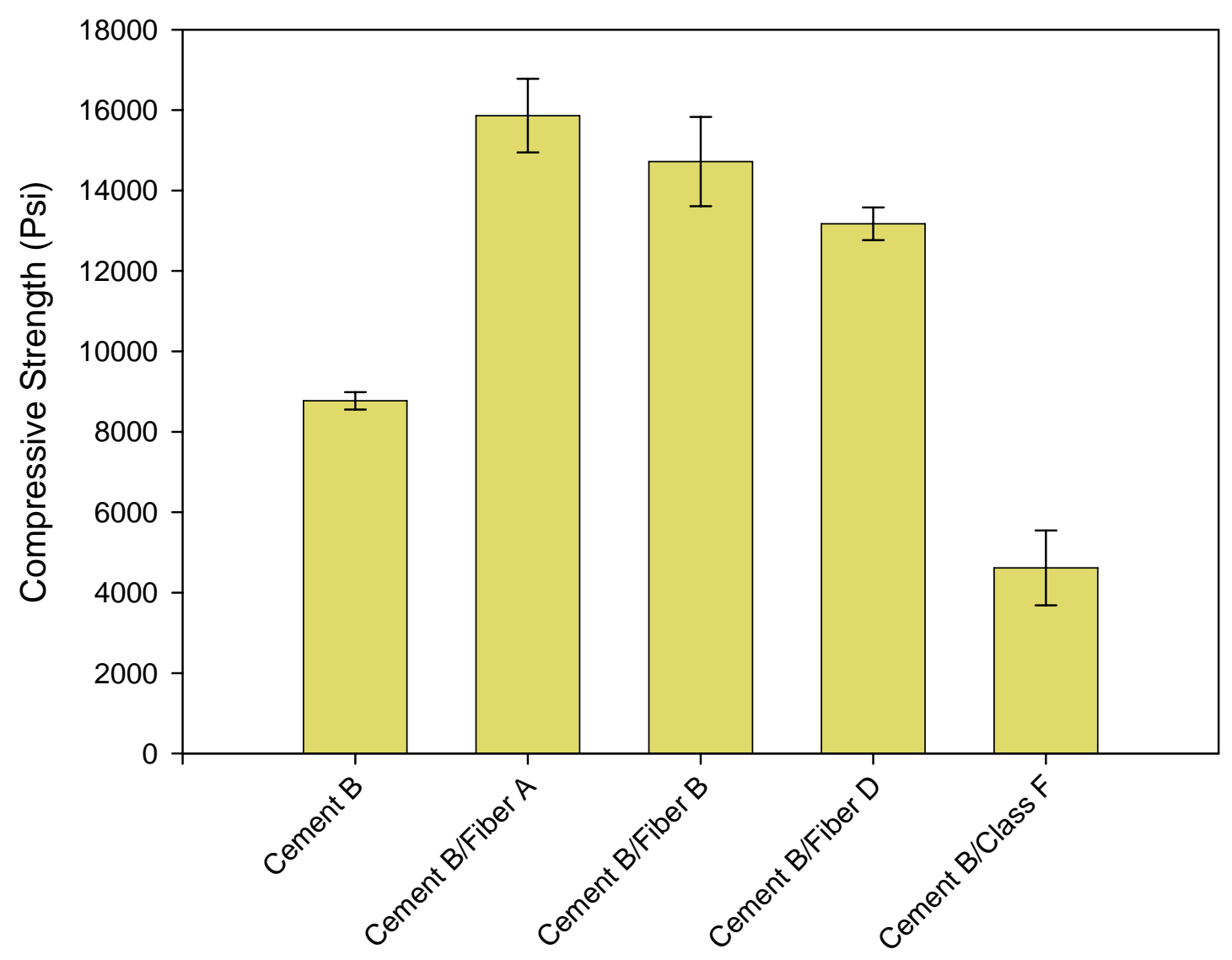

Figure 17B: Unconfined compressive strengths for Cement $B$ with and without fiber and with the addition of Class F DFGD ash.

Figures 17A through 17C show the three different cements having considerably different unconfined compressive strengths, ranging from 5,000 to 9,000 psi. All three cements show unconfined compressive strength gains with the addition of fiber. Cement $C$ showed an increase in unconfined compressive strength with the addition of a Class F DFGD ash, while Cement B showed a marked decrease on unconfined compressive strength with addition of the same ash. Clearly, the chemistry of the interaction of the cements and the DFGD ashes has a major impact on strength. 


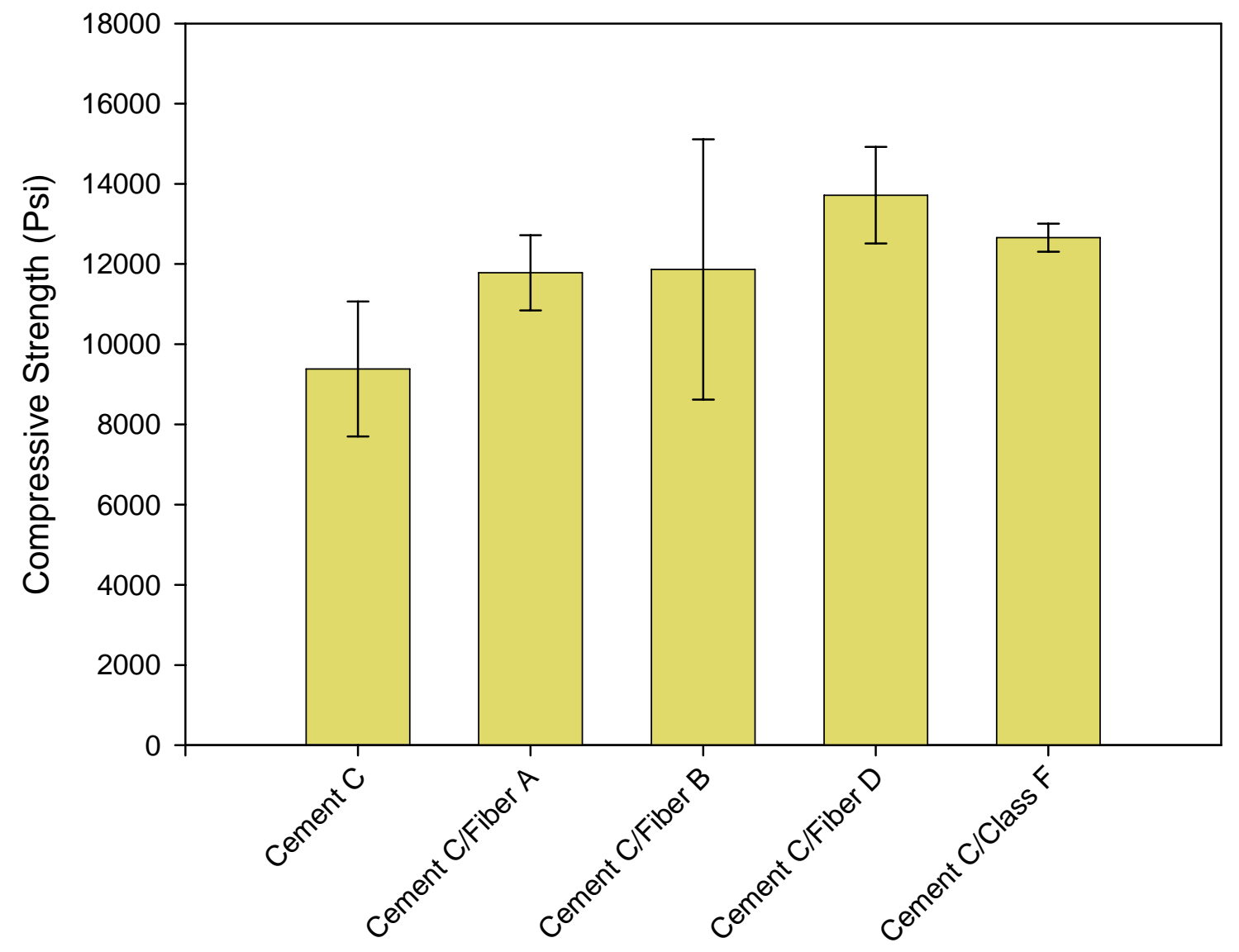

Figure 17C: Unconfined compressive strengths for Cement $C$ with different fibers and the addition of Class F DFGD ash.

Although the unconfined compressive strengths of the cements used in this study are below the typical 15,000 psi range for wood decking products, it was possible, through the addition of fibers, to increase AeRock values and even exceed the range of typical wood products.

2.2.2. Tension Strength Testing: Brittle materials, such as cement and ceramics, are notorious for being weak in tension. Bending a beam involves a complex set of forces distributed across the cross section of the beam. These forces are modeled and described as depicted in Figure 18. 


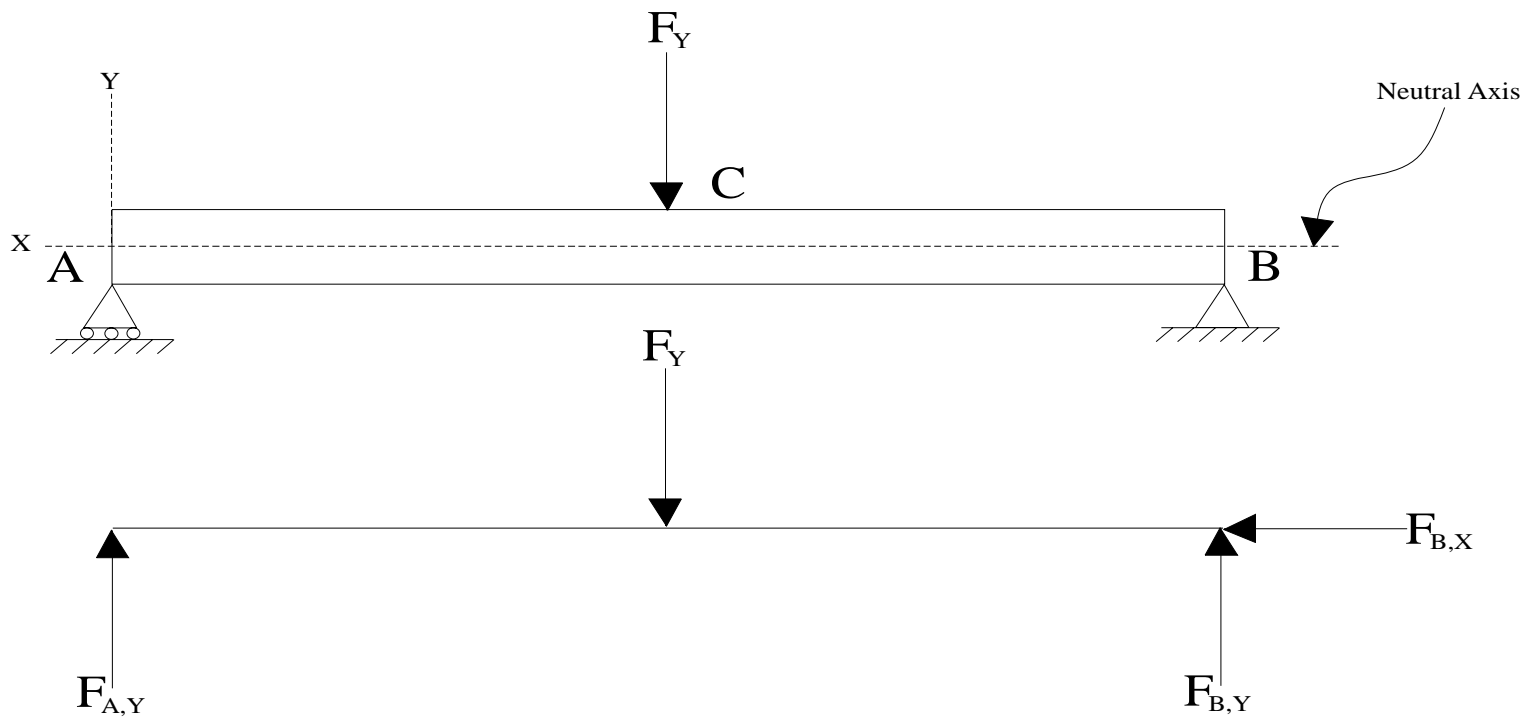

Figure 18: Schematic and free body diagram for beams in Bending (top to bottom)

Where the bending moment at point $C$ is defined as:

$$
M_{C}=\frac{F \cdot L}{4}
$$

The stress in the beam at point $\mathrm{C}$ varies with distance from the neutral axis,

$$
\sigma_{C}=\frac{M_{C} \cdot y}{I}
$$

Where I is the area moment of the beam and is cross-section dependent, and $\mathrm{L}$ is its length. This shows that the beam is experiencing different stress states along the thickness of the beam, i.e. the beam is in compression on the top and tension on the bottom.

As a result, WRI and AeRock designed the composite formulations to transfer the loading on the tension side of the beam to a material that functions well in tension. Fiber addition was employed for this purpose due to its relatively high tensile strength, low cost and low specific weight. The effects of fiber addition generally tend to increase a material's Modulus of Rupture (MOR) or maximum bearing load in bending, while decreasing the overall Modulus of Elasticity (MOE) when used in a brittle material matrix.

Flexural properties of the composites were carried out under a single point bending condition. This type of bending represents the worst case scenario for these materials in that it introduces a shear maximum at the failure point to which brittle materials are also relatively weak. The compression data was used to determine the material constituent mixes that would be 
used as a baseline for these tests. The three point bending apparatus shown in section 2.1 was used, and an example is illustrated below in Figures 19 and 20.

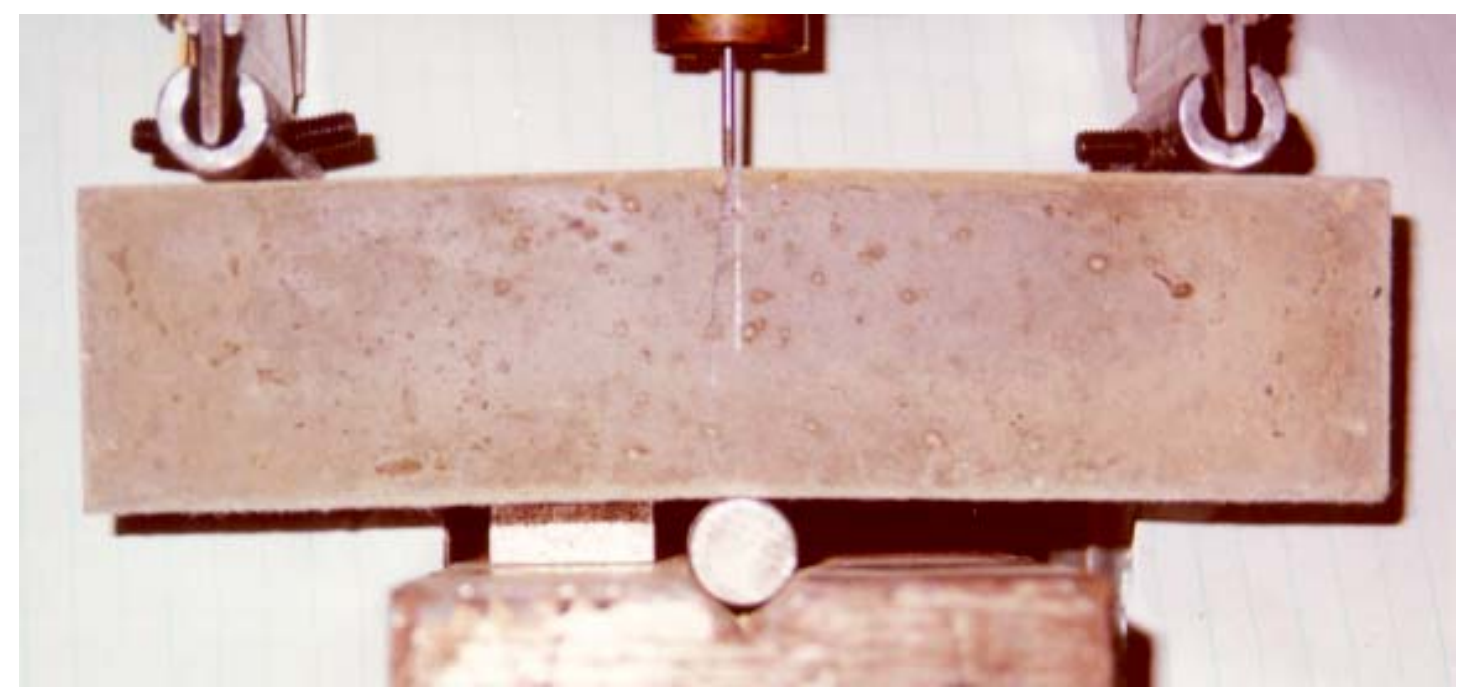

Figure 19: Flexure testing apparatus for the AeRock panel composite.

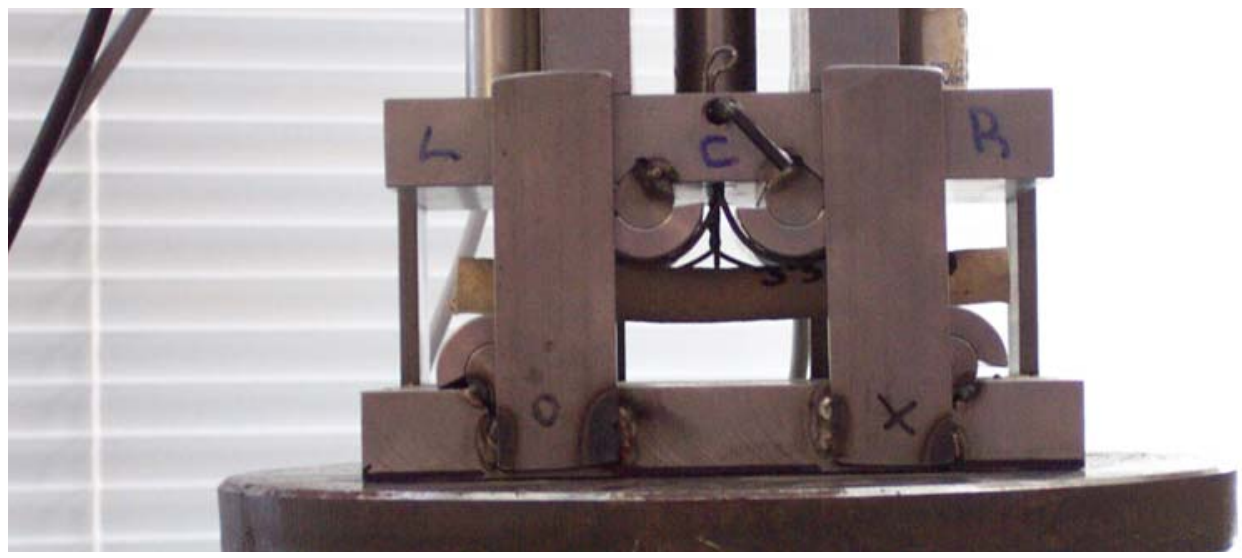

Figure 20: Small beam flexure testing apparatus used for rod specimens of the AeRock composite.

The data in triplicate from these tests were used to generate force vs. displacement plots for the different composite mixes and were used to determine the MOE and MOR. A typical plot produced for three different AeRock composites is presented in Figure 21. The force vs. displacement plot for the optimum performing mixtures is represented in Figure 22. 


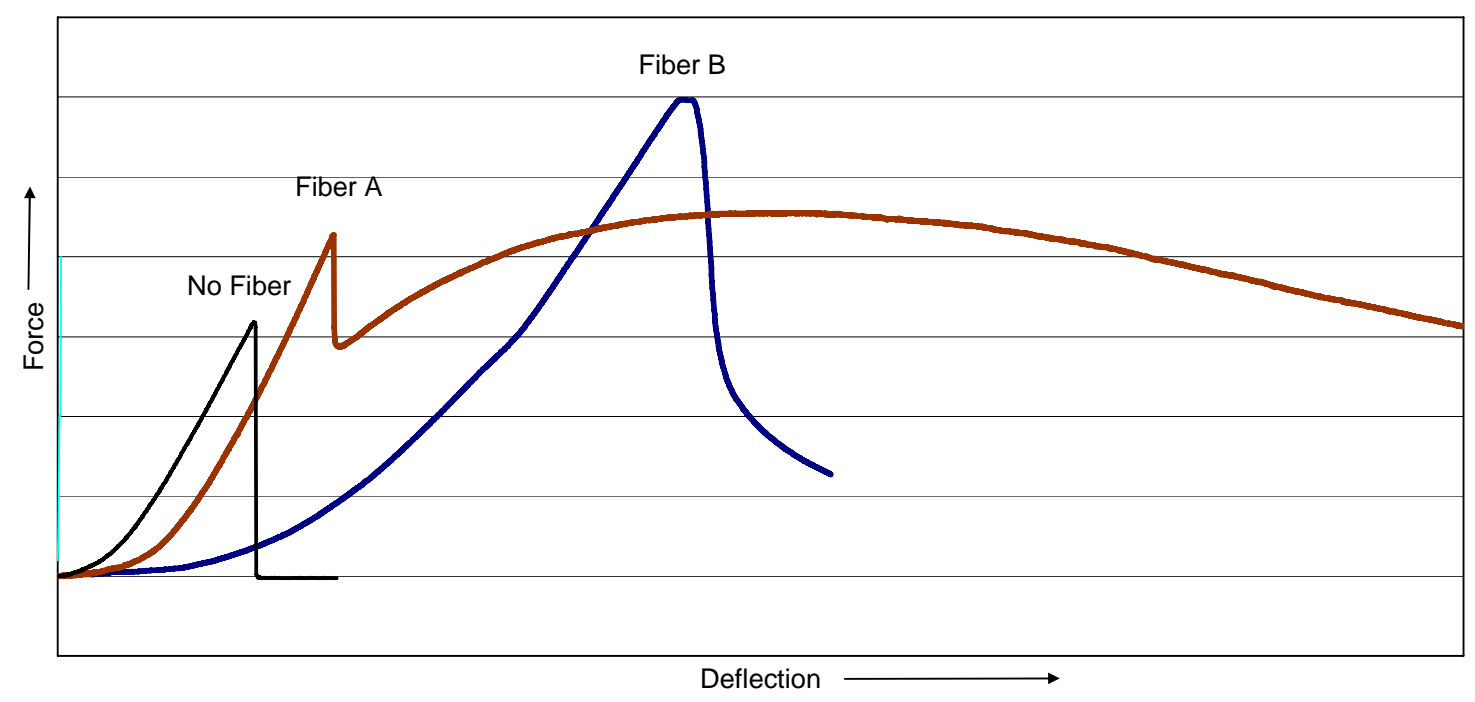

Figure 21: Generalized force vs. displacement plot for typical AeRock composites.

Figure 21 illustrates that through the addition of different fibers the failure mode of the engineered material can be altered. Three main failure modes are represented in the above plot; brittle failure with no fiber addition, failure with good fiber adherence to the matrix material, and failure with fiber pullout of the matrix material.

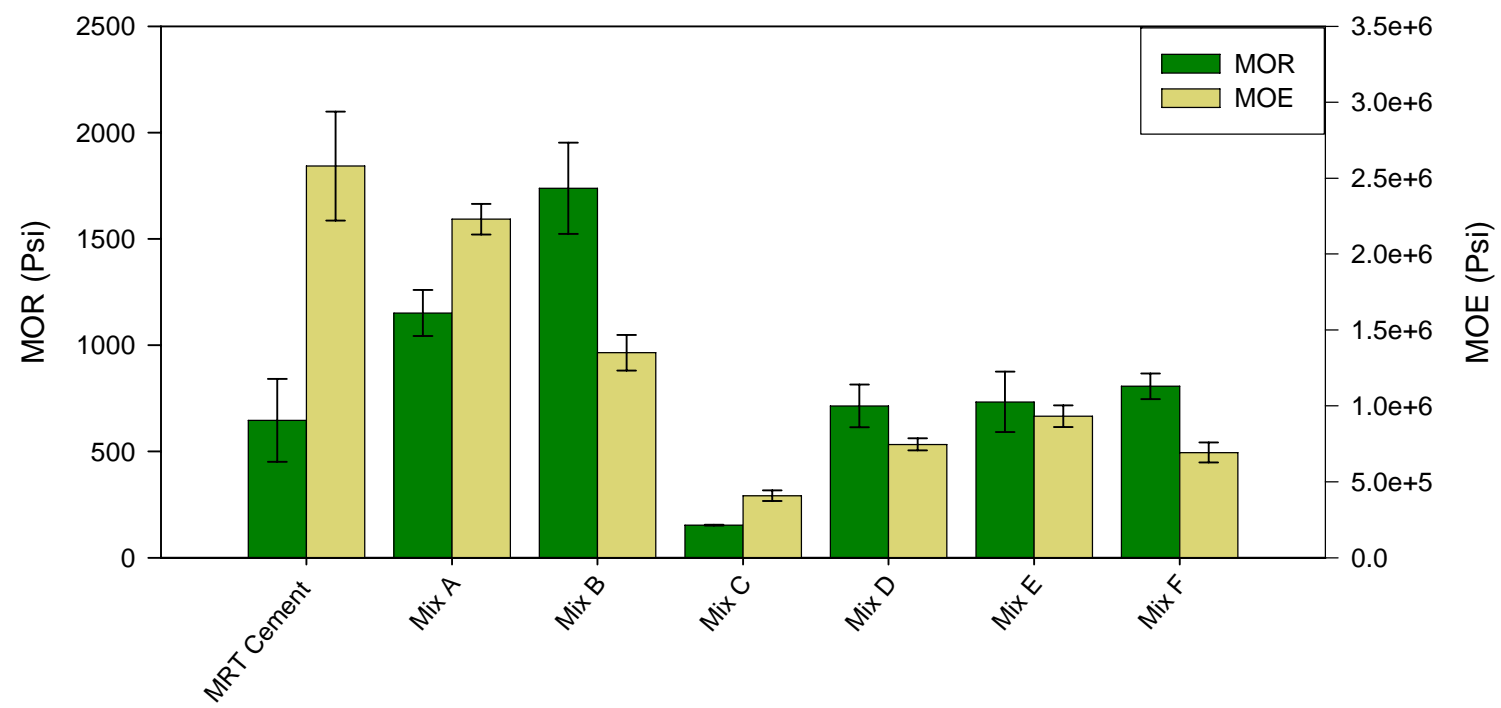

(Mix A - High ratio Class C Ash/MRT cement; Mix B - High ration Class C ash/fiber A/MRT cement; Mix C - Low ratio Class F Ash/MRT cement; Mix D - High ratio Class F ash/fiber A/MRT cement; Mix E - Low ratio Portland cement/Class C ash; Mix F - Class C ash/Fiber A)

Figure 22: Representative flexure results for AeRock composites. 
The above plot is representative of the maximum values for each composite formulation. These results were developed through extensive testing of single constituent addition formulations in order to understand the impact of each constituent on the overall material properties of the composite. Figures 23A and B illustrate the impact of fiber addition on the flexural properties of Cement B.

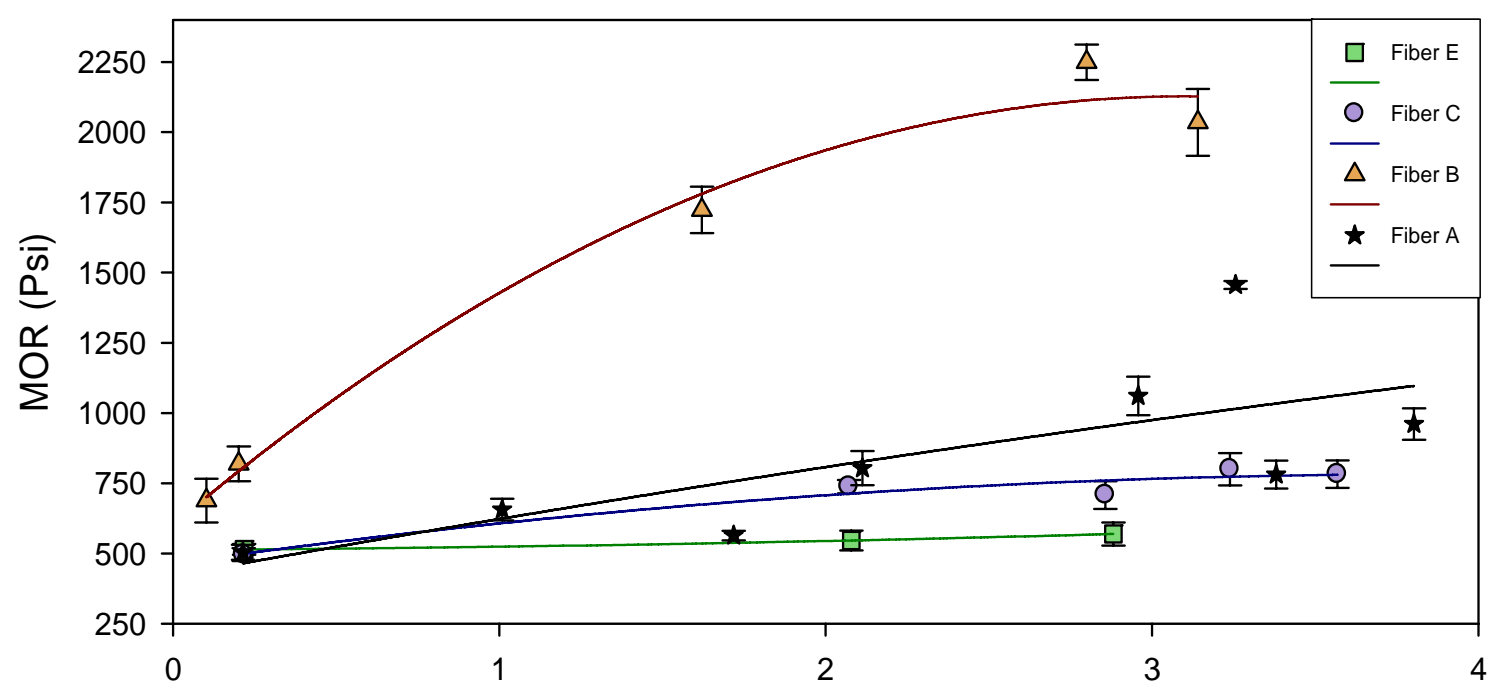

Fiber Addition (\% weight)

Figure 23A: Impact on MOR for different fiber additions to Cement B.

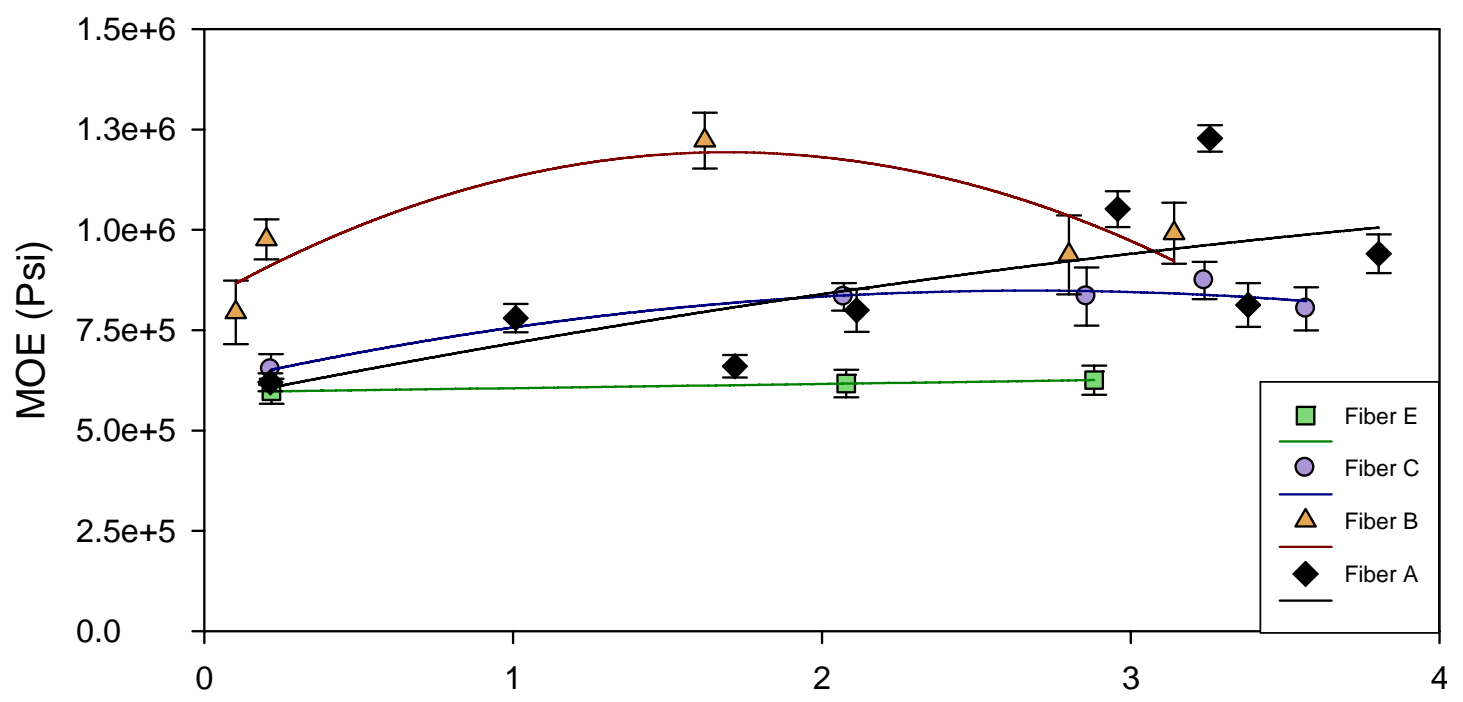

Fiber Addition (\% weight)

Figure 23B: Impact on MOE for different fiber additions to Cement B. 
These results indicate that an optimized composite can be realized through the addition of fiber and ash. Overall flexural strengths and modulus of elasticity can be tailored to the application. In general, there is a significant improvement in modulus of rupture and a decrease in modulus of elasticity making a stronger, less brittle material. This is apparently due to the fibers, cement and ash working in harmony. The addition of ash to these composites result in additional chemical bonding of the resultant hydration reaction compounds. The cumulative effect of ash addition on the AeRock composites is illustrated in Figure 24A and B.

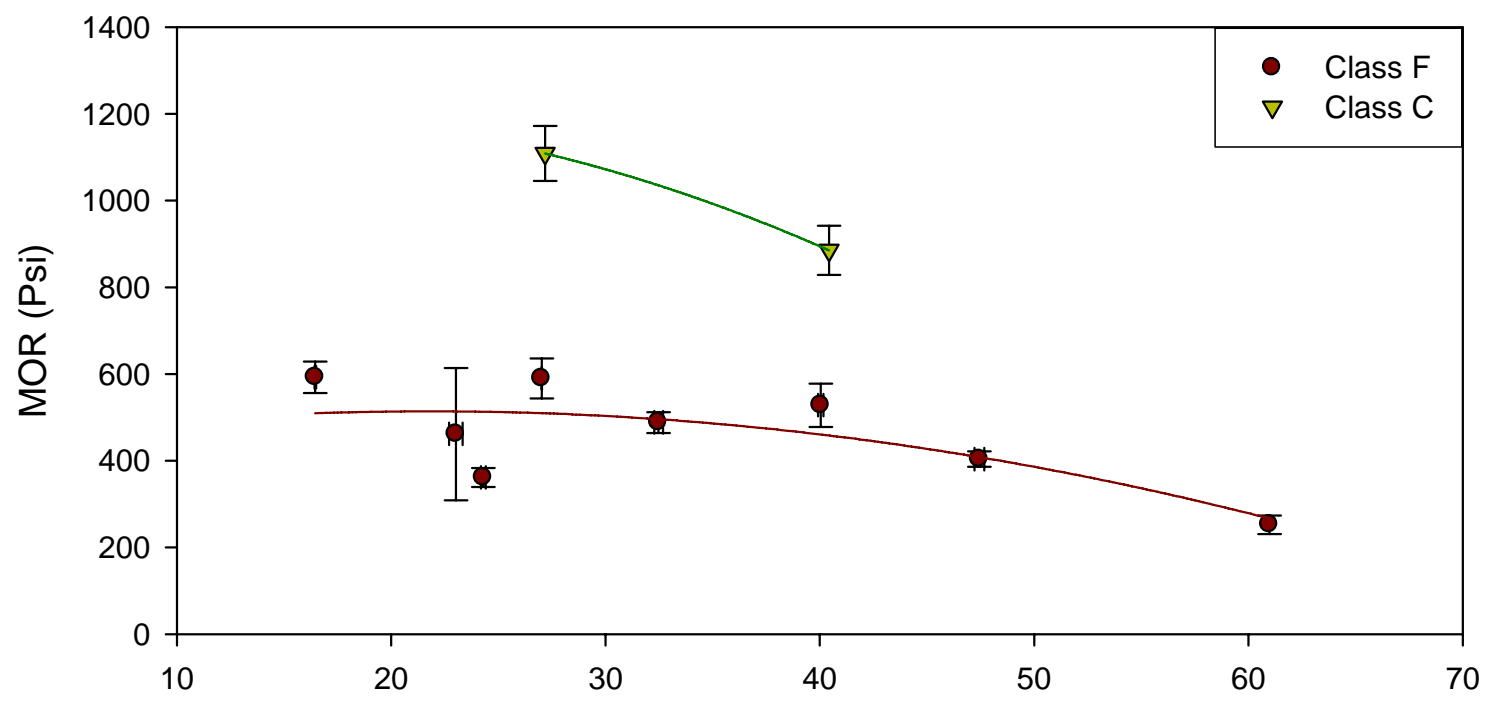

Fly-Ash Addition (\% weight)

Figure 24A: MOR analysis for ash addition.

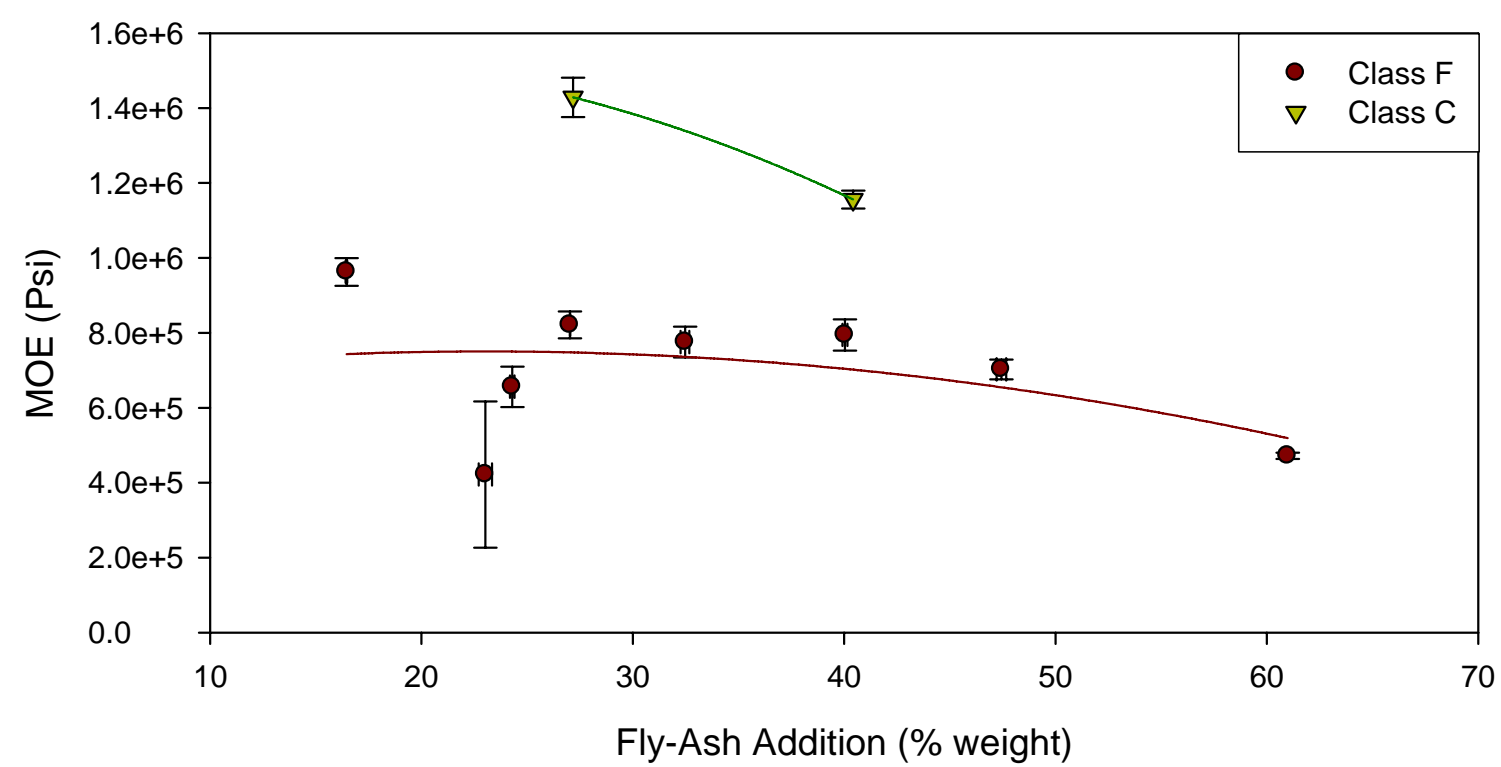

Figure 24B: MOE analysis for ash addition. 
In order to develop a material that possesses optimum material properties while also performing well under the harsh conditions presented by the extrusion process, additional chemical enhancements were needed. These chemical additions are specifically selected as activators to produce a material that would have an initial set rate that is compatible to the processing times required to mix and extrude the material. These chemical constituents are specific to the set requirements and are affected by the amount of fiber, ash, cement and water added. Optimization testing was conducted to ascertain the appropriate chemical addition for each formulation. Comparative plots were then developed and an example of such a plot is illustrated below.

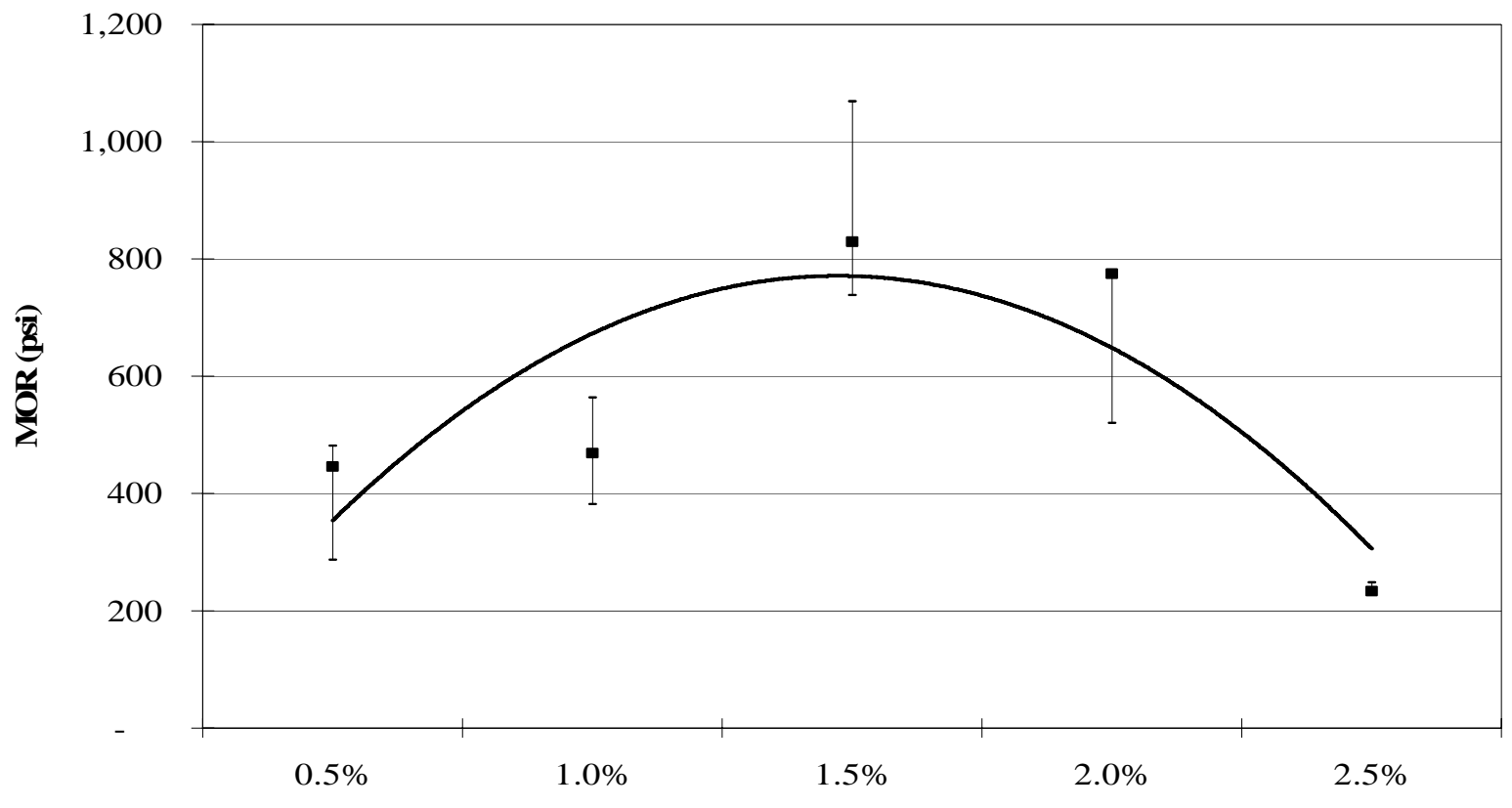

Activator Addition

Figure 25: Typical optimization testing of activators needed for certain AeRock formulations.

2.2.3. Micro-chemical Observations. A better understanding of the chemical and physical interactions of the constituents in the composite was sought through the use of scanning electron microscopy (SEM) and other such techniques. SEM can provide both a microscopic view the interactions of the composite constituents, but also a chemical distribution of the constituents. These chemical interactions, like the fiber and cement interaction shown earlier (Figure 17A-C, 23A and B), are important in understanding interaction of the ash, filler and cement interaction. The SEM effort was conducted by Susan Swapp of the University of Wyoming Materials Laboratories. Figures 26 and 27 are representative of the data derived from these studies. 

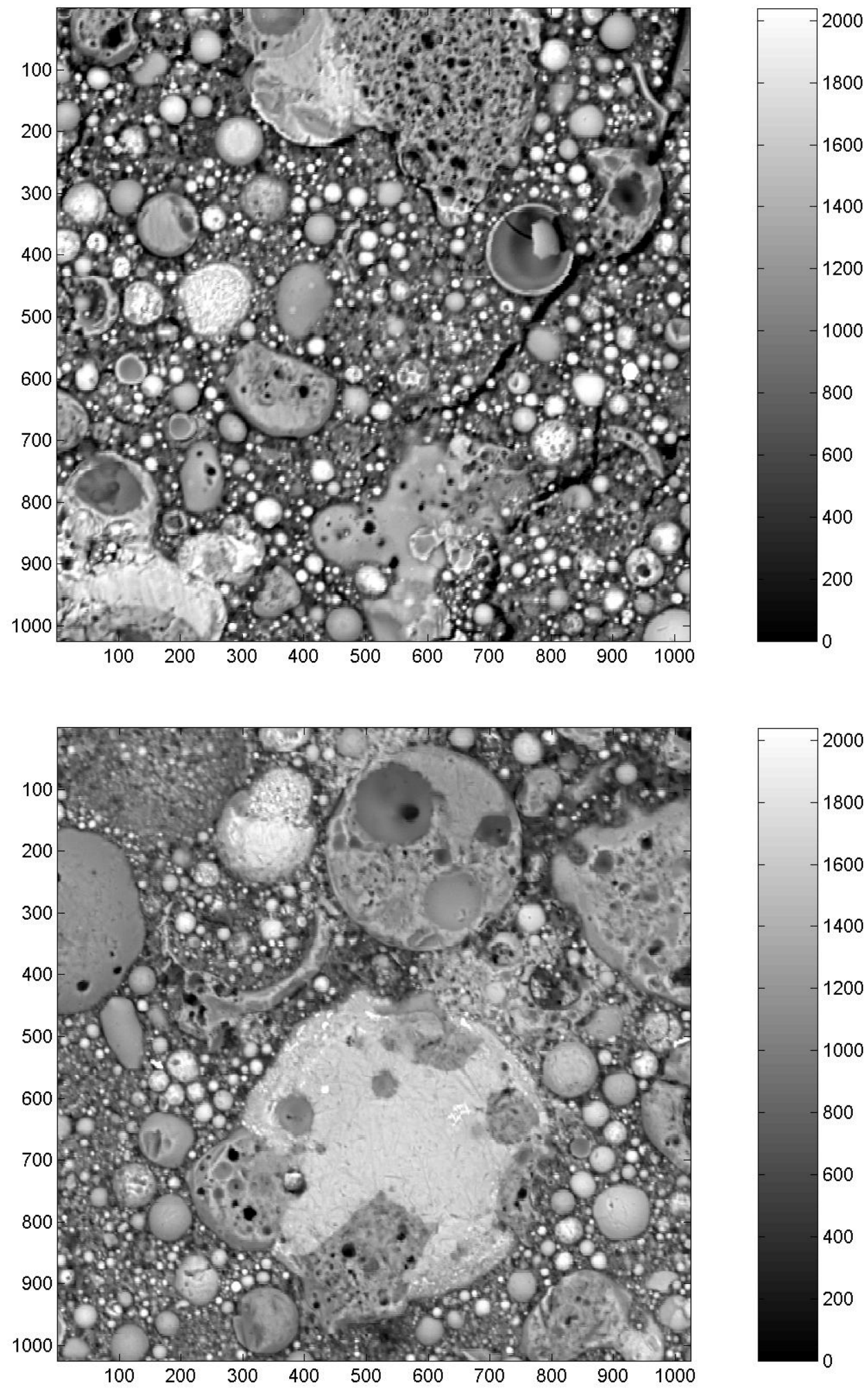

Figure 26: Electron backscatter images of MRT cement/Class C ash (top) and MRT cement/Class F ash (bottom). 
It is evident from Figure 26 above that there are significant difference between the Class $\mathrm{F}$ and the Class C-derived DFGD ash/MRT cement composites. Although it is easy to see the cenospheres in each of the electron backscatter images, the difference in size between the two is also abundantly clear. The interaction of the ash and the cement is surface dependent and in this case the Class $\mathrm{C}$ ash seems to have a higher surface and therefore a higher ultimate chemical interaction. This is consistent with the higher MOE and MOR data in Figure 24A and B for Class $\mathrm{C}$ ash addition. One suspects that this is due, in part, to other components also in the Class $\mathrm{C}$ derived DFGD ash that makes results in strength differences.
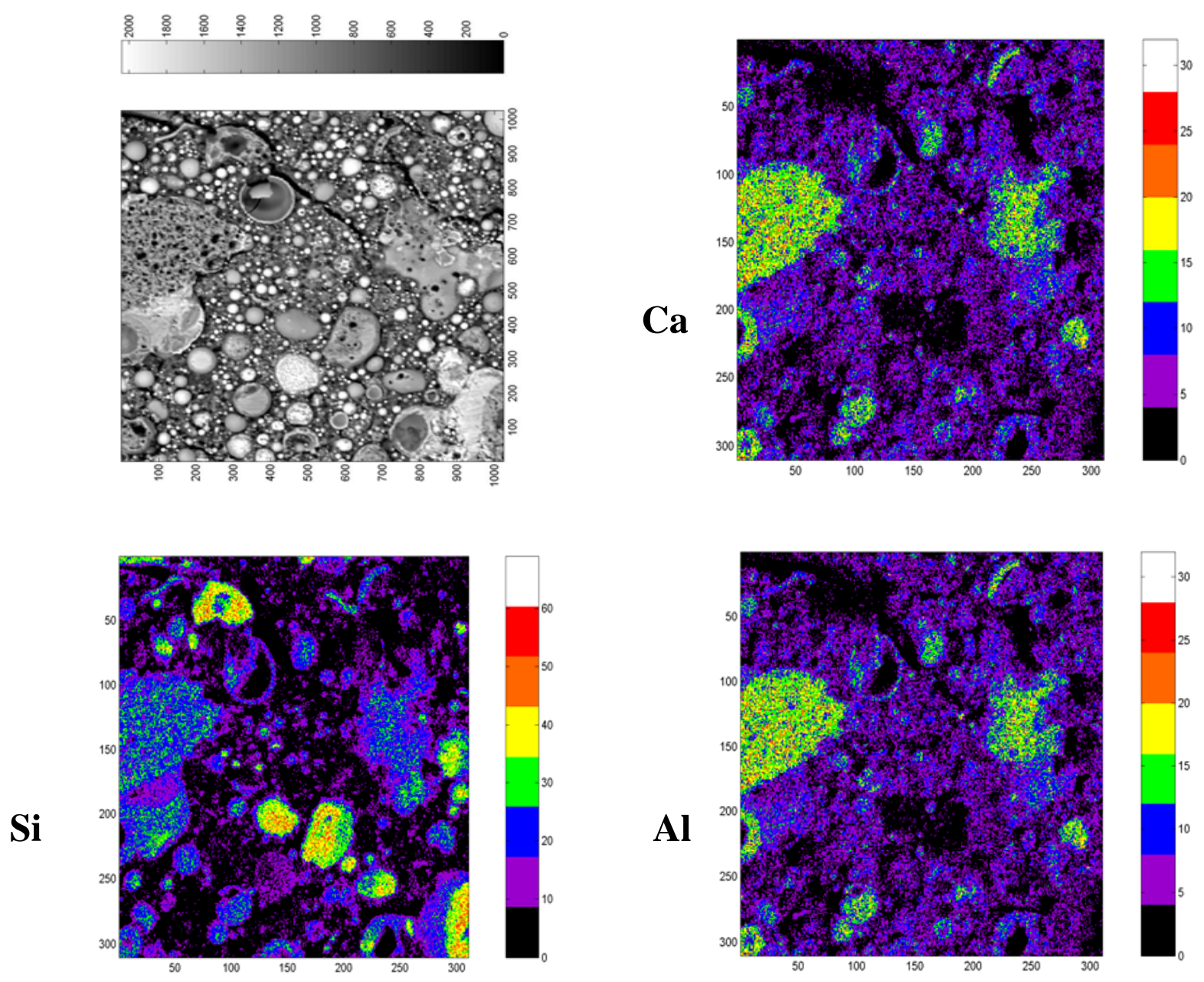

Figure 27A: Elemental map of MRT cement /Class C-derived DFGD ash.

Composite specimens were also analyzed for elemental distribution using energy dispersive x-ray spectroscopy(EDXS) as shown in Figures 27A and 27B. 

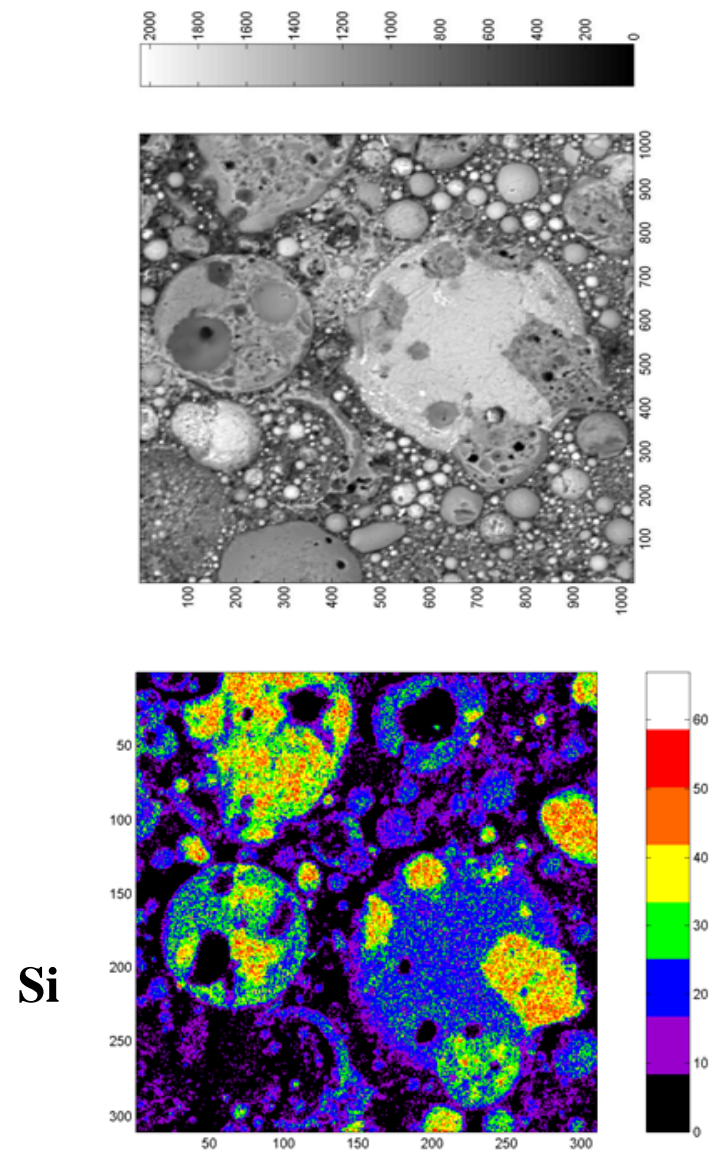
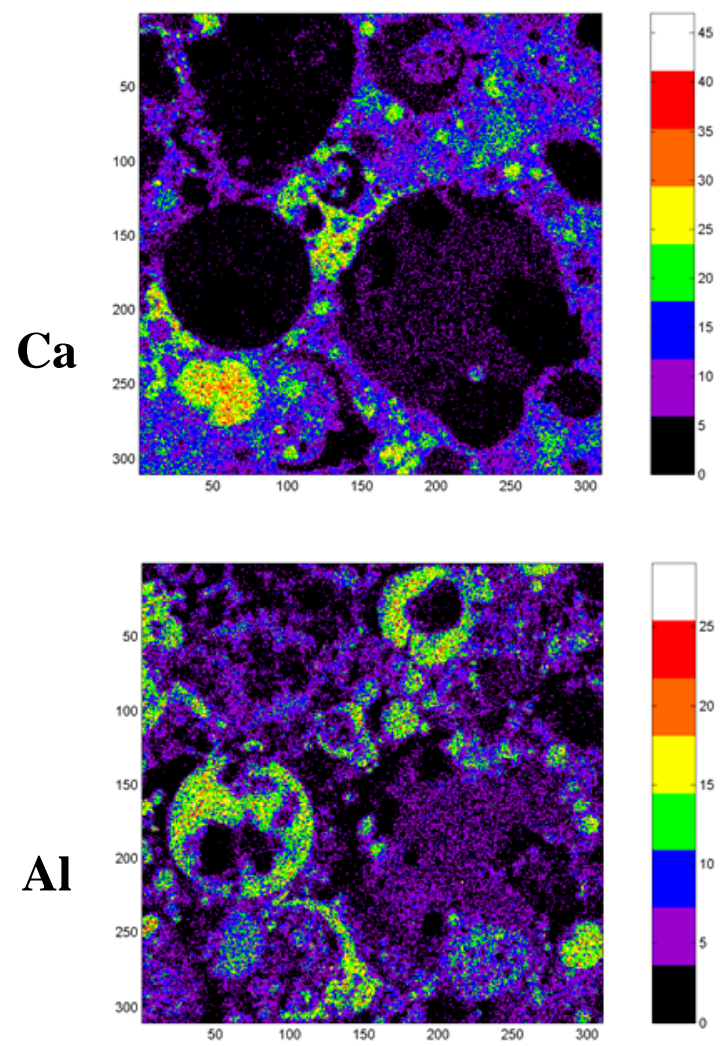

Figure 27B: Elemental map of MRT cement /Class F fly ash.

It is evident that the constituent mixes do not yield an entirely homogeneous material. Figures 27A and 27B show the ash forms a micro-aggregate in the MRT matrix. This phenomenon occurs even though MRT cement is primarily made of fly ash due to the proprietary chemical and mechanical pre-treatments used by MRT. One can also distinguish the particles with high $\mathrm{Ca}$ and $\mathrm{Al}$ indicating the cement particle. There are several Si-only particles, which reflect a $\mathrm{SiO}_{2}$ compound.

2.2.4. Fiber Pull-Out Investigation. The mechanical properties of fiber-reinforced composite materials depend upon the mechanical properties of both the fiber and the matrix material. In load-bearing applications some of the load is transferred through the matrix to the fiber. In order to gain the maximum benefit from this phenomenon, the fiber must adhere itself to the matrix. When the fiber is not adhered to the matrix, the fibers pull out of the matrix and reinforcement is limited to the mechanical bond between the fiber and matrix rather than the mechanical properties of the fiber. When good fiber to matrix adhesion occurs, the composite strength approaches the tensile strength of the fiber and also reduces dimensional instabilities (warping). 
In the AeRock composites, fiber pullout was noted when certain types of fibers were used. Figure 28 shows the pullout of fiber from one of the AeRock composites tested.

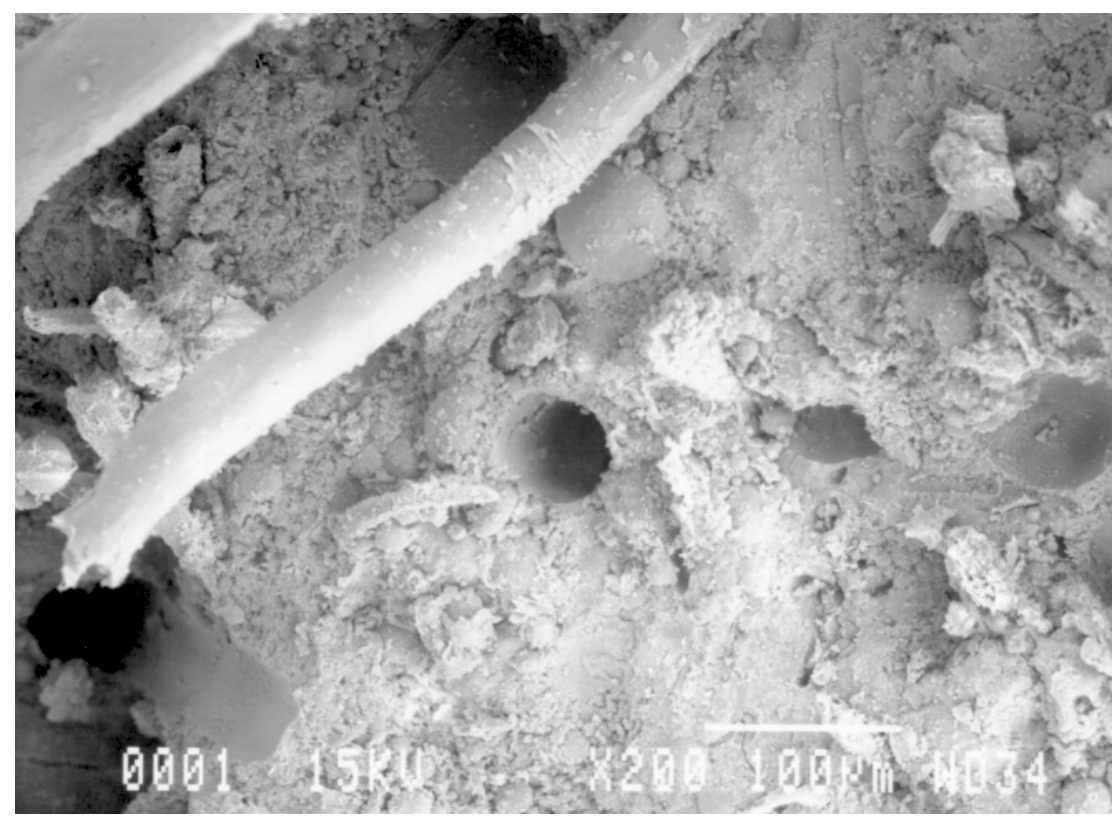

Figure 28: Illustration of untreated fiber pull-out in AeRock material.

Fiber pullout can be indirectly noted from the flexural test data by examination of the resultant force vs. displacement plots as illustrated in Figure 29 - 31 .

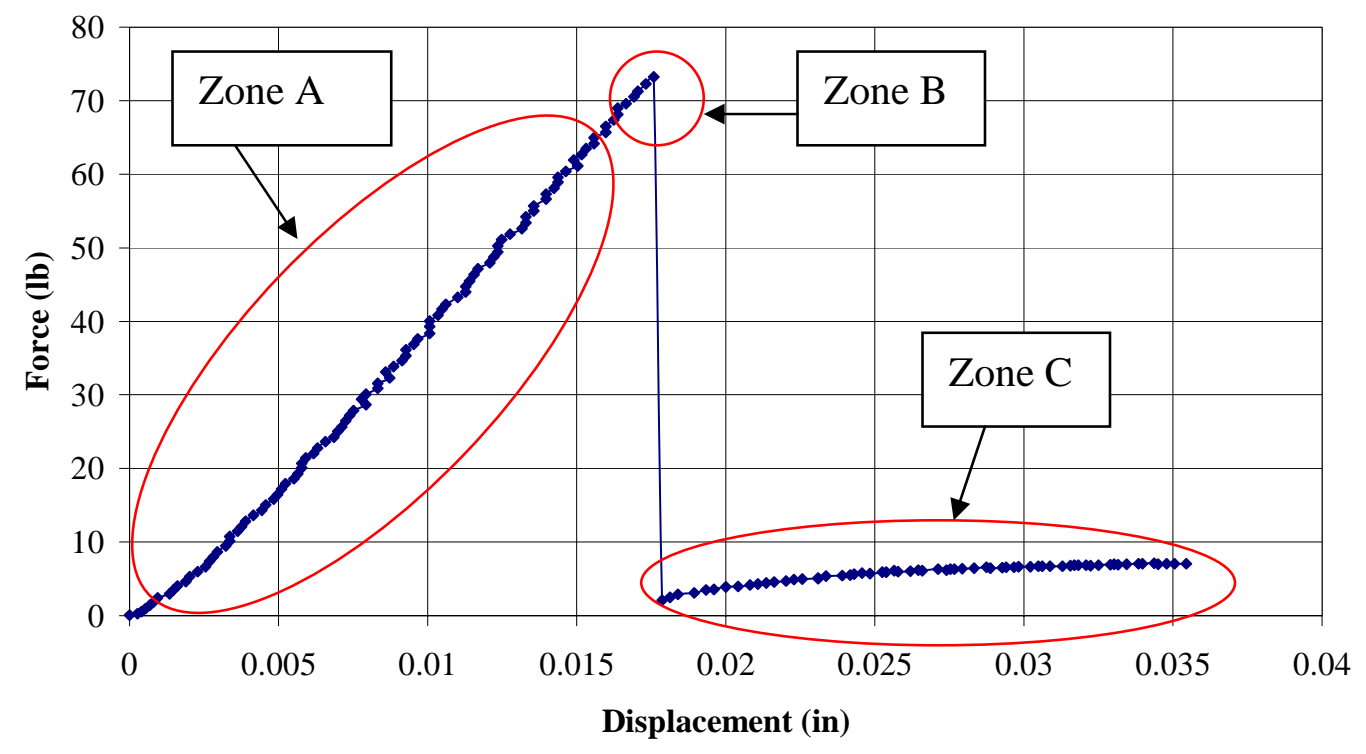

Figure 29: Flexural testing results with fiber pullout 
Figure 29 illustrates that with loading of the specimen elastic deformation is initiated in Zone A, followed by a brittle failure of the matrix material in Zone B. In Zone C, fiber pullout occurs with the maximum value in this section being dependent on displacement rate due to it being a measure of the mechanical adhesion failure of the fiber matrix interface (i.e.. friction). This can be compared to the same base matrix without fiber addition which shows both Zone A and $\mathrm{B}$, but lacking the tell-tale zone $\mathrm{C}$ force vs. displacement behavior related to the fiber (Figure 30).

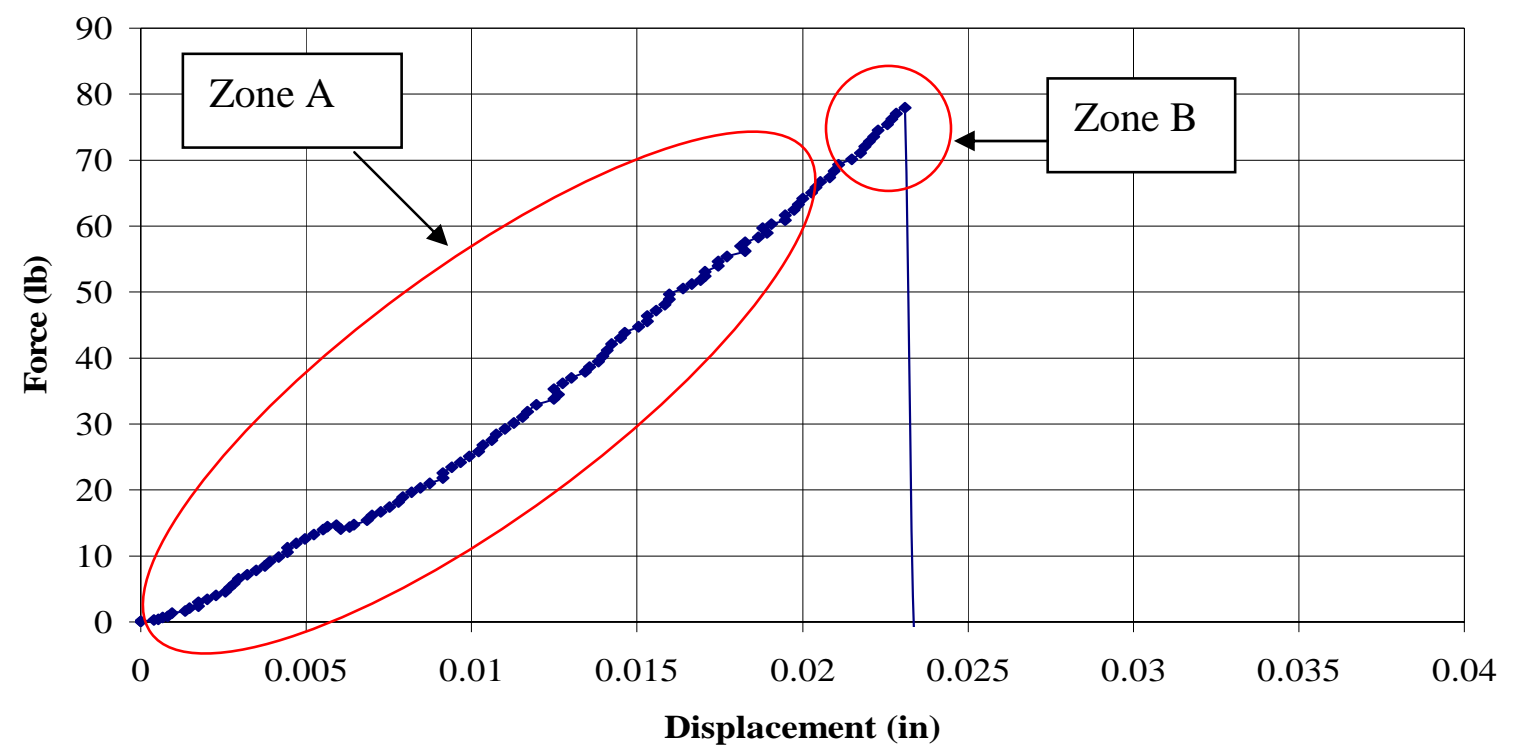

Figure 30: Flexural testing results without fiber addition.

In order to prevent this from happening, the fibers can be functionalized in such a way as to promote adhesion with the composite matrix. Functionalizing of fiber can occur either by changing the chemical properties of the fiber in such a way as to promote chemical bonding between the fiber and the matrix, or by modifying the surface of the fiber to promote stronger mechanical bonding with the matrix. There are many ways that a fiber may be functionalized. A fiber needs to be functionalized only to the point where pull-out is prevented.. Anything more is not beneficial and creates higher materials costs.

Good fiber adhesion to the matrix produces a material that behaves like both materials instead of two separate materials. This is illustrated in Figure 31. Composite materials of all types perform similarly to this situation in all respects. There is an initial elastic deformation zone (Zone A), an initial matrix failure (Zone B), secondary failure of either the matrix or the fiber reinforcing material (Zone $\mathrm{C}$ ). This is followed by plastic deformation of the fiberreinforcing material (Zone D) and finally catastrophic failure of the entire material (Zone E). 


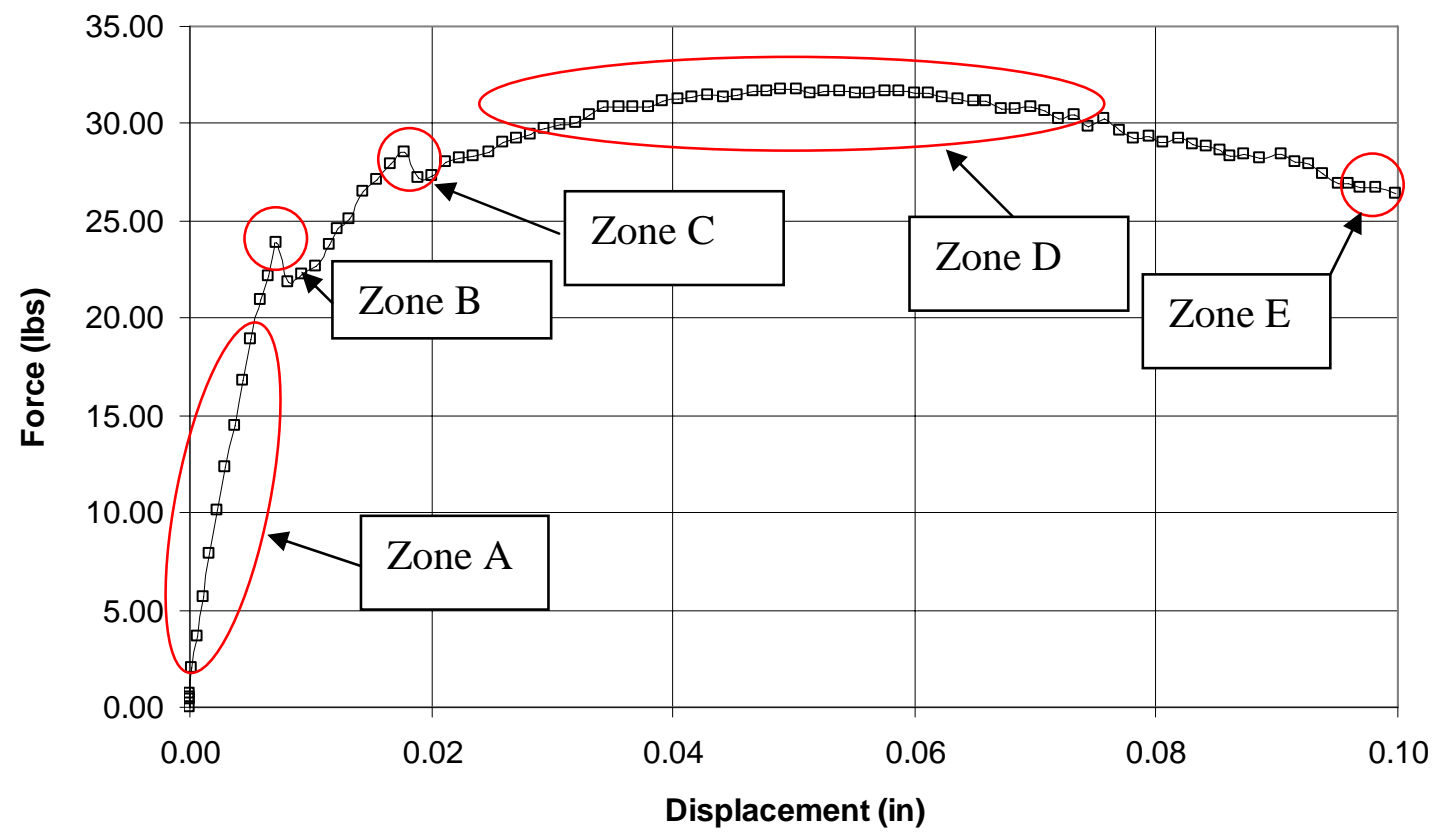

Figure 31: Flexural testing results with good fiber adhesion

2.2.5 Other Performance Tests. A number of other tests are commonly conducted when one evaluates wood and other building products. AeRock has conducted the relevant ones. Flame penetration is one of these tests. Flame penetration, flame spread and smoke tests were conducted using the AeRock composite material. In a flame penetration test, a flame is directed at the center of the board and thermocouples are placed at the center, and along the edge of the top and side to record the temperature. The results show a steady rise in temperature with no points of combustion, as shown in Figures 33 and 34. Eventually, the sample becomes brittle and crumbles.

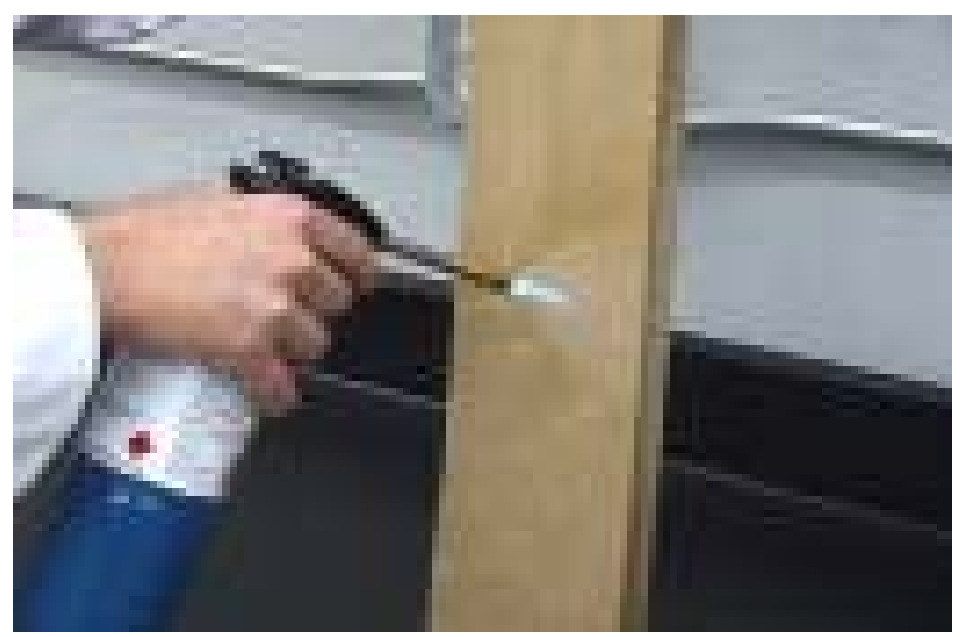

Figure 32: Impact of direct flame on AeRock product 


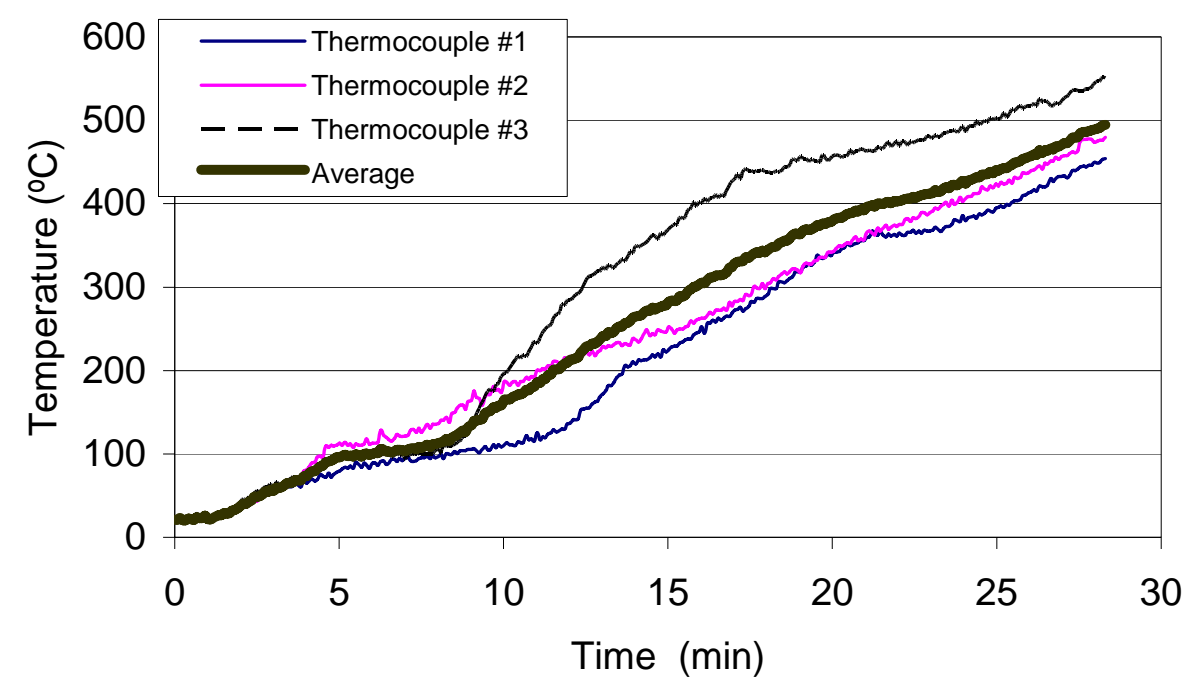

Figure 33: Flame penetration test results for the AeRock composite.

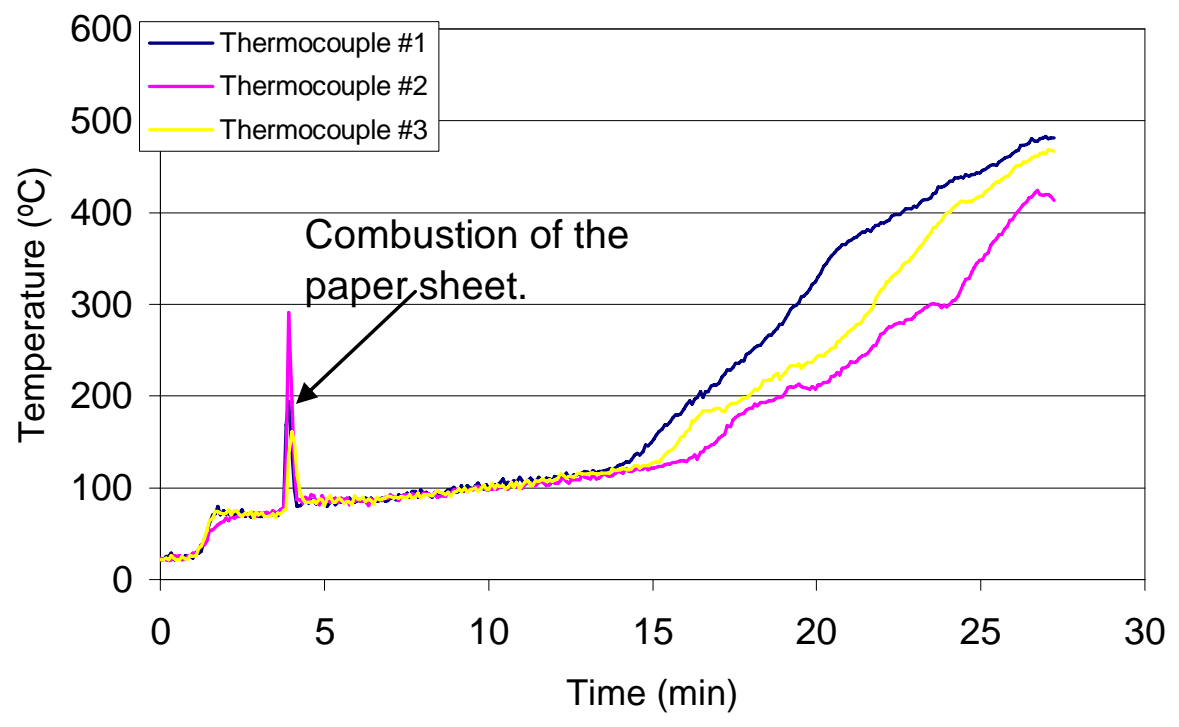

Figure 34: Flame penetration test results for gypsum wall board.

Initially, the AeRock composite heated up slightly more rapidly than a gypsum wall board sample. In the end, however, both materials reach roughly the same temperature. The gypsum sample also ignites the paper sheet at some point, something the AeRock product does not do. 
Specimens taken from the same AeRock board were tested according to ASTM E-84 for flame spread and smoke developed. These tests indicated that all of the emission values were well within the acceptable range. Also, flame spread indexes and smoke developed indices were negligible.

\subsection{Pilot-scale Production of Extruded Decking Material}

Upon completion of the composite formulation tests and the associated strength testing, a pilot-scale production of the AeRock product was undertaken. The optimum composite mix was continuously extruded in the Haendle Lab Extruder. These production trials must extrude more complex shapes than the previous square and round beams testing specimens (Figure 35 and 36).

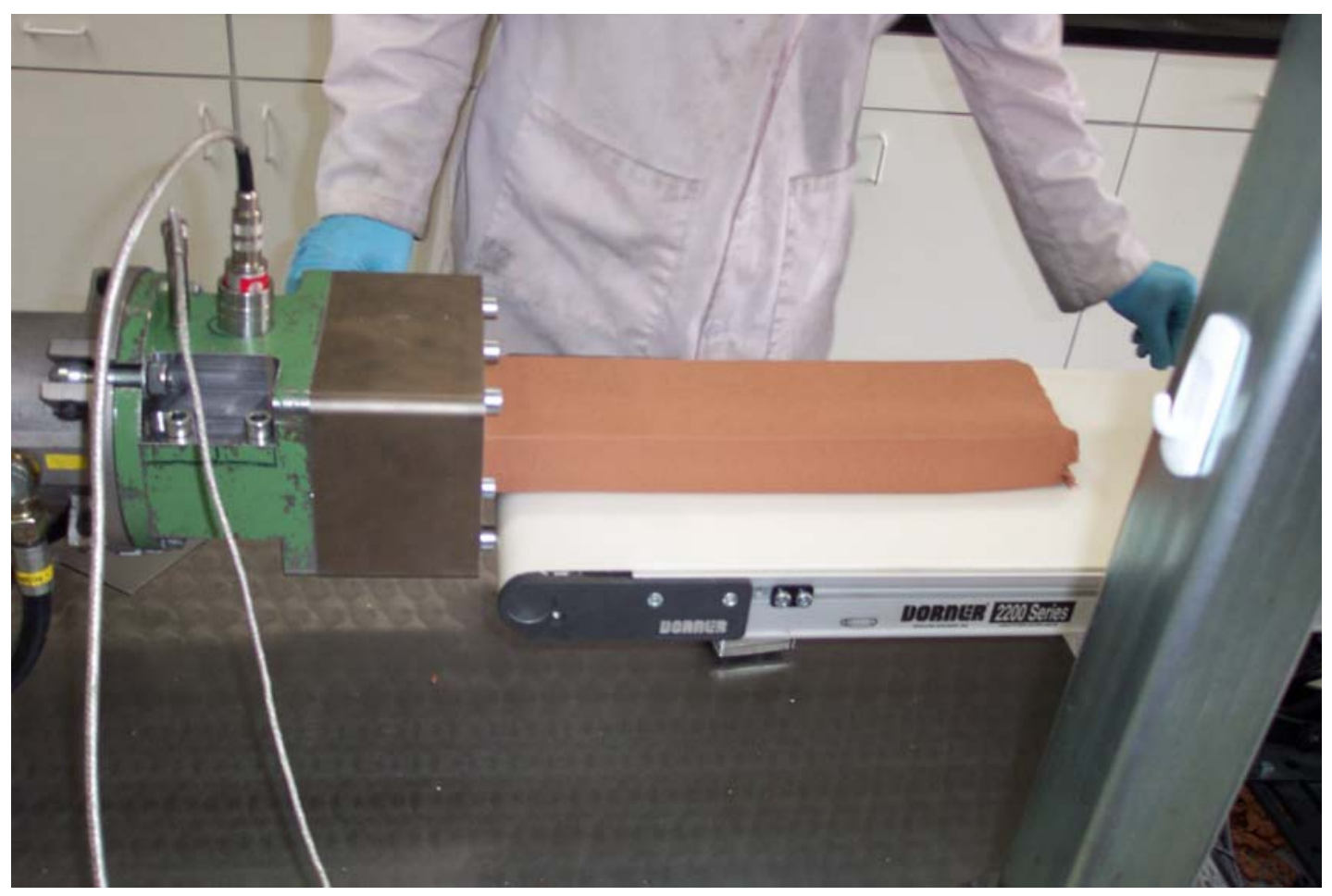

Figure 35: Photograph of the extrusion of the AeRock wall panel product. 


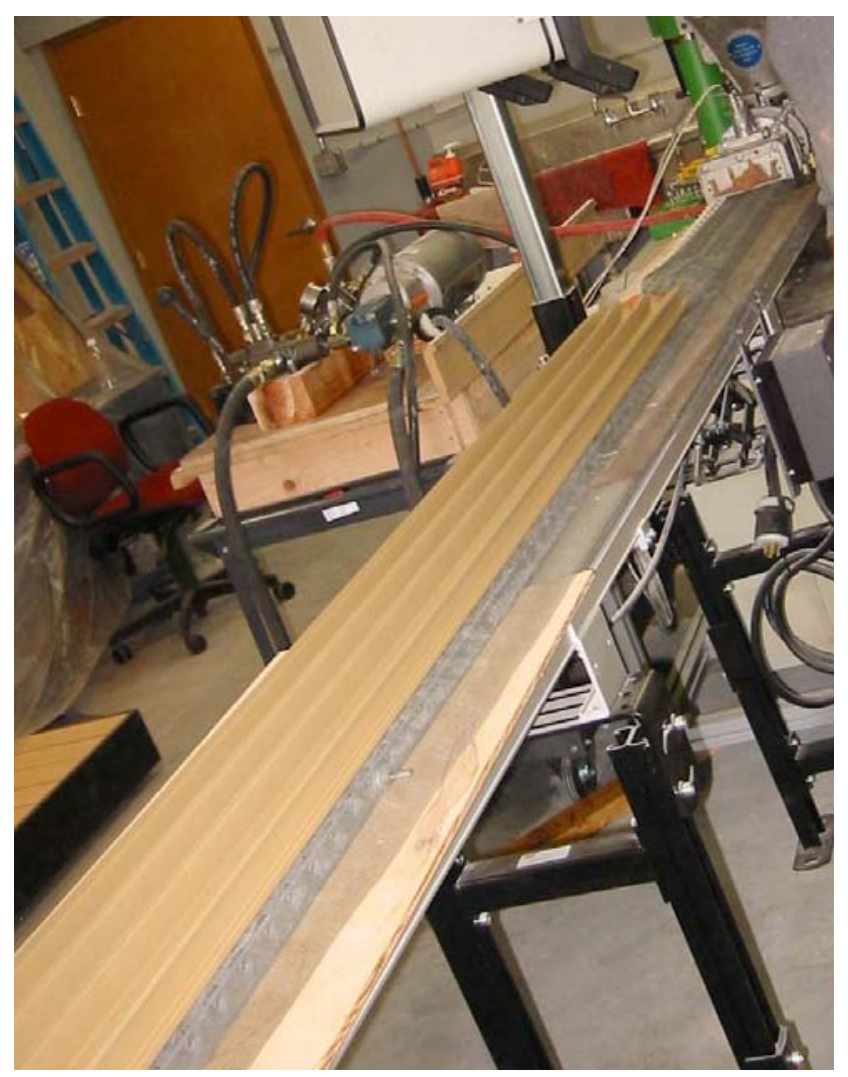

Figure 36: Photograph of laboratory (pilot-scale) extrusion of AeRock decking product.

The operation of the extruder to produce complex building product shapes was initially a challenge. The die design is critical and subtle changes in ingredients, such as the water, can cause significant changes in the extrudability. After a number of iterations of water and chemical addition were undertaken, a composite formulation was produced that would extrude smoothly, yet hold its shape for the curing process. Material testing confirmed the mechanical and physical properties measured earlier and installation details for the product (i.e. fasteners) were developed.

One of the products that were produced with the pilot-scale extruder was a decking material. Various finishes were developed that could easily be applied during the mixing and extrusion process. Figure 37 and 38 shows the range of the finishes, from plain to marbled, from bright reds to muted earth tones, with various textured finishes as well. These finishes were developed based on conventional Portland cement dye techniques, using acid etching and other dye techniques available in the industry. 


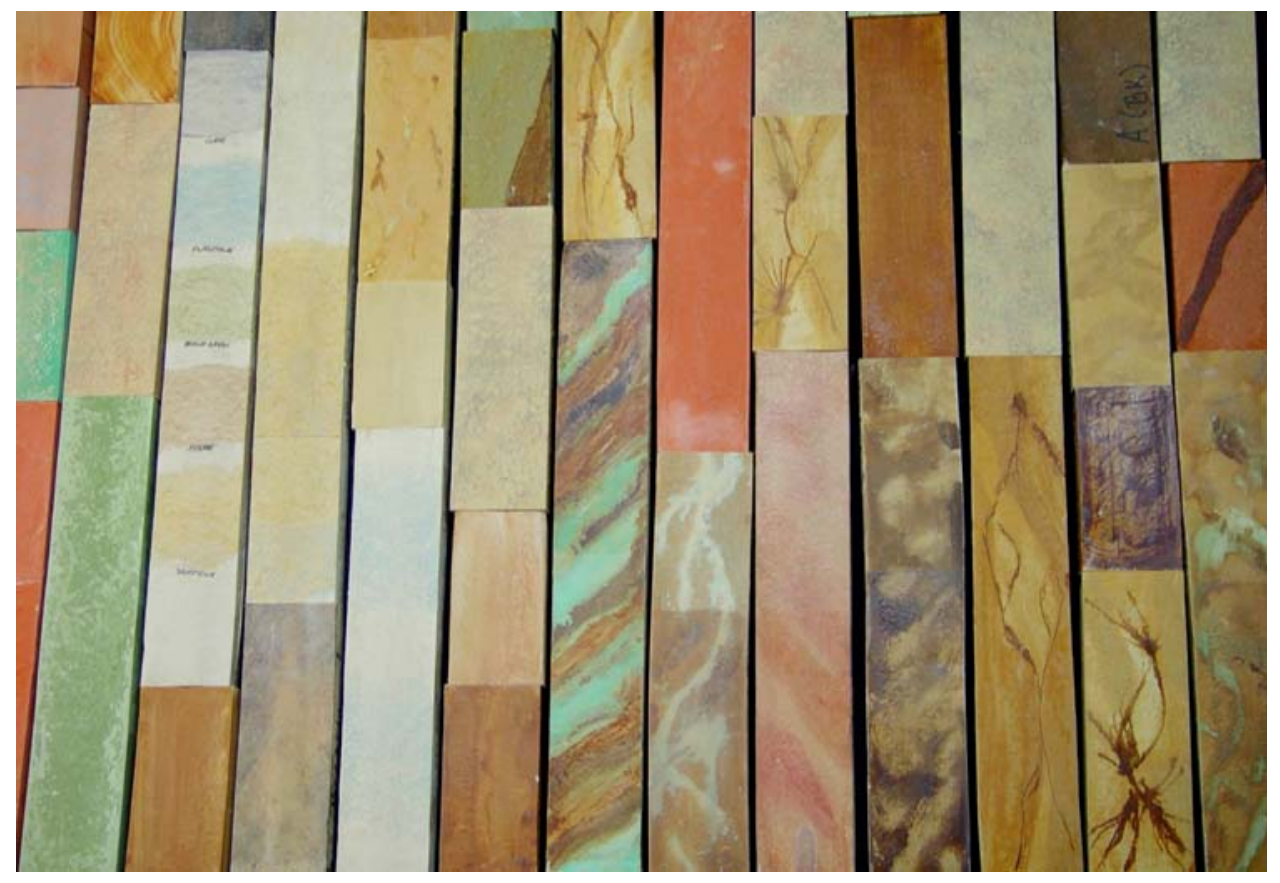

Figure 37: AeRock’s decking product with various finishes applied.

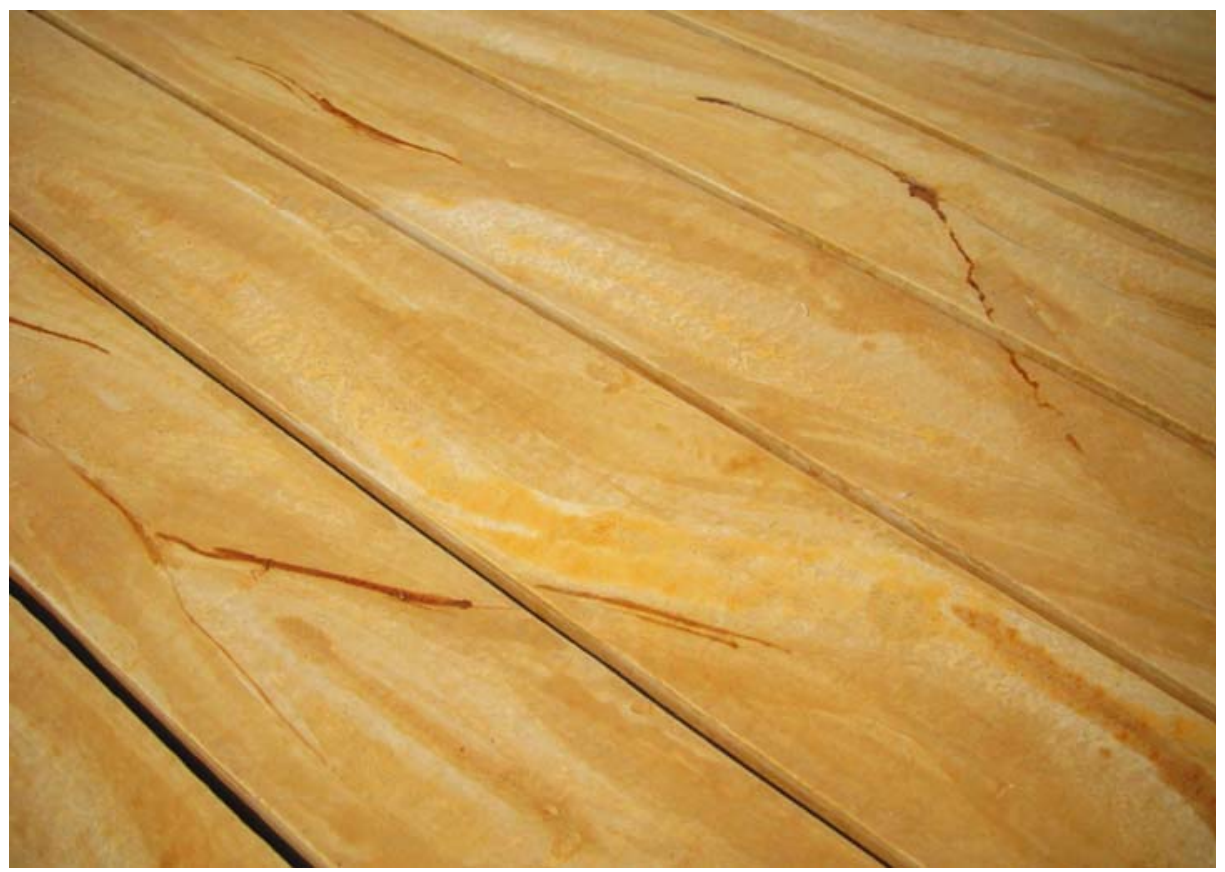

Figure 38: Photograph of wood-grained finished AeRock decking product 
A product demonstration was assembled from the laboratory extruded decking product, which was used for durability testing. Figure 39 shows the different finishes for the decking illustrating the diverse appearance of the product and its broad aesthetics appeal.

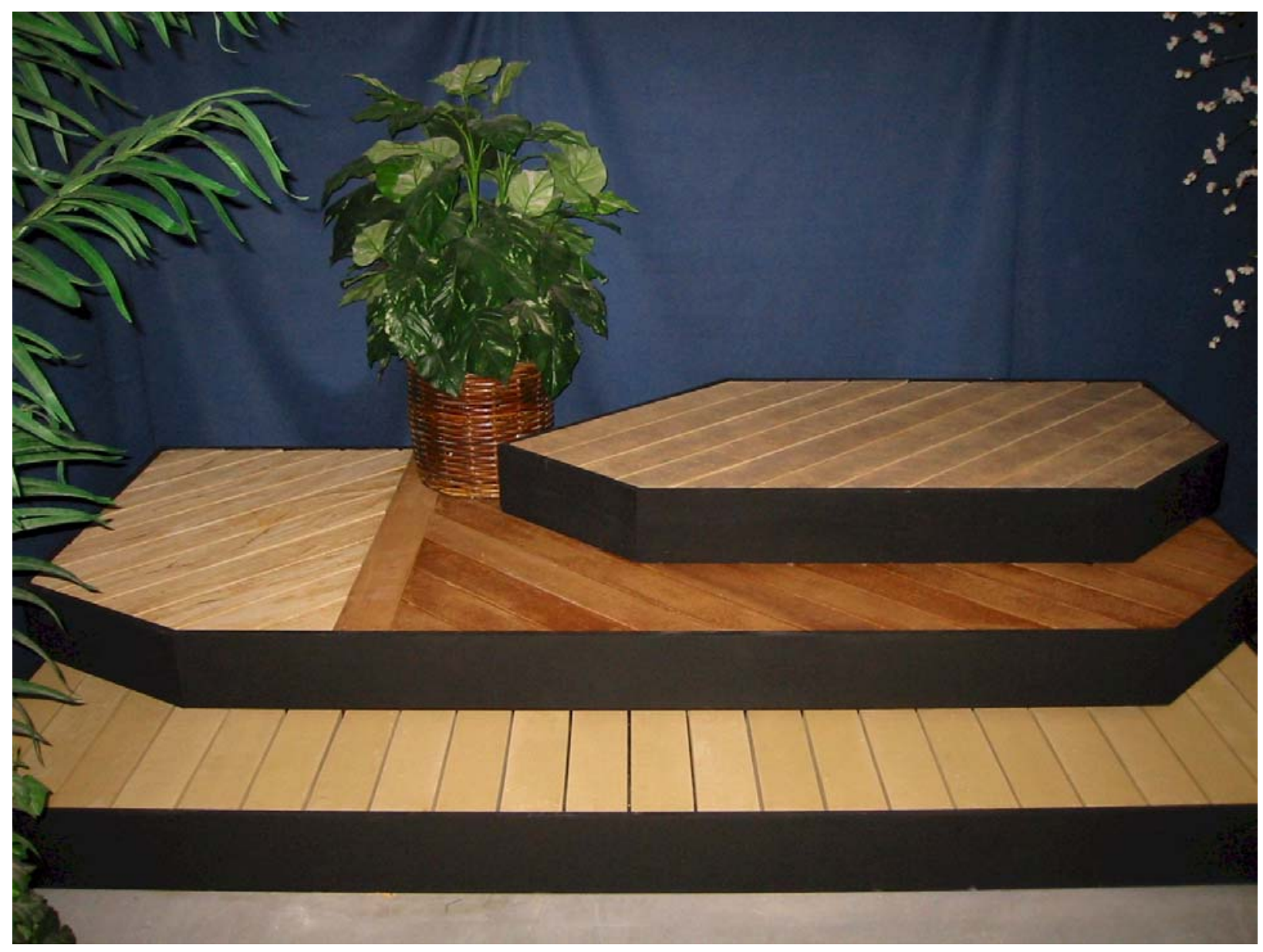

Figure 39: Photograph of the AeRock decking product demonstration.

\subsection{PHASE II - COMMERCIAL-SCALE DEMONSTRATION}

Based on the successful development of a quick-setting, high-strength, ash-cement-fiber composite, AeRock decided to evaluate commercial-scale demonstration of their decking product called AeRock Decking. This same AeRock composite material can ultimately be made into a wide range of building materials, including whole walls, floors, and roofs without the need for additional internal or external cladding, as described earlier. But residential and commercial decking represents an outstanding, quick-entry, and high-growth market opportunity. 


\subsection{The Market For Decking Products}

Government statistics state that over $85 \%$ of all single-family homes include deck-like structures. Annually, over $4 \%$ of all households either add a deck or replace an existing deck, leading to the construction of more than 3.5 million new decks onto existing single-family structures each year. US sales of decking totaled approximately \$3 billion in 2001, and annual sales were forecasted to grow to \$5-6 billion in 2005 with residential decking comprising approximately $90 \%$ of that volume. The growth in demand for residential decking reflects the increasing popularity of decks as a means of extending living areas and providing outdoor recreation and entertainment spaces. The wood alternative market has grown at vigorous $40 \%+$ per year, compared to $8 \%$ overall for the decking industry. Non-wood products represent only a small percentage of the total decking market.

The majority of decks built for existing homes are new or replacement decks. Deck repair, modernization and replacement are expected to increase as existing decks age. Another study indicates that four percent of existing decks are replaced each year. The result is that the combination of both new and replacement deck construction indicates a highly attractive marketplace for years to come. In addition, commercial decks, constructed for restaurants, hotels, nature walks and boardwalks represent another market opportunity.

\subsection{AeRock Deck Product Installation}

The AeRock process can produce all the components necessary for the total construction of all of the visible portions of a deck. The standard sizes include:

$\begin{array}{ll}\text { Decking } & 1 \frac{1 / 4}{4} 513 / 16 \text { inch } \\ \text { Railings } & 1 \frac{1 / 2}{2} 3 \frac{11}{2} \text { inch } \\ \text { Balusters } & 1 \frac{1}{2} \text { X } 1 \frac{1}{2} \text { inch } \\ \text { Posts } & 31 / 2 \text { X } 3 \frac{112 \text { inch }}{}\end{array}$

Also, because AeRock Decking is strong and lightweight compared to other decking products, it is easy to handle. Wood and resin products available in the marketplace weigh over 5 lbs. per board foot. AeRock on the other hand, weighs 2.7 lbs. per board foot and does not shrink or expand in winter and summer.

AeRock Decks are simply installed with clips on the structure's joists (see Figure 40 and 41). AeRock Decks are first laid out on the structure joists with the individual deck planks held together with these clip-screw fittings. When the installer (or homeowner) is satisfied with the 
look, the deck is quickly and easily secured to the joists by screwing down the clips. The clipscrew fittings are not visible after they are set.

One of the outstanding advantages of a precision-extruded product is that special function channels can easily be molded into the decking boards as part of their manufacture, and at no extra cost. This feature can be turned to an advantage because a locking clip can be pushed home into a double-groove system. The second groove catches a barb molded to the edge of a clip. This enables the installer to lock all the boards together for very high speed, precision installation. Once all of the boards are locked together, the screws that go through the locking clips, and which are integrated with them, can be driven home in a very rapid process. A deck fixed with screws will always be superior to a deck fixed with nails.
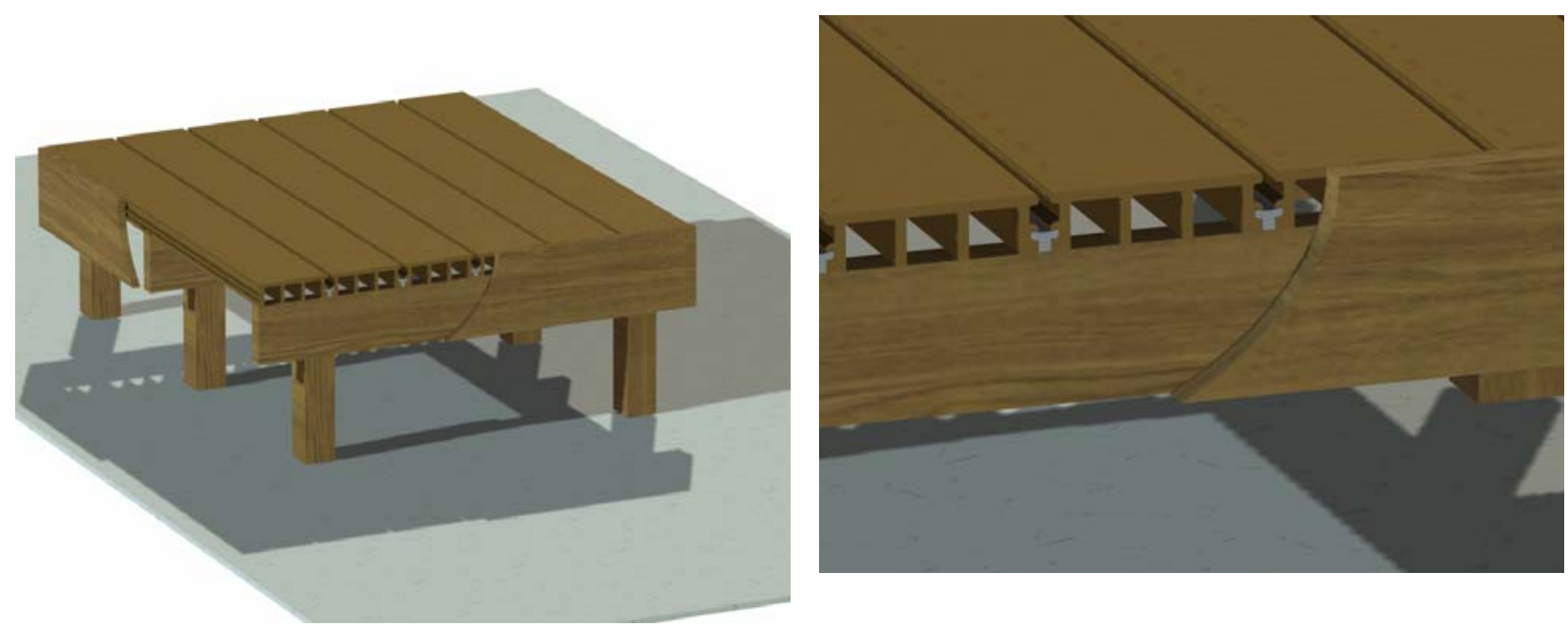

Figure 40:. CAD view of the AeRock Decking product.

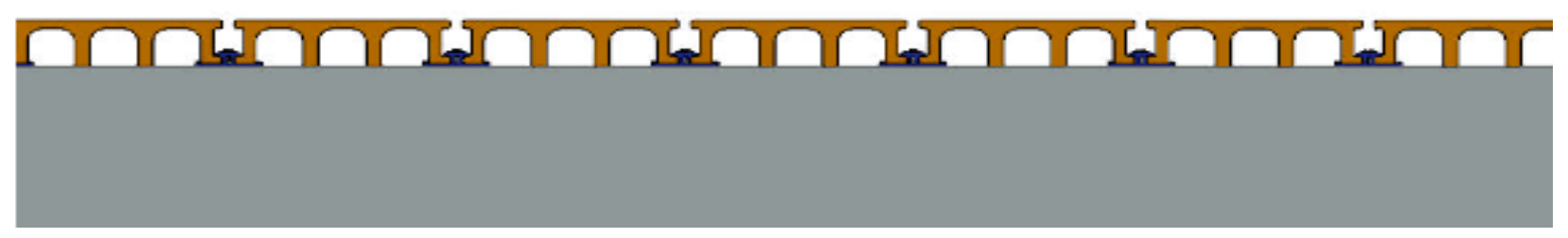

Figure 41: Cross-section profile of the AeRock Decking product fastened to support joist. 


\subsection{Commercial-Scale Production Runs}

The objectives Phase II effort was to conduct commercial-scale production runs for the AeRock Decking product and the AeRock wall structural member. Secondly, the AeRock Decking product would be placed in service and monitored.

3.3.1 AeRock Decking Composite Formulation. Phase I of the project resulted in a proprietary and optimal composite formulation for use in Phase II. The chosen mix was characterized by a modulus of rupture (MOR) measured between 1,931 and 2,221 psi flexural strength

3.3.2 Materials Shipped for Demonstration. A full-sized cargo container of composite ingredients was sent to AeRock’s Australian partner, Ultrapanel Pty, Ltd. in Ballarat, Australia for extrusion. The container included all the required ingredients: fly ash cement, filler, fiber reinforcement, and additives to ensure an exact replica of the optimized laboratory extrusions. The materials for the first pilot run included approximately 24 tons of ash-based cement, two tons of fibers, and nearly two tons of chemicals. In addition upwards of 12 tons of dry flue gas desulphurization (DFGD) ash from a U.S. coal-fired power plant was shipped in a second cargo container.

3.2.3 Die Design. Engineering of the dies so that the pressure and velocity profiles at the die exit were precisely uniform was somewhat difficult. Dies were specially engineered by Ultrapanel through the German company Haendle and its partner Braun. They developed sophisticated software to predict the profiles needed to handle the fluid dynamics of the cementious materials.

A profile of the AeRock Decking product for which the die was designed can be seen in Figure 42. The dimensions are approximately 6 " $\mathrm{W}$ by 1.5 ” $\mathrm{H}$, in order to accommodate four deck planks to be extruded simultaneously.

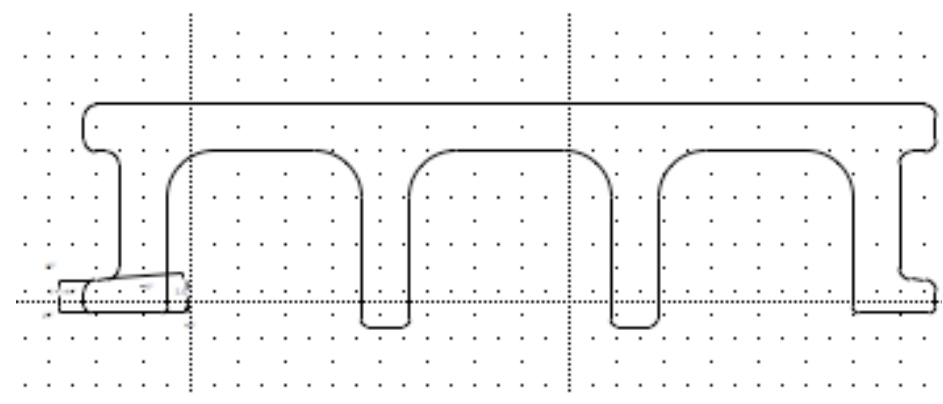

Figure 42: Profile of the AeRock Decking product. 
3.2.4. Production Runs. AeRock signed an agreement to use the Ultrapanel facility in Ballarat, Australia for commercial-scale production of the AeRock Decking product. The facility was a fully automated plant able to feed raw materials from silos into the mixing process and then to the extruder. The Ultrapanel location was selected since they were AeRock's licensee and since there were no suitable manufacturing facilities available in the U.S.

The Ultrapanel facility was modified to accommodate the use of the AeRock Decking materials and its unique processes including hopper/feeder modifications, chemical injection systems, and dies for the AeRock Decking formulation and size specifications.

Two commercial-scale production trials were conducted at Ultrapanel's manufacturing facility in Ballarat, Australia. These trials were designed to produce decking (AeRock Decking) and to produce the structural component for the AeRock wall panels. Initial trial showed difficulty in producing an extruded product that maintained its shape (Figures 43 and 44). The green panels showed sagging and irregular surfaces from drag on the extruder die.

After considerable efforts the initial extrusion issues were resolved and quality decking and AeRock wall structural members were produced of good quality. Figures 45 and 46 show the extrusion of the AeRock Decking and the AeRock wall members, respectively.

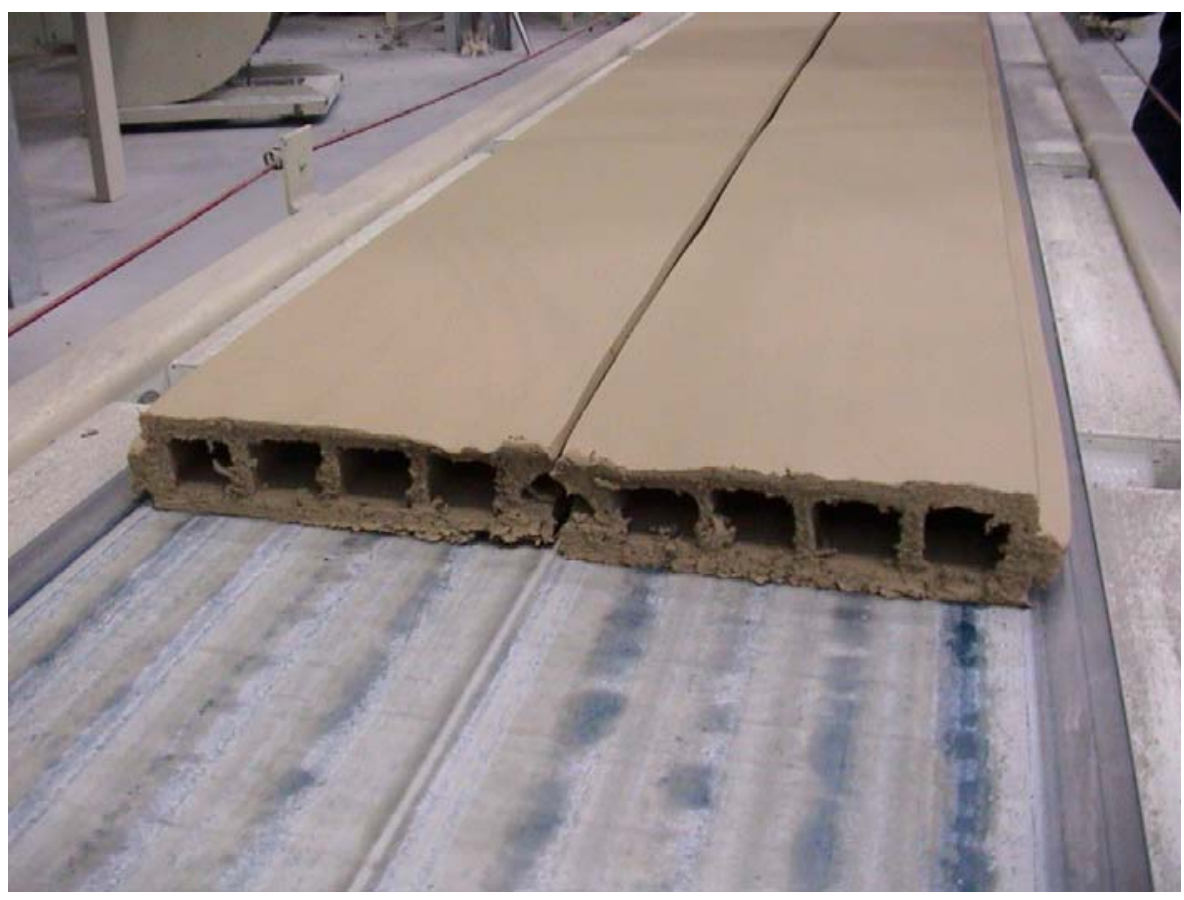

Figure 43: Initial AeRock Decking production runs showing green product deformation. 


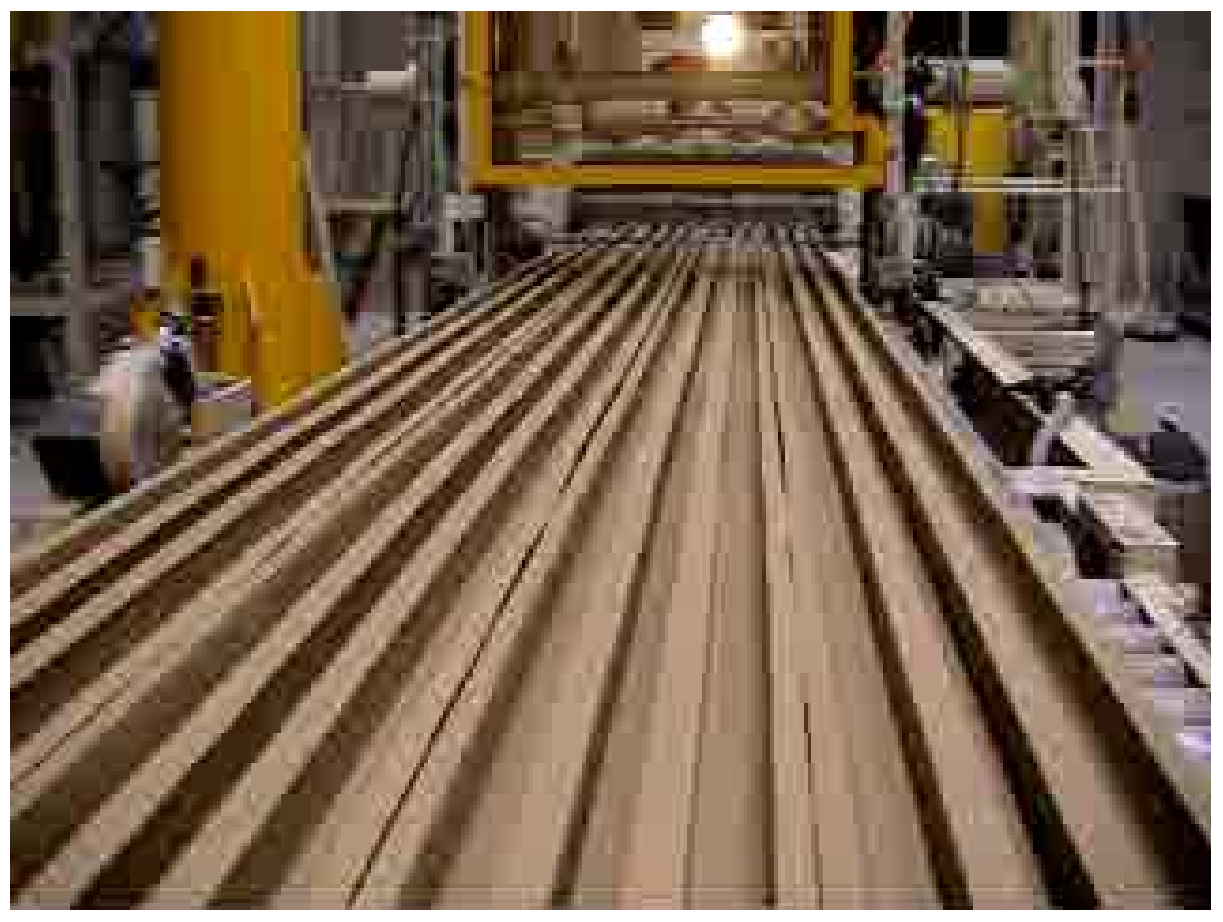

Figure 44: Initial AeRock wall member production runs showing green product deformation.

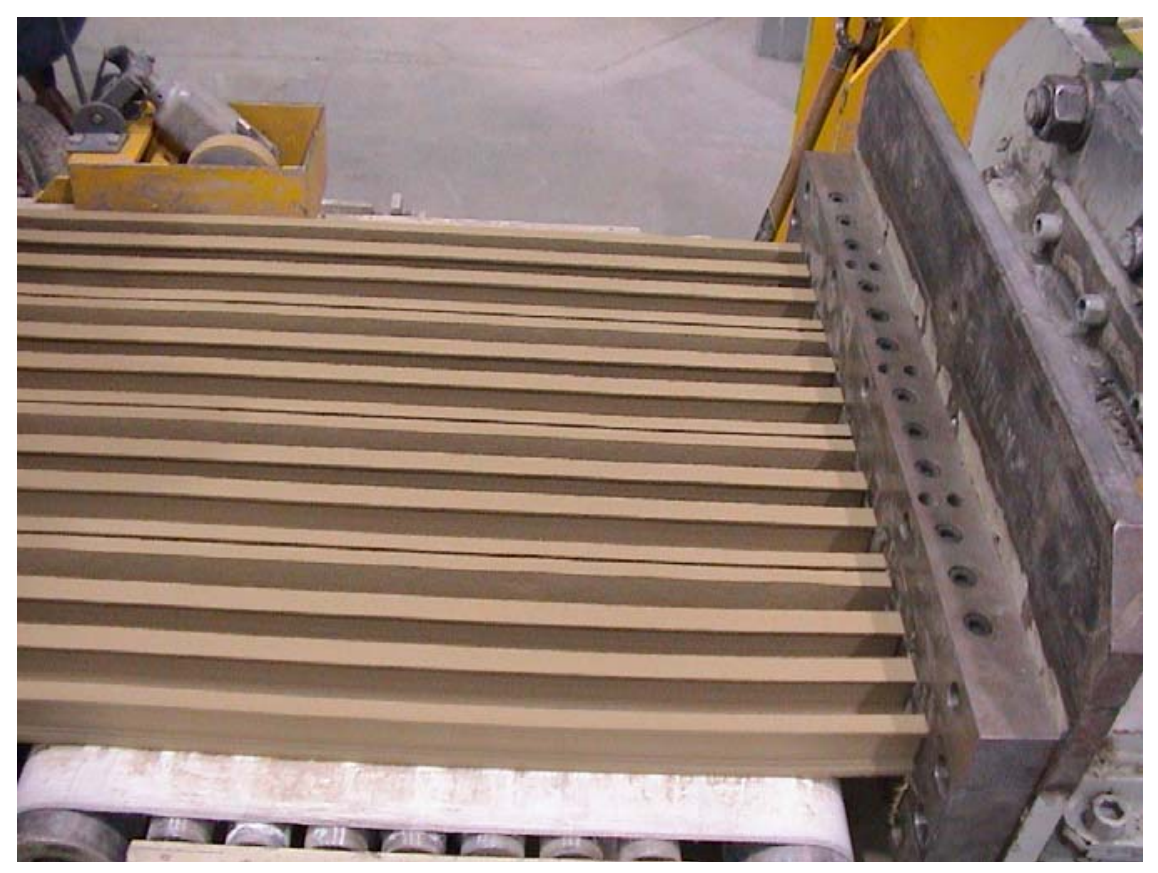

Figure 45: Simultaneous commercial-scale extrusion of four separate trains of AeRock Decking product. 


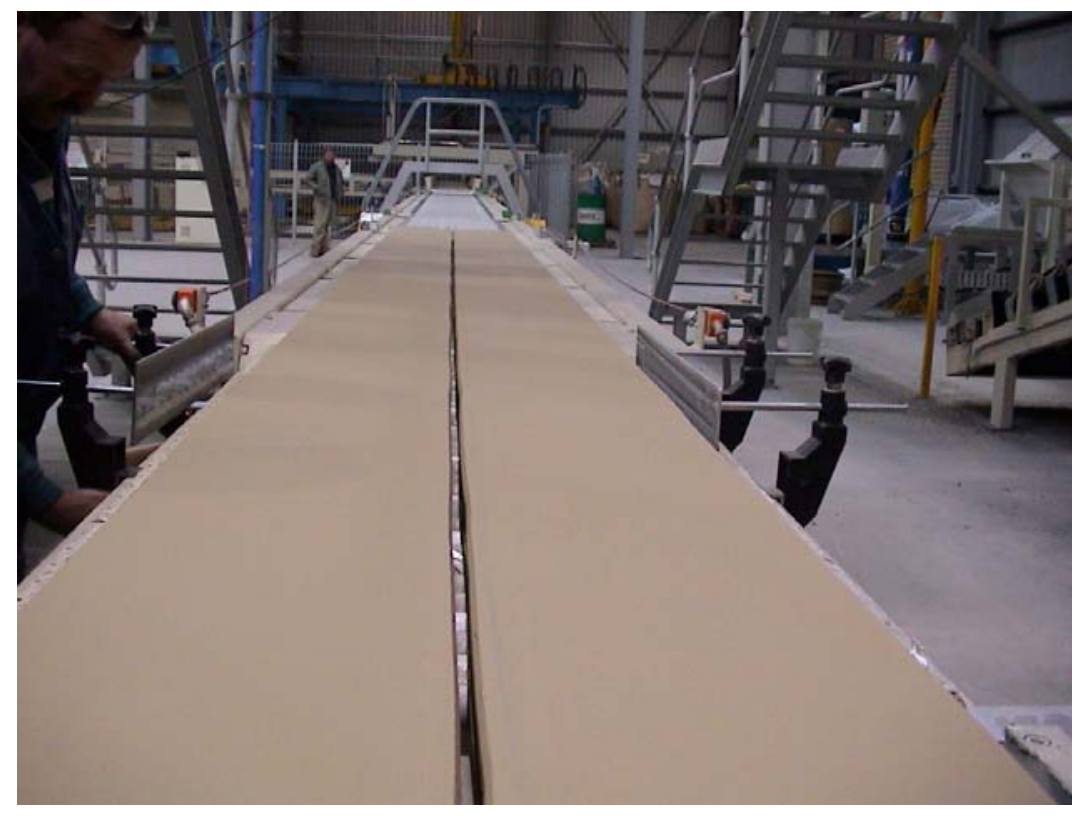

Figure 46: Simultaneous commercial-scale dual train production of AeRock wall structural members.

Using the first two generations of the commercial die, rippling and other undesirable effects occurred, thereby causing the die to be twice modified before a satisfactory profile was found. The final die was then fitted to the extruder and satisfactory deck planks were produced.

As a result of the evaluation of the present deck design, a new design has been developed as illustrated in Figure 47. In this design, the section generally should be much more robust, making it both easier to extrude and safer for transportation.

The limited quality sections of the finished decking were shipped back to the AeRock facility in the U.S. Unfortunately, the packing was inadequate as some of the pieces were severely damaged upon arrival. As a result, it was decided that the present four-footed decking design shown in Figure 42 was unsatisfactory, and that a commercial-scale product of that design could lead to unacceptable levels of product returns.

With the limited AeRock Decking available from the production trials in Australia, a small demonstration was constructed. The product was monitored for one year for performance for structural and durability characteristics. 


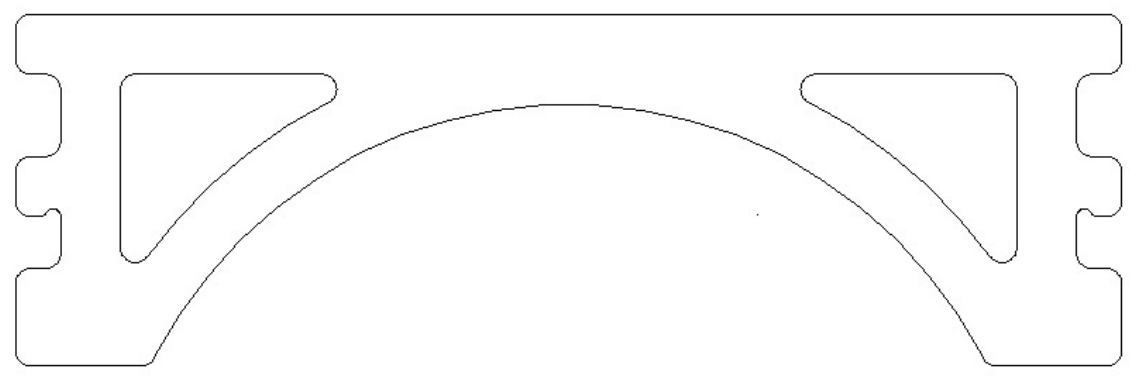

Figure 47: Proposed profile of the AeRock Decking product.

\subsection{Demonstration of Applications of the AeRock Decking Product}

The AeRock Decking demonstration was constructed of extruded ash-based panels of standard patio decking width. Due to its strength, the decking was installed on 24-inch centers. It is known that some non-wood alternative products deteriorate over time, including other fading in color and warping and sagging. For example, the Decking Industry Association now recommends fixing 14 inches on center to avoid sagging (down from 16 inches) resulting in increased installation cost.

Adjacent decking pieces were held together by means of clips. The outer leg is shorter than the inner legs and sits on top of the clip foot. Figure 48 shows the decking and deck clip in final assembly with the unique support clips is clearly visible.

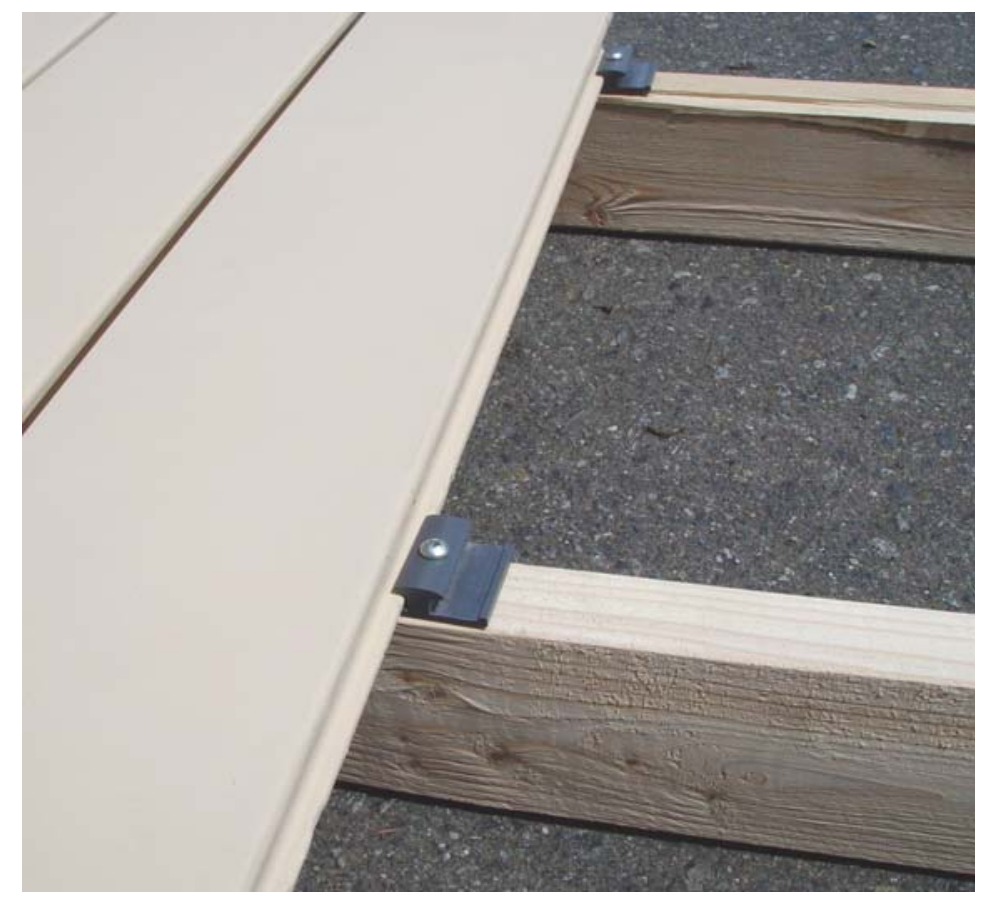

Figure 48: Photograph of the AeRock Decking product installation including support clip. 
The surface of the AeRock Decking was modified and stained to meet select color and stain specifications and an example is shown in Figure 49.

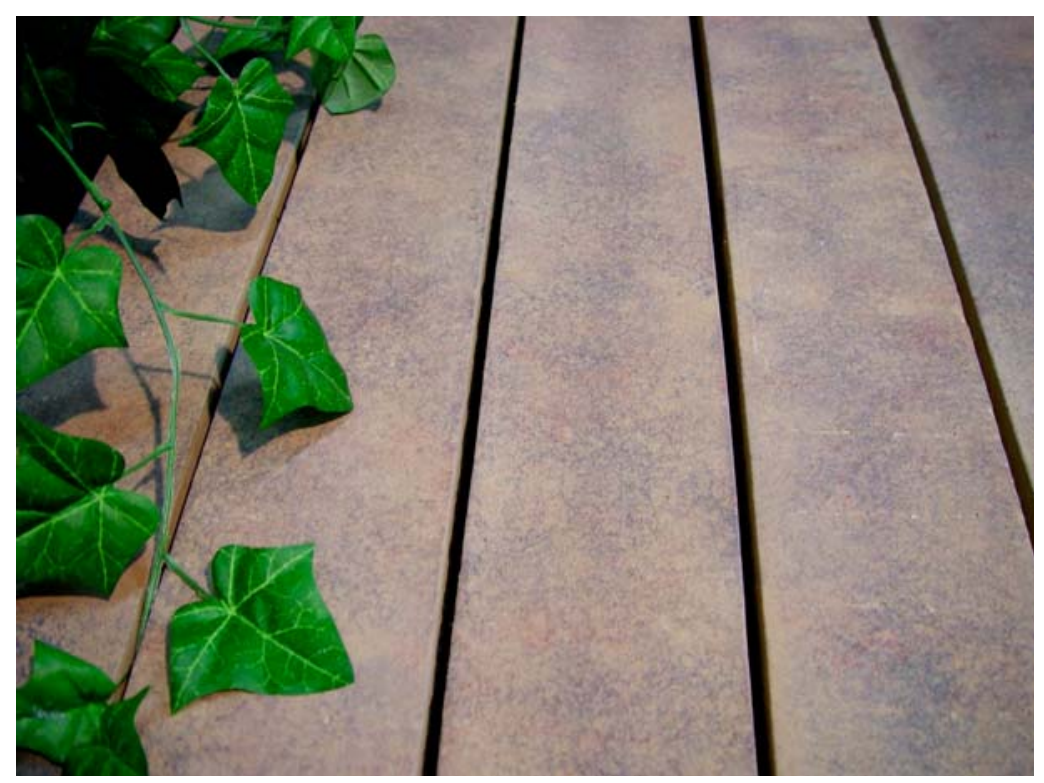

Figure 49: Photograph of a marbled AeRock Decking finish.

The deck demonstration was successful, both in terms of performance, as well as appearance. Sections of decking were placed on high-traffic walk areas in order to test the decking. Some wear occurred, but not to excess. Impacts did cause some chips, but no failures. Some of the samples were somewhat slippery when wet, an indication that texturing would be needed in a commercial product.

\subsection{Product Comparison}

As described earlier in this report (Section3.1), the decking market in the United States is rapidly growing. Combining both new and replacement deck construction needs, the US market appears to be highly attractive for a product such as AeRock. Also according to market surveys, a large opportunity for non-wood alternative decking products also exists in United States. AeRock's Decking main competitor in the non-wood sector of the decking industry is the TREX Company, who commands by far the largest market position.

Given that consumer choice of decking material depends more upon product quality than image, AeRock Decking could be a commercially accepted product. AeRock Decking compares favorably in performance, modulus of rupture (MOR) and modulus of elasticity (MOE). Sheath grade plywood has an MOR of 3,000 to 7,000 psi and an MOE of 1.0 to $1.9 \times 10^{6}$ psi, while sheathing grade orient strand board (OSB) has a MOR of 3,000 to 4,000 and an MOE of 0.7 to $1.2 \times 10^{6}$ psi. 
A review of MOR and MOE for non-wood products from the website demonstrates that the AeRock product is equal to or superior to other commercial deck products.

Table 1. Comparison of the MOR and MOE of AeRock Decking and other deck products.

AeRock

Trex Deck - Ultimate Value

Trex Deck - Design Value

Portico Decking

Correct Deck

Alaskan Cedar

Plastic Lumber

\section{$\underline{\mathrm{MOE}(\mathrm{ksi})}$}

1350

155

100

561

850

960

115
MOR (ksi)

1700

1423

250

2814 psi

$5440 \mathrm{psi}$

6.2

not available

AeRock Decking answers the problems of wood (i.e. maintenance) and those of composites such as fading in ultraviolet light and sagging due to the high coefficient of expansion. The AeRock Decking product is attractive and features great fire resistance, low maintenance, is insect proof, and extremely durable in all weather conditions. In addition, the cost of the product could provide the added incentive to purchase.

AeRock commissioned a confidential market analysis to compare the estimated cost of AeRock Decking with that of leading non-wood decking companies. The AeRock product is comparable to wood in price and requires no maintenance where as wood decking requires and average maintenance cost of $\$ 0.76 /$ square foot (2003 costs). In addition, the AeRock Decking is approximately 1/3 less expensive that non-wood alternative decking products on the market.

Given the above and the characteristics of AeRock Decking - improved durability, ease of installation, and design flexibility - the AeRock product should be well positioned in the decking market.

\subsection{CONCLUSIONS AND RECOMMENDATIONS}

WRI and AeRock developed a composite formulation that is composed essentially of $100 \%$ "green" recycle materials, principally ash, ash-based cement and fiber, for use in producing alternative building products. The AeRock process and resultant products showed a number of environmental benefits. The AeRock composite saves landfill space and potential pollution. Also compared to wood, every square foot of AeRock panel saves approximately one tree, while compared with Portland cement, every ton of ash or ash-based cement used saves approximately one ton of $\mathrm{CO}_{2}$ emitted to the atmosphere. 
Decking for residential and commercial building that is produced with this proprietary composite, brand-named AeRock Decking, is fire, moisture and insect resistant and is wholly resistant to the destructive properties of UV rays. Unlike wood, it will not rot, crack, split, warp, sag, stain resistant, become unstable or splinter. Also the AeRock Decking is easy and less expensive to install, can be stained and textured to customer specifications, requires no protective sealant, essentially maintenance free and cost competitive with wood and non-wood products.

In Phase I, the AeRock-WRI team conducted engineering and chemical tests on a wide range of composite formulations, in order to optimize the ingredients. The optimized composite was characterized by a modulus of rupture (MOR) measured between 1,931 and 2,221 psi flexural strength, comparable to other wood and non-wood building materials. Using the Phase I composite formulation, a very successful pilot-scale production trial of the AeRock Decking product and a small demonstration using the stained and textured decking was conducted.

This successful pilot-scale demonstration was used to design the parameters and extruder dies for a commercial-scale demonstration at Ultrapanel in Ballarat, Australia under Phase II of the project. A die was designed; a cargo-container of ton-sized composite ingredients shipped to Australia, and the Ultrapanel facility was modified to handle these commercial-scale production trials with the AeRock composite formulation.

The initial commercial-scale production trials showed green product sagging, but these issues were ultimately overcome. In the end, two successful production runs of the AeRock wall structural members and the AeRock Decking residential decking product were conducted. Cured decking was shipped to the U.S. but experienced significant breakage and damage during transport.

Detailed examination of the shipped product confirmed a deficiency in the die design and an alternative die was designed that would produce a more robust product that would be more resistant to damage during transport. Unfortunately, the cost of conducting another production trial, including the cost of the new dies was prohibitive.

AeRock Decking can be a viable non-wood alternative decking product. This project has provided WRI and AeRock the knowledge and understanding to make AeRock Decking a success. As such, it is recommended that additional pilot-scale testing using the new die design be conducted. If successful, commercial-scale production trials, employing the new die design, could be conducted in the U.S. in order to produce sufficient quantities of product for field 
demonstrations of the AeRock Decking. The product would undergo the full range of product performance tests necessary to launch the product to the industry. 